Universidade de São Paulo

Escola de Engenharia de São Carlos

Departamento de Engenharia de Estruturas

Rafael Corrêa Salomão

\title{
Análise da Influência do Campo Higrométrico sobre a Reação Álcali-Agregado
}

São Carlos, SP

2017 

Rafael Corrêa Salomão

\title{
Análise da Influência do Campo Higrométrico sobre a Reação Álcali-Agregado
}

\author{
VERSÃO CORRIGIDA \\ A versão original encontra-se na Escola de Engenharia de São Carlos \\ Dissertação apresentada ao Departamento de \\ Engenharia de Estruturas da Universidade \\ de São Paulo, como parte dos requisitos para \\ obtenção do título de Mestre em Engenharia \\ Civil (Engenharia de Estruturas). \\ Orientador: Prof. Dr. Rogério Carrazedo
}

São Carlos, SP

2017 
AUTORIZO A REPRODUÇÃO TOTAL OU PARCIAL DESTE TRABALHO, POR QUALQUER MEIO CONVENCIONAL OU ELETRÔNICO, PARA FINS DE ESTUDO E PESQUISA, DESDE QUE CITADA A FONTE.

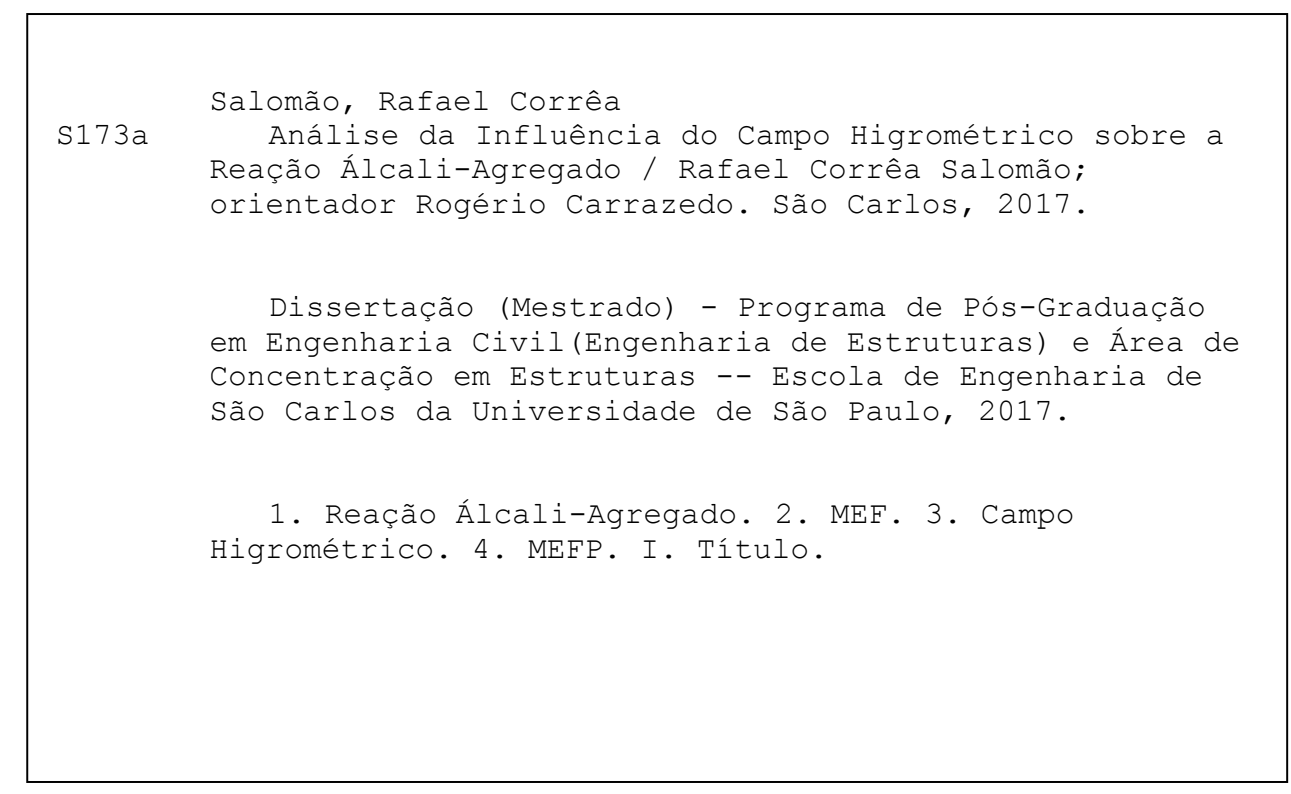




\section{FOLHA DE JULGAMENTO}

Candidato: Engenheiro RAFAEL. CORRÊA SALOMÃO.

Título da dissertação: "Análise da influência do campo higrométrico sobre a reação álcali-agregado".

Data da defesa: 10/04/2017.

Comissão Julgadora:

Prof. Dr. Rogério Carrazedo (Orientador)

(Escola de Engenharia de São Carlos/EESC)

Prof. Dr. Marcos Arndt

(Universidade Federal do Paraná/UFPR)

Profa. Dra. Glaucia Maria Dalfré

(Universidade Federal de São Carlos/UFSCar)
Resuliado:
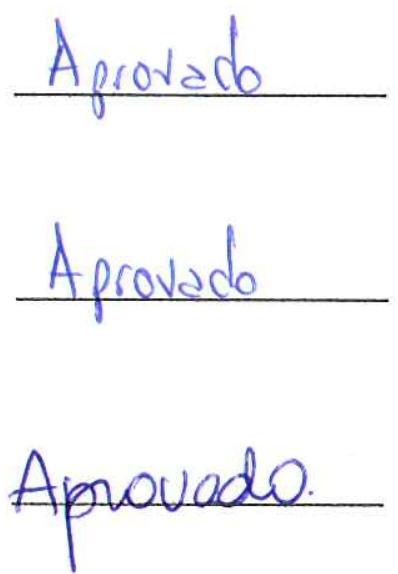

Coordenador do Programa de Pós-Graduação em Engenheira Civil (Engenharia de Estruturas):

Prof. Titular Humberło Breves Coda

Presidente da Comissão de Pós-Graduação:

Prof. Associado Luís Fernando Cosła Alberło 

Dedico este trabalho aos meus amados pais, Egilson e Alba, e à minha querida família. 



\section{Agradecimentos}

Primeiramente, gostaria de agradecer à Deus por todas as oportunidades e bênçãos ao longo de minha jornada.

Agradeço de todo o coração os meus pais, Egilson e Alba, pelo amor, zelo e educação. Sem os quais, não conseguiria chegar até este ponto em minha caminhada. Sou grato pela enorme paciência e dedicação despendidos em mim.

Também agradeço à minha família pelo apoio e carinho.

Gostaria de agradecer em especial ao professor Dr. Rogério Carrazedo pela orientação, conhecimento, apoio e paciência durante o mestrado.

Aos colegas e amigos, pelos momentos de descontração, companheirismo e contribuição para a realização deste trabalho.

Aos professores do Departamento de Engenharia de Estruturas da EESC-USP pelo conhecimento e experiência transmitidos e ao departamento pela infraestrutura e apoio indispensáveis.

Por fim, a Coordenação de Aperfeiçoamento de Pessoal de Nível Superior (CAPES) pelo apoio financeiro para o desenvolvimento da pesquisa. 

"Mais fácil me foi encontrar as leis com que se movem os corpos celestes, que estão a milhões de quilômetros, do que definir as leis do movimento da água que escoa frente aos meus olhos." 



\section{Resumo}

SALOMAO, R. C. Análise da Influência do Campo Higrométrico sobre a Reação Álcali-Agregado. 2017. p. 98. Dissertação (Mestrado em Engenharia Civil (Engenharia de Estruturas)) - Escola de Engenharia de São Carlos, Universidade de São Paulo, São Carlos, SP.

A reação álcali-sílica é uma patologia de origem química que ocorre em estruturas de concreto. A partir desta reação há a formação de um gel de álcali-sílica que em contato com a água provoca expansão e deformação da estrutura. Esta patologia traz muitos transtornos e prejuízos, principalmente em obras que estão em contato direto com a água (barragens, pontes, piers, etc) e a possibilidade de prever o comportamento e deformações em uma estrutura desse porte é de grande valia. Neste trabalho é feita a modelagem da percolação d'água em meio poroso por meio do método dos elementos finitos, sem movimentação de malha e fazendo uso de função Heaviside contínua para a percolação. A modelagem da reação álcali-sílica é feita por meio de um modelo paramétrico, com alteração para contemplar regimes não uniformes de umidade e sua interferência na taxa de expansão. A modelagem do campo mecânico é feita pelo Método dos Elementos Finitos Posicional.

Palavras-chave: Reação Álcali-Agregado. Método dos Elementos Finitos Posicional. Campo Higrométrico. 



\section{Abstract}

SALOMAO, R. C. Analysis of the Higrometric's Field Influence on the AlkaliAggregate Reaction. 2017. p. 98. Dissertation (Masters in Structural Engineering) Department of Structural Engineering, Escola de Engenharia de São Carlos, Universidade de São Paulo, São Carlos, SP.

The alkali-silica reaction (ASR) is a pathology that occurs in concrete structures. Such pathology creates an alkali-silica gel that when in contact to water promotes expansion and strain on a affected structure. Most buildings that are susceptible to this fenomena are the ones in contact with water, such as dams, piers and bridges. The possibility to predict the ASR behavior and total strain developed would be helpful. In this work, finite element method with fixed mesh is employed to model seepage in a porous media. Also, it's used a Heaviside function for the percolation coefficient. The modeling of the alkali-silica reaction is done by a parametric model, modified to non-uniform humidity conditions and it's interference on the expansion rate. The modeling of the mechanical field is done by the Positional Finite Element method.

Keywords: Alkali-Aggregate Reaction. Positional Finite Element Method. Higrometric Field. 



\section{Lista de ilustrações}

Figura 1 - Vista Superior de Pilar e do Bloco de Fundação atacados pela RAA. 24

Figura 2 - Fluxograma do modelo numérico desenvolvido e interação com o préprocessador e pós-processador. . . . . . . . . . . . . . 27

Figura 3 - Fluxograma específico do modelo numérico higromecânico desenvolvido. 27

Figura 4 - Formação de gel de sílica em dois agregados distintos. . . . . . . . . . . 32

Figura 5 - Diversos tipos de arranjo estrutural para sílica. . . . . . . . . . . . 33

Figura 6 - Regiões de ocorrência ou não de RAA de acordo com quantidade de álcalis no cimento e quantidade de cimento. . . . . . . . . . . . . 35

Figura 7 - Vários estados de confinamento em corpo de prova e respectivas expansões. 37

Figura 8 - Expansão em corpo de prova submetido a estado uniaxial de compressão. 37

Figura 9 - Interpretação petrográfica e evolucionária da reação álcali-agregado. . . 40

Figura 10 - Fatores de normalização dos parâmetros que influenciam na RAA. . . . 45

Figura 11 - Fatores de influência e de calibração do modelo paramétrico. . . . . . . 46

Figura 12 - Representação da função mudança de configuração e dois estados de configuração de um sólido deformável. . . . . . . . . . . . . . . . . . . 49

Figura 13 - Representação da função mudança de configuração e mudança de área. 51

Figura 14 - Representação gráfica do método de Newton-Raphson e procedimento incremental para convergência e obtenção da solução. . . . . . . . . . . 55

Figura 15 - Mapeamento do elemento bidimensional nas configurações inicial e final. 56

Figura 16 - Fluxo d'água estacionário de superfície livre em meio poroso. . . . . . . 63

Figura 17 - Função de permeabilidade não-linear do elemento. . . . . . . . . . . . . 66

Figura 18 - Posição da Superfície Freática em relação aos pontos de integração. 66

Figura 19 - Comparação entre as funções Heaviside e quasi-Heaviside. . . . . . . . 67

Figura 20 - Comportamento e $\varepsilon$ e $A_{2}$ em função de $t_{a}$. . . . . . . . . . . . . 70

Figura 21 - Diferentes curvas de expansão para diferentes regimes de umidade. . . . 72

Figura 22 - Imagem das vigas de concreto armado e do esquema das condições de contorno de umidade aplicadas ao longo do ensaio. . . . . . . . . . . 72

Figura 23 - Deformação x Tempo de corpos de prova cilíndricos submetidos à condições diferentes de umidade. . . . . . . . . . . . . . . . 73

Figura 24 - Esquema e malha empregados para o exemplo da barragem retangular. 75

Figura 25 - Valores de $\phi$ ao longo da espessura da barragem. . . . . . . . . . . 76

Figura 26 - Valores de saturação ao longo da barra em três instantes diferentes. . . 77

Figura 27 - Mapas de saturação ao longo da barra em três instantes de tempo. . 77

Figura 28 - Deformada da viga engastada em centímetros. . . . . . . . . . . . . 78

Figura 29 - Gráfico de Força x Deslocamento para a extremidade direita da viga. . 78 
Figura 30 - Gráfico de Força x Deslocamento para a extremidade direita da barra tracionada. . . . . . . . . . . . . . . . . 79

Figura 31 - Curvas de expansão calibradas do modelo paramétrico em comparação com as curvas experimentais de Multon e Toutlemonde (2010). . . . . . 80

Figura 32 - Mapas de deformação em milímetros. . . . . . . . . . . . . . . . . . . . 80

Figura 33 - Posicionamento e nomenclatura dos medidores virtuais. . . . . . . . . . 81

Figura 34 - Curvas de expansão do corpo de prova. . . . . . . . . . . . . . . . 82

Figura 35 - Curvas do grau de saturação do extensômetro para o corpo de prova ao longo do tempo. . . . . . . . . . . . . . . . . . . . . . . . . . 82

Figura 36 - Deformada do corpo de prova ao longo do tempo em metros. . . . . . . 83

Figura 37 - Curvas de expansão do corpo de prova sob regime variável. . . . . . . . 83

Figura 38 - Curvas de saturação sem a lei de evolução. . . . . . . . . . . . . . . . . 84

Figura 39 - Curvas de expansão sem a lei de evolução. . . . . . . . . . . . . . . . . 85

Figura 40 - Curvas de saturação com a lei de evolução. . . . . . . . . . . . . . . . . 85

Figura 41 - Curvas de expansão com a lei de evolução. . . . . . . . . . . . . . . 86

Figura 42 - Deformada da barra prismática com a lei de evolução da expansão em milímetros. . . . . . . . . . . . . . . . . 8 86

Figura 43 - Representação e malha utilizados para o exemplo da barragem. . . . . 87

Figura 44 - Nível do reservatório ao longo do tempo. . . . . . . . . . . . . . . . 87

Figura 45 - Grau de saturação na altura dos extensômetros verticais. . . . . . . . . 87

Figura 46 - Curvas de expansão dos extensômetros horizontais. . . . . . . . . . . . 88

Figura 47 - Curvas de expansão dos extensômetros verticais. . . . . . . . . . . . . 88

Figura 48 - Mapa de cores da deformação sofrida pela barragem em metros. . . . . 89

Figura 49 - Curvas de expansão dos extensômetros horizontais. . . . . . . . . . . . 89

Figura 50 - Curvas de expansão dos extensômetros verticais. . . . . . . . . . . . . 89 


\section{Lista de tabelas}

Tabela 1 - Principais estruturas hidráulicas afetadas pela RAA no Brasil. . . . . . 23

Tabela 2 - Minerais reativos mais comuns e suas reações químicas. . . . . . . . . . 29 



\section{Sumário}

INTRODUÇÃO $\ldots \ldots \ldots \ldots \ldots \ldots \ldots \ldots$

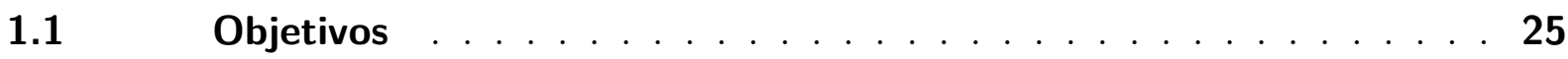

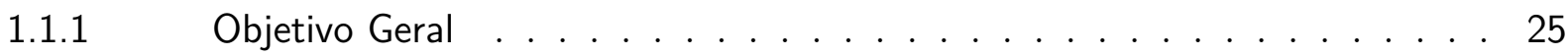

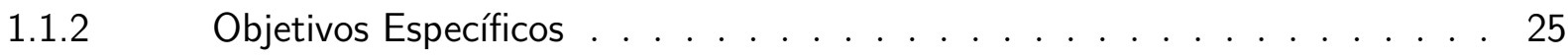

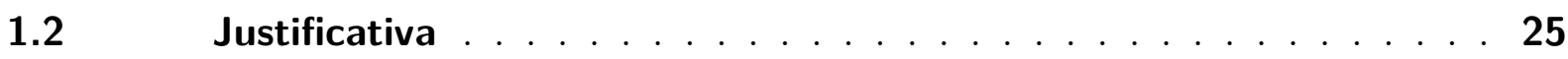

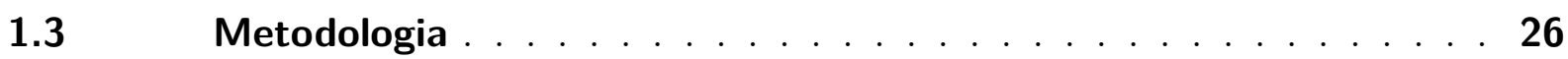

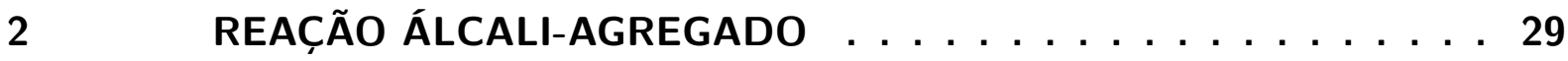

2.1 Reação Álcali-Carbonato . . . . . . . . . . . . . . 29

2.2 Reação Álcali-Sílica $\ldots \ldots \ldots \ldots \ldots$

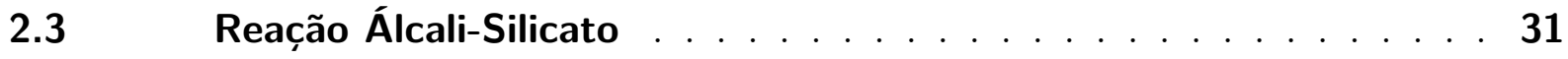

$2.4 \quad$ Gel de Sílica . . . . . . . . . . . . . . . . . . . 32

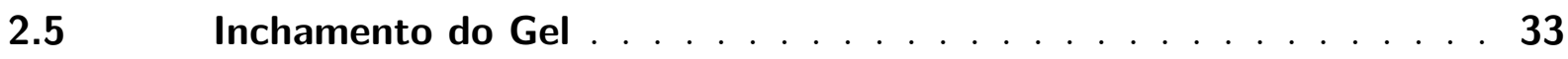

$2.6 \quad$ Fatores que influenciam a reação álcali-sílica . . . . . . . . . . 34

2.6 .1 Quantidade de álcalis no concreto . . . . . . . . . . . . . . . 34

2.6 .2 Temperatura . . . . . . . . . . . . . . . . . 35

2.6.3 Granulometria e Mineralogia do Agregado . . . . . . . . . . . . 35

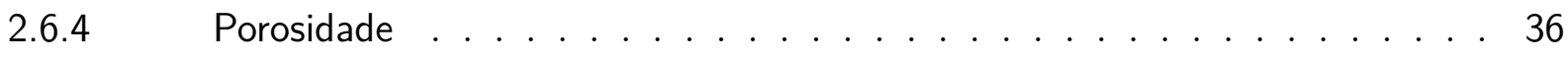

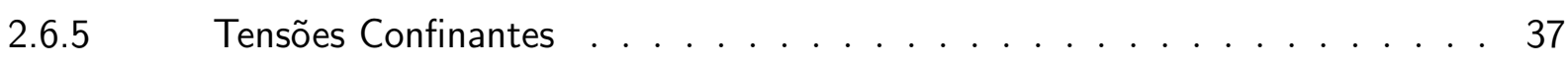

2.6.6 Grau de Umidade . . . . . . . . . . . . . . . . . . . . . . . . 38

3 MODELAGEM dA REAÇÃO ÁlCALI-SÍlICA . . . . . . . . . . 39

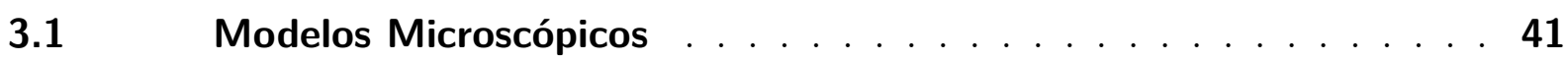

3.1.1 Modelo matemático para a cinética da reação álcali-sílica . . . . . . . . . . 41

3.1.2 Modelo Químico-Mecânico . . . . . . . . . . . . . . . . . . . . . 42

3.1.3 Modelo Poro-Mecânico . . . . . . . . . . . . . . . . . . 43

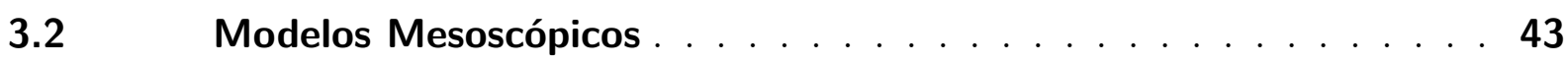

3.2.1 Modelo Elasto-Plástico Mecânico . . . . . . . . . . . . . . . 43

3.3 Modelos Macroscópicos . . . . . . . . . . . . . . . . . . . 44

3.3.1 Modelo Constitutivo Mecânico . . . . . . . . . . . . . . . . . 44

3.3.2 Modelo Paramétrico . . . . . . . . . . . . . . . . . . . . . 44

$3.4 \quad$ Modelo Adotado . . . . . . . . . . . . . . . . . . 47

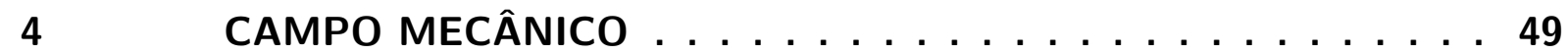

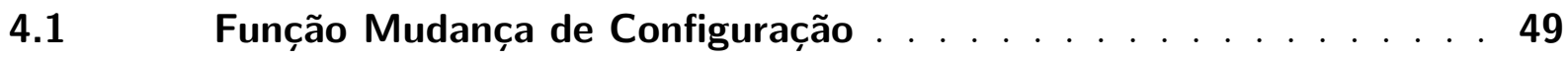

4.1.1 Mudança ou Variação de Volume . . . . . . . . . . . . . . . . . 50 
$4.1 .2 \quad$ Mudança de Área . . . . . . . . . . . . . . . . . . . . . 51

4.2 Tensor de Deformação de Green-Lagrange . . . . . . . . . . . . . . 52

4.3 Lei Constitutiva de Saint-Venant-Kirchhoff . . . . . . . . . . . . . . 53

$4.4 \quad$ Princípio da Energia Potencial Total Estacionária . . . . . . . . . . . 53

$4.5 \quad$ Método Iterativo de Newton Raphson _ . . . . . . . . . . . . . . . 54

4.6 Método dos Elementos Finitos Posicional Estático . . . . . . . . . 55

5 CAMPO HIGROMÉTRICO ..................... 59

$5.1 \quad$ Potencial Hidráulico Total . . . . . . . . . . . . . . . . . . . 59

$5.2 \quad$ Lei de Darcy . . . . . . . . . . . . . . . . . . . . . . 60

$5.3 \quad$ Lei de Darcy nas Três Direções . . . . . . . . . . . . . . . . 60

$5.4 \quad$ Equação de Continuidade para o Fluxo Estacionário . . . . . . . . 61

$5.5 \quad$ Equação de Laplace . . . . . . . . . . . . . . . . . . . 61

5.6 Modelagem da Percolação . . . . . . . . . . . . . . . 62

5.6.1 Modelagem de acordo com a segunda Lei de Fick . . . . . . . . . . . . . . 62

5.6.2 Modelagem da Percolação em Meio Poroso . . . . . . . . . . . . . . . . . 62

$5.6 .3 \quad$ Formulação por Elementos Finitos . . . . . . . . . . . . . . . . . . . . . . 64

6 ACOPLAMENTO HIGROMECÂNICO . . . . . . . . . . . 69

6.1 Expansão da RAA Levando em Consideração o Regime de Umidade. 69

6.2 Ensaio Laboratorial da Viga Semi-Imersa . . . . . . . . . . . . . . 72

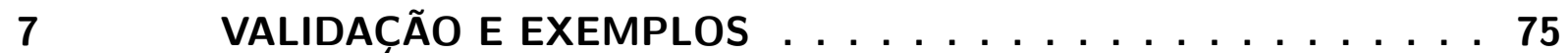

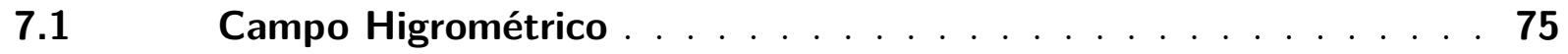

7.1.1 Barragem Retangular . . . . . . . . . . . . . . . 75

$7.1 .2 \quad$ Segunda Lei de Fick . . . . . . . . . . . . . . . . . 76

$7.2 \quad$ Campo Mecânico . . . . . . . . . . . . . . . . . . . . 77

7.2.1 Análise Não-Linear Geométrica de Viga Engastada . . . . . . . . . . . . 77

7.2.2 Barra Tracionada . . . . . . . . . . . . . . 78

7.3 Campo Higromecânico . . . . . . . . . . . . . . . . . . 79

7.3.1 Viga Sob Regime Não Uniforme de Umidade . . . . . . . . . . . . . . . . 79

7.3.2 Corpo de prova sob regime variável . . . . . . . . . . . . . . 81

7.3.2.1 Corpo de prova sob regime variável sem a implementação do $t_{a} \ldots \ldots$. . . . . . 83

$7.3 .3 \quad$ Barra Prismática . . . . . . . . . . . . . . . . 83

7.3.4 Barragem do tipo Pine Flat com Variação do Nível d'água . . . . . . . . . 86

CONCLUSÃO . . . . . . . . . . . . . . . . 91

REFERÊNCIAS . . . . . . . . . . . . . . . 93 


\section{Introdução}

Embora o concreto seja um material que apresente inúmeras características favoráveis para aplicações na construção civil, este também apresenta susceptibilidade à deterioração por diversos fatores. De acordo com Mehta e Monteiro (2005), o processo de degradação do concreto pode ser entendido dentro de dois grandes grupos, o da deterioração física e química. Como degradação física pode-se incluir a abrasão superficial, cavitação, cristalização de sais nos poros, erosão devido ao escoamento d'água, exposição à temperaturas extremas e ciclos de gelo e degelo. Dos exemplos de deterioração química é possível destacar a carbonatação, lixiviação, ataques por substâncias ácidas, reações expansivas por ataques de sulfatos, corrosão de armaduras, etc. A reação álcali-agregado se insere dentro dos fenômenos de deterioração química, dado o fato que ocorrem transformações químicas entre os compostos constituintes do concreto. Vale destacar que dentre os processos de degradação de uma estrutura de concreto, o denominador comum é a presença de água e, portanto, a permeabilidade de uma estrutura é de suma importância. Neste sentido, a água propicia o transporte dos íons alcalinos e a formação do gel de álcali-sílica durante o processo da reação álcali-agregado.

De acordo com a ABNT NBR 15577-1 (2008), a reação álcali-agregado (RAA) é classificada em dois grupos, reação álcali-sílica (RAS) e reação álcali-carbonato (RAC), por possuírem natureza química e sintomas distintos. Um terceiro tipo de reação, a reação álcali-silicato, é entendida como um caso específico da reação álcali-sílica. Neste trabalho será abordado especificamente a reação álcali-sílica por ser o tipo de reação mais nociva para o concreto. Na RAS há a formação de um gel com propriedades higroscópicas que, ao entrar em contato com íons hidroxila, absorve a água. Com a absorção da água, sua estrutura cristalina expande, promovendo variação volumétrica, perda de resistência e redução brusca do modo de elasticidade do concreto, afetando principalmente estruturas hidráulicas tais como barragens e piers (MEHTA; MONTEIRO, 2005).

Segundo Silveira (2006), os sintomas associados à presença de RAA são:

- Fissuras padrão tipo "mapa", sendo que há uma tendência de ordenação quando em estruturas de concreto armado;

- Eflorescência e exsudação de gel, no caso de reação álcali-sílica;

- Descoloração do concreto;

- Agregados graúdos com bordas de reação;

- Poros do concreto preenchidos total ou parcialmente por material esbranquiçado com composição do gel e

- Microfissuração da argamassa com preenchimento de material branco. 
Segundo Gomes Neto e Barreto (2013), até o presente momento, não há solução definitiva para o problema da RAA. Já foi comprovada a eficiência das pozolanas (sílica ativa, cinzas volantes, metacaulim, etc) na redução dos efeitos da RAA. Entretanto, não há a garantia da estabilização da reação a longo prazo, principalmente se agentes externos contribuem para o processo. Ademais, muitas das soluções podem ser onerosas ou tecnicamente inviáveis em sua execução.

De acordo com Pecchio et al. (2006), na região metropolitana do Grande Recife, nos últimos anos vem aumentado drasticamente o número de obras relatadas que sofrem manifestações patológicas, principalmente nos blocos e sapatas de fundação de edifícios residenciais e comerciais. Estima-se que são aproximadamente duas dezenas de casos identificados.

Historicamente falando, o primeiro pesquisador a estudar o que viria a ser a reação álcali-agregado foi Stanton (1940), analisando corpos de prova de estruturas danificadas na Califórnia nas décadas de 1920 e 1930.

Já no Brasil, os primeiros trabalhos a abordarem a RAA são da década de 60, com os estudos dos agregados naturais para construção da barragem de Jupiá. Em 1985, no XVI Seminário Nacional de Grandes Barragens é divulgada suspeita de reação álcali-agregado na Usina Hidrelétrica de Moxotó, concedida para Companhia Hidrelétrica do São Francisco (CHESF). Em 1988, por meio de estudos desenvolvidos pela Associação Brasileira de Cimento Portland (ABCP), é confirmado a presença de RAA no vertedouro da barragem de abastecimento de Joanes II, na Bahia (SCANDIUZZI; BATTAGIN; KIHARA, 2001).

A tabela 1 faz um breve apanhado de algumas das hidrelétricas que relataram sofrer de reação álcali-agregado no Brasil. 
Tabela 1 - Principais estruturas hidráulicas afetadas pela RAA no Brasil.

\begin{tabular}{|c|c|c|c|c|c|}
\hline Estrutura & $\begin{array}{l}\text { Fim da } \\
\text { Construção }\end{array}$ & $\begin{array}{l}\text { Evidenciado a } \\
\text { RAA }\end{array}$ & Litologia & $\begin{array}{l}\text { Local Afetado } \\
\text { pela RAA }\end{array}$ & Ref. \\
\hline Barragem Atibainha & 1973 & 1992 & $\begin{array}{l}\text { Biotita gnaisse cata- } \\
\text { clástico }\end{array}$ & Muro da Tulipa & 4 \\
\hline Barragem Cascata & 1976 & 1992 & Granito gnaisse & $\begin{array}{l}\text { Travessia a Ju- } \\
\text { sante }\end{array}$ & 4 \\
\hline Barragem de Pedras & 1970 & 1990 & Quartzito & Barragem & 3 \\
\hline Barragem de Pirapora & 1956 & 1998 & - & Barragem & 5 \\
\hline Barragem Joanes II & 1971 & 1994 & Gnaisse & Barragem & 3 \\
\hline Barragem Paiva de Castro & 1972 & 1992 & Biotita granito-gnaisse & $\begin{array}{l}\text { Vertedouro e } \\
\text { Muro Esquerdo }\end{array}$ & 4 \\
\hline Barragem Reguladora Billings-Pedra & 1926 & 1995 & Granito & Barragem & 3 \\
\hline Barragem Reguladora Pedro Beicht & 1932 & 1995 & Granito-gnaisse & Barragem & 3 \\
\hline Barragem Ribeirão do Campo & 1962 & 1992 & Biotita granito-gnaisse & Galeria & 4 \\
\hline Barragem Rio das Pedras & 1970 & 1996 & Gnaisse & Barragem & 3 \\
\hline Barragem Tapacurá & 1975 & 1990 & - & Barragem & 2 \\
\hline Túnel 2 & 1973 & 1992 & Granito & Emboque & 4 \\
\hline Túnel 7 & 1981 & 1992 & $\begin{array}{l}\text { Granito-gnaisse cata- } \\
\text { clástico }\end{array}$ & Contraforte & 4 \\
\hline UHE Furnas & 1964 & 1976 & Quartzito & Barragem & 3 \\
\hline UHE Ilha dos Pombos & 1930 & 1990 & Gnaisse & Barragem & 3 \\
\hline UHE Jaguara & 1971 & 1996 & Quartzito & Barragem & 3 \\
\hline UHE Jaguari & 1982 & 1992 & Gnaisse milonitizado & $\begin{array}{l}\text { Crista verte- } \\
\text { douro }\end{array}$ & 4 \\
\hline UHE Jurupá & 1970 & 1995 & Gnaisse & Barragem & 3 \\
\hline UHE Luiz Carlos Barreto e Carvalho & - & - & Quartzito & Vertedouro & 1 \\
\hline UHE Mascarenhas de Morais & 1957 & - & Quartzito & Barragem & 1 \\
\hline UHE Moxotó & 1977 & 1985 & Granito-gnaisse & Casa de força & 3 \\
\hline UHE Paulo Afonso I & 1954 & 1978 & Granito-gnaisse & Barragem & 3 \\
\hline UHE Paulo Afonso II & 1960 & 1978 & Granito-gnaisse & Barragem & 3 \\
\hline UHE Paulo Afonso III & 1973 & 1978 & Granito-gnaisse & Barragem & 3 \\
\hline UHE Paulo Afonso IV & 1979 & 1985 & Granito-gnaisse & Barragem & 3 \\
\hline UHE Peti & 1946 & 1990 & Gnaisse & Barragem & 3 \\
\hline UHE Porto Colômbia & 1973 & 1985 & Cascalho e Basalto & $\begin{array}{l}\text { Vertedouro e } \\
\text { Casa de força }\end{array}$ & 1 \\
\hline UHE Sá Carvalho & 1975 & 1995 & Gnaisse & Barragem & 3 \\
\hline UHE Santa Branca & 1960 & 1995 & Gnaisse & Barragem & 3 \\
\hline Usina Elevatória de Traição & 1940 & 1990 & Milonito & Barragem & 3 \\
\hline UTE Piratininga & 1962 & 2002 & - & $\begin{array}{l}\text { Recalque do } \\
\text { Pórtico }\end{array}$ & 5 \\
\hline
\end{tabular}

Referências:

1 Veiga, Gonçalves e Hasparyk (1997)

2 Hasparyk (1999)

3 Andriolo (2000)

4 Tung et al. (2006)

5 Braun (2006)

Fonte: Apud Couto (2008) 
Na figura 1 é possível ver o padrão de fissuração não ordenado por reação álcaliagregado em um bloco de fundação de uma obra residencial em Recife.

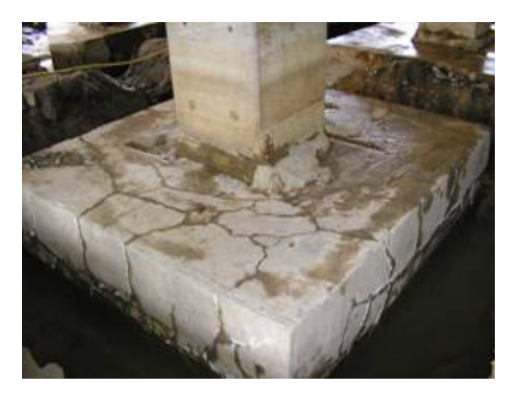

Figura 1 - Vista Superior de Pilar e do Bloco de Fundação atacados pela RAA.

Fonte: Pecchio et al. (2006)

A forma como a água participa da expansão e da formação do gel é bem conhecida tal como elaborado em Steffens, Li e Coussy (2003), Poyet et al. (2006), Grimal et al. (2008a), Grimal et al. (2008b) e usualmente empregada na modelagem de estruturas como demostrado em Léger, Coté e Tinawi (1996), Pappalardo, Pauletti e Pimenta (2000), Ulm et al. (2000) e Carrazedo (2004). Ademais, é possível calibrar um modelo a condições distintas de umidade e predizer, de forma satisfatória, a resposta mecânica de uma estrutura. No entanto, cabe questionamento quanto a variação deste campo ao longo do tempo, pois usualmente as estruturas não estão sujeitas a um gradiente constante, com exceção das submersas.

Neste trabalho é estudada numericamente a influência do campo higrométrico na reação álcali-sílica e em especial, o comportamento da expansão no provimento tardio de umidade a uma estrutura que apresenta o desenvolvimento desta manifestação patológica.

É realizada a implementação numérica do campo higrométrico e sua influência sobre a RAS. Normalmente é considerado que a estrutura está sujeita a um campo higrométrico constante e igual em todos os pontos, o que não reflete a realidade. Por isso é feita uma análise em regime quase-estático de percolação em meios porosos indeformáveis, propiciando assim dados para a obtenção da deformação da estrutura pela RAS, de acordo com uma equação de expansão da reação.

Para tanto é proposto e implementada uma nova função para a representação da expansão da RAS quando submetida a diferentes regimes de umidade, dissociando a presença da água para a formação do gel, refletindo pesquisas mais recentes como as de Multon e Toutlemonde (2010) e Pignatelli, Comi e Monteiro (2013). O provimento tardio de água altera significantemente a curva de expansão do concreto. A partir desta nova função, é possível simular condições com regimes de umidade diversos e em tempo distintos, a partir do momento em que o corpo entra em contato com a água. 


\subsection{Objetivos}

Este trabalho tem o propósito de realizar análises numéricas relacionadas à expansão do concreto promovida pela reação álcali-sílica, com o intuito de propiciar ferramentas de controle e recuperação de estruturas de concreto em processo de deterioração.

\subsubsection{Objetivo Geral}

Desenvolver um modelo numérico para análise plana de percolação em meios porosos de estruturas hidráulicas e implementação da deformação do material devido à RAS por meio do Método dos Elementos Finitos, ao longo do tempo, agregando questões relativas a dinâmica do campo higrométrico.

Conjuntamente, são realizados exemplos numéricos e comparação de resultados com ensaios para verificação e comprovação do modelo proposto.

\subsubsection{Objetivos Específicos}

- Estudar a influência do campo higrométrico sobre a reação álcali-sílica a partir das referências bibliográficas.

- Desenvolver um modelo numérico bidimensional baseado no Método dos Elementos Finitos para modelagem do campo higrométrico e no Método dos Elementos Finitos Posicional para a modelagem do campo mecânico para estruturas de concreto.

- Implementar uma nova função para a expansão da RAS que contemple regimes não-uniformes de umidade, refletindo os resultados de pesquisas mais recentes.

\subsection{Justificativa}

A caracterização do comportamento mecânico ao longo do tempo em estruturas de grandes volumes, como por exemplo, pontes, barragens e obras industriais, é de grande interesse no que diz respeito à segurança estrutural, durabilidade, performance e economia. As estruturas sujeitas a reação álcali-agregado tem uma redução considerável em sua vida útil, e diversas ações corretivas são necessárias para minimizar a intensidade dos efeitos sobre uma estrutura.

Este trabalho se baseia na continuação da pesquisa realizada em Carrazedo (2004), em que um modelo paramétrico foi proposto para a simulação da expansão volumétrica isotrópica do concreto devido à reação álcali-agregado. Alguns pontos de aprimoramento foram apresentados em Carrazedo, Sanches e Lacerda (2014), em que foi proposto um modelo paramétrico simulando a expansão ortotrópica do gel da RAS decorrente dos diferentes estados de tensão. Ademais, em Oliveira (2013) foi introduzido ao modelo para- 
métrico a redução do módulo de elasticidade, conforme o desenvolvimento da manifestação patológica.

Para sequência aos trabalhos citados anteriormente, é implementada a deformação do material devido à RAS no que diz respeito a percolação do meio, de acordo com uma função que represente a expansão promovida pela manifestação patológica, por meio do Método dos Elementos Finitos. Também é almejado propor uma melhor representação da umidade no desenvolvimento da mesma, dissociando a presença da água na formação do gel e na expansão da RAS.

\subsection{Metodologia}

Esta pesquisa faz uso de duas abordagens para a modelagem do campo higrométrico. Numa delas, por meio da percolação d'água em meios porosos, utilizando o algoritmo proposto em Bathe e Khoshgoftaar (1979) com mudança na forma de se tratar a superfície de percolação quando esta atravessa um elemento finito. Para fins de convergência do algoritmo, foi feita alteração na consideração do coeficiente de percolação no ponto de integração, como demonstrado em Zheng, Dai e Liu (2009), garantindo assim menor dependência de malha e também consideração da capilaridade. A outra abordagem é por meio da difusão d'água regida pela segunda lei de Fick.

Neste sentido, é necessário propor e implementar nova função de expansão da RAS representado regimes distintos de umidade, como provimento tardio de água e ciclos de molhagem e secagem.

Conjuntamente com a obtenção da superfície de percolação em meios porosos e nova função de expansão da RAS sob regimes não uniformes de umidade, a modelagem do campo mecânico é realizada mediante o Método dos Elementos Finitos Posicional.

A implementação do modelo numérico higromecânico é feita por meio da linguagem de programação FORTRAN, fazendo-se uso do compilador Intel@Visual Fortran versão 1564 bits. A geração da malha de elementos finitos, tanto para o campo mecânico como higrométrico, é feita pelo programa AcadMesh e os resultados gerados são exportados para o visualizador AcadView. Na figura 2 está representado um fluxograma global do modelo numérico e sua relação com os outros dois programas supracitados. Na figura 3 está o fluxograma específico do modelo numérico higromecânico. O modelo é executado a cada instante de tempo $t$, até chegar no tempo final $t_{\text {final }}$. 


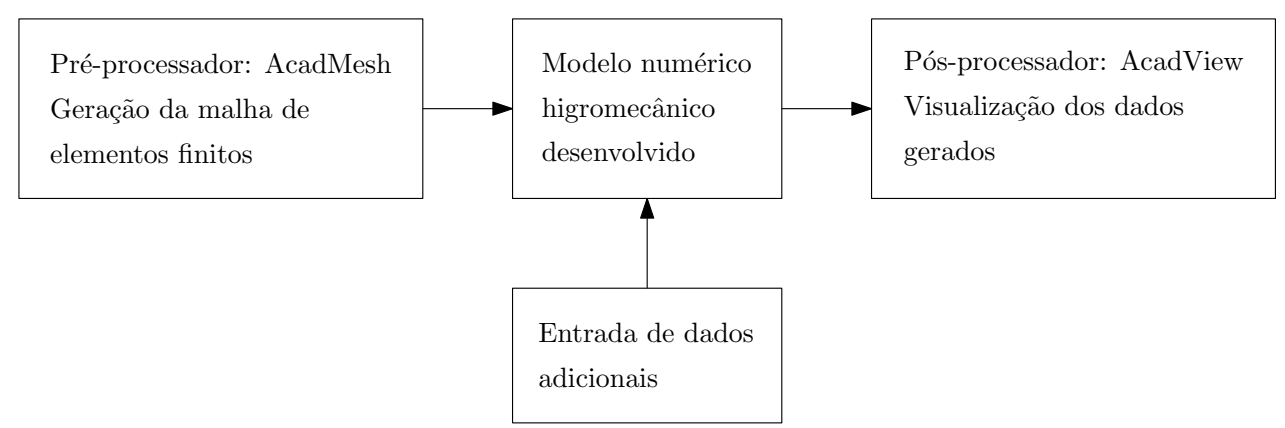

Figura 2 - Fluxograma do modelo numérico desenvolvido e interação com o pré-processador e pós-processador.

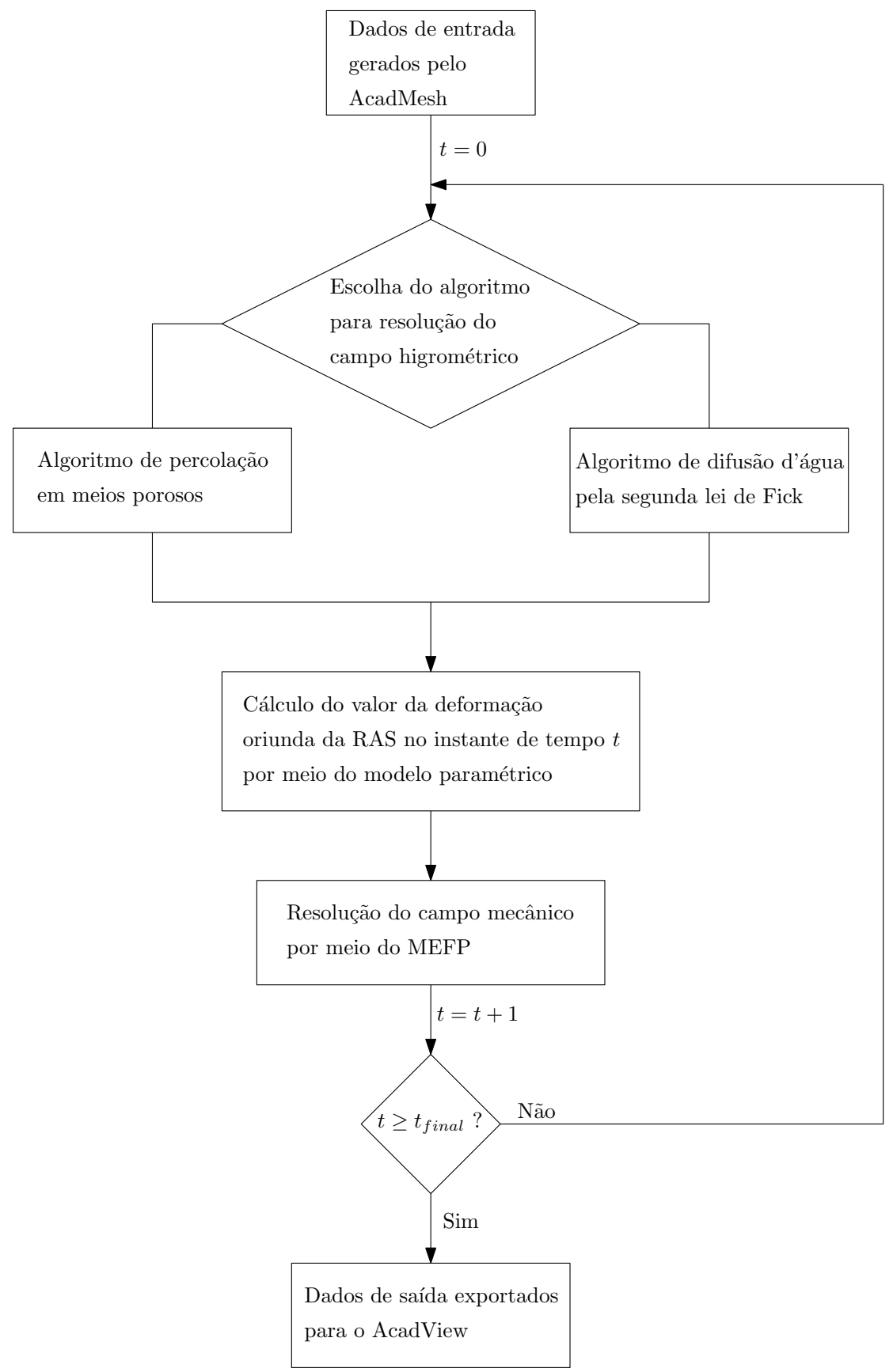

Figura 3 - Fluxograma específico do modelo numérico higromecânico desenvolvido. 
A organização do trabalho é dada pela seguinte ordem. No capítulo dois é discutido com mais detalhes a manifestação patológica. É mostrado o processo de formação do gel e os fatores que podem influenciar a expansão. No capítulo três são abordados os modelos de expansão por RAS mais comuns e o modelo adotado. No capítulo quatro é apresentada a modelagem do campo mecânico, juntamente com sua fundamentação. No capítulo cinco encontra-se os modelos utilizados para descrever o campo higrométrico. Ao todo o campo higrométrico foi modelado de duas formas distintas, a depender da aplicação. O capítulo seis elucida como é realizado o acoplamento entre o campo mecânico e o campo higrométrico. Neste capítulo é mostrada a nova equação de expansão, modificada para contemplar regimes não uniformes de umidade. Também é descrito como a expansão pela RAS $(\varepsilon)$ e a taxa de expansão $\left(A_{2}\right)$ variam quando deixam de entrar em contato com a água. No capítulo sete encontram-se exemplos numéricos que validam e demonstram os conceitos desenvolvidos até então. Ao fim, está o capítulo oito com as conclusões obtidas com o trabalho. 


\section{Reação Álcali-Agregado}

Segundo Mehta e Monteiro (2005), os materiais utilizados para a fabricação do clínquer do cimento Portland são as principais fontes dos álcalis presentes no concreto, podendo seu teor variar de $0,2 \%$ a $1,5 \%$ de $\mathrm{Na}_{2} \mathrm{O}$. Dependendo do teor de álcalis presentes no cimento, o pH de misturas convencionais de concreto pode ficar na faixa de 12,5 a 13,5, representando um fluído extremamente alcalino que em presença de rochas ácidas, compostas de sílica e minerais siliciosos, não se mantém estável em períodos longos de tempo.

A reação álcali-agregado pode ser separada em basicamente dois tipos de reação, reação álcali-sílica (RAS) e reação álcali-carbonato (RAC). Um terceiro tipo, a reação álcali-silicato, é derivado da RAS devido a sua grande similaridade.

Na tabela 2 são apresentados os tipos de minerais reativos e quais os tipos de reações que estes provocam.

Tabela 2 - Minerais reativos mais comuns e suas reações químicas.

\begin{tabular}{ccc}
\hline Mineral Reativo & Composição Química Reativa & Natureza da Reação \\
\hline \hline Quartzo Deformado & $\mathrm{SiO}_{2}$ & Álcali-Silicato \\
\hline Opala & $\mathrm{SiO}_{2} \cdot \mathrm{H}_{2} \mathrm{O}$ & Álcali-Sílica \\
\hline Calcedônia & $\mathrm{SiO}_{2}$ & Álcali-Sílica \\
\hline Tridimita / Cristobalita & $\mathrm{SiO}_{2}$ & Álcali-Sílica \\
\hline Vidros & Silicosos com $\mathrm{Al}_{2} \mathrm{O}_{3}$ e $\mathrm{Fe}_{2} \mathrm{O}_{3}$ & Álcali-Sílica \\
\hline Calcita & $\mathrm{CaMg}\left(\mathrm{CO}_{3}\right)_{2}$ & Álcali-Carbonato \\
\hline
\end{tabular}

Fonte: Mehta e Monteiro (2005)

Embora os mecanismos de expansão sejam diferentes para cada tipo de reação, todos exigem a presença de álcalis liberados durante a hidratação do cimento e os componentes químicos reativos do agregado.

\subsection{Reação Álcali-Carbonato}

O processo de expansão da reação álcali-carbonato, num consenso entre os pesquisadores, ocorre em duas etapas. Primeiramente acontece a desdolomitização, que se trata da modificação da estrutura do calcário, provocando aumento de volume e enfraquecimento da ligação pasta-agregado. Posteriormente, ocorre a regeneração dos íons alcalinos. 
Segundo Liang e Mingshu (1995), a desdolomitização é a reação que ocorre entre os íons alcalinos e o calcário dolomítico. Tal reação é apresentada na equação 2.1:

$$
\mathrm{CaMg}\left(\mathrm{CO}_{3}\right)_{2}+2 \mathrm{MOH}=\mathrm{Mg}(\mathrm{OH})_{2}+\mathrm{CaCO}_{3}+\mathrm{M}_{2} \mathrm{CO}_{3}
$$

em que $\mathrm{CaMg}\left(\mathrm{CO}_{3}\right)_{2}$ é a dolomita, ou calcário dolomítico. $M$, na equação 2.1, pode ser sódio $(\mathrm{Na})$, potássio $(\mathrm{K})$ ou lítio $(\mathrm{Li}) .2 \mathrm{MOH}$ e $\mathrm{M}_{2} \mathrm{CO}_{3}$ podem ser hidróxido e carbonato de sódio, potássio ou lítio, respectivamente. Do processo de desdolomitização, surgem cristais de brucita $\left(\mathrm{Mg}(\mathrm{OH})_{2}\right)$ e calcita $\left(\mathrm{CaCO}_{3}\right)$. Logo após a desdolomitização vem a segunda reação, de álcali-magnesita, como apresentada na equação 2.2 :

$$
\mathrm{MgCO}_{3}+2 \mathrm{MOH}=\mathrm{Mg}(\mathrm{OH})_{2}+\mathrm{M}_{2} \mathrm{CO}_{3}
$$

com $\mathrm{MgCO}_{3}$ sendo carbonato de magnésio e $M$ um íon alcalino. Por fim, tem-se a liberação de mais íons alcalinos e formação de calcita, mantendo o pH da solução alcalino. O álcali, neste caso, funciona apenas como catalisador da reação.

De acordo com Liang e Mingshu (1999), a partir dos seus estudos em Liang et al. (1997) e Liang e Mingshu (1997), a expansão ocorre por causa da formação e crescimento de produtos cristalinos em um espaço confinado, na interface entre cristais dolomíticos e a matriz, mesmo sabendo-se que a reação de desdolomitização gera partículas de volume menor.

\subsection{Reação Álcali-Sílica}

Dependendo do grau de desarranjo da estrutura cristalina do agregado, da porosidade e tamanho da partícula, géis álcali-silicato de composição variada são formados na presença de hidroxilas e íons álcali-metálicos. A forma de ataque no concreto envolve a despolimerização da estrutura da sílica do agregado pelos íons de hidroxila, seguido da absorção dos íons álcali-metálicos na superfície recém formada pela reação química. Quando o gel entra em contato com a umidade, este incha, absorvendo por osmose grande quantidade de água. Se o grau de restrição do sistema for baixo, a pressão hidráulica desenvolvida pode ser suficiente para causar a expansão e fissuração da partícula de agregado afetada e também da pasta de cimento envolvente (MEHTA; MONTEIRO, 2005).

Durante o processo de hidratação do cimento, ocorre uma liberação de grande quantidade de hidróxidos alcalinos, tornando o fluído dos poros de concreto altamente básico. Conjuntamente têm-se íons hidroxila $\left(\mathrm{OH}^{-}\right)$dissociados que em contato com o dióxido de silício $\left(\mathrm{SiO}_{2}\right)$ presente nos agregados, modificam sua estrutura e possibilitam associação do mesmo com íons metálicos alcalinos, tais como o sódio $(N a)$ e potássio $(K)$, formando assim o gel. Segundo Trembley et al. (2010), o íon Lítio ( $L i)$ também pode 
fazer parte da associação, entretanto este possui um resultado benéfico pois aumenta a estabilidade química e redução da dissolução da sílica.

Segundo Vayghan, Rajabipour e Rosenberger (2016), a mera formação de gel de álcali-sílica nem sempre resulta em danos ao concreto e diferentes composições do gel podem propiciar comportamentos distintos. A tensão de escoamento do gel, aquela que impede do gel escoar pelos poros do concreto, é maior em casos de baixas concentrações de cálcio $(C a)$ e sódio $(N a)$, seguida logo depois dos casos em que há grande presença tanto de $C a$ como de $N a$. Ademais, o cálcio não mostrou ter influência significativa na pressão osmótica em composições com baixo teor de sódio enquanto que mostrou reduzir a pressão osmótica em formações com bastante presença de $N a$. Entretanto, o aumento da concentração de $N a$ igualmente eleva a pressão osmótica do gel. Por fim, a pressão causada pela expansão do gel é maior em casos de concentrações moderadamente altas de $\mathrm{Ca}$ e $\mathrm{Na}$.

No trabalho de Urhan (1987) é dito que ocorre a dissolução de átomos de sílica na superfície do agregado pela absorção de íons hidroxila. O cálcio é absorvido mais rapidamente, formando cristais de C-S-H (silicatos de cálcio hidratados). Se a taxa de cristalização for maior que a dissolução de sílica, os cristais de C-S-H vão se formar na superfície da sílica e o processo pára. Se ocorrer o contrário haverá a continuação da dissolução, propiciando penetração de íons alcalinos e formação do gel de álcali-sílica.

Segundo Glasser e Kataoka (1981), no que diz respeito à reatividade, o ataque de álcalis de cristais bem definidos de sílica na superfície de agregado é lento. Cristais mais dispersos permitem a penetração de hidróxidos e álcalis em seu interior e, portanto, a reação ocorre de forma mais rápida.

\subsection{Reação Álcali-Silicato}

Segundo a ABNT NBR 15577-1 (2008), a reação álcali-silicato é um tipo específico da reação álcali-sílica em que participam os álcalis e alguns tipos de silicatos presentes em certas rochas. Os silicatos reativos mais comuns são os quartzos tensionados por processos tectônicos e os minerais da classe dos filossilicatos, os quais estão presentes em ardósias, filitos, xistos, gnaisses, granulitos, quartzitos, entre outros.

De acordo com Valduga (2002), a maior parte das barragens que apresentam esse tipo de reação foram construídas com rochas do tipo quartzo-feldspáticas, tais como o quartzito, granito e gnaisses. Essas rochas são encontradas ao longo de vasta faixa territorial, o que justifica a grande ocorrência da reação álcali-silicato.

Será dado maior enfoque a este tipo de reação por ser a reação mais comum no Brasil. A partir deste ponto, tanto a reação álcali-sílica como a reação álcali-silicato serão denominadas como RAS. 


\subsection{Gel de Sílica}

A sílica é um composto polimórfico, e portanto, pode ser encontrada com diversos arranjos estruturais apesar de possuir a mesma composição química, assim como o carbono. Na sua forma estável ela forma uma rede cristalina de tetraedros de sílica, conectados entre si por meio dos seus átomos de oxigênio que formam seus vértices. O problema é quando o agregado utilizado se encontra contaminado com sílica reativa, ou seja, sílica metaestável que, em contato com o ambiente extremamente alcalino do concreto, é atacada e reações químicas passam a ocorrer. A estrutura da sílica metaestável não é tão definida, possuindo um arranjo mais caótico, além de apresentar também impurezas e outros elementos, facilitando assim o ataque por agentes agressivos (RAJABIPOUR et al., 2015).

Pode-se ver na figura 4 a presença de agregados afetados pela reação álcali-sílica. Na figura 4a está um agregado de granito com formação de gel concentrada basicamente no seu entorno formando uma borda de reação, justamente na zona de transição, região de interface entre a pasta de cimento com o agregado. Na figura $4 \mathrm{~b}$ é representado um agregado de vidro sodo-cálcico e é possível ver a formação de gel no interior do agregado, atravessando-o, e pouca concentração de gel em seu entorno. Isto demonstra a complexidade da RAS frente às variáveis que governam sua formação e comportamento.

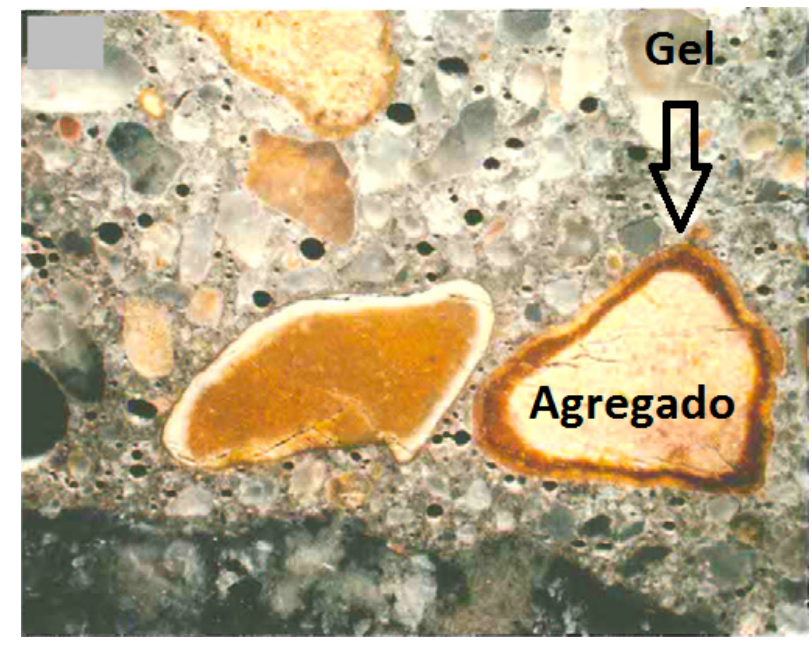

(a) Granito

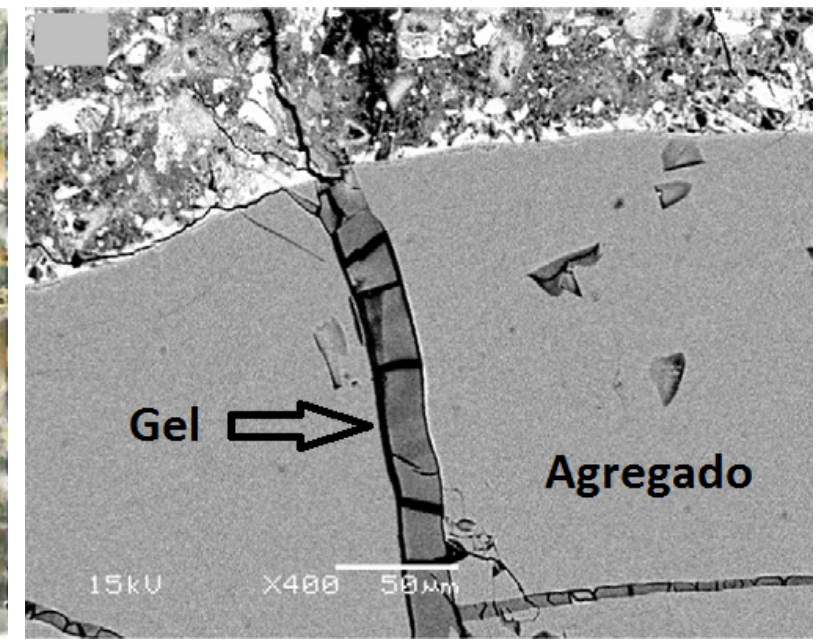

(b) Vidro Sodo-Cálcico

Figura 4 - Formação de gel de sílica em dois agregados distintos. Fonte: Adaptado de Rajabipour et al. (2015)

$\mathrm{Na}$ figura 5a pode-se perceber uma rede cristalina e estável de sílica (quartzo), com átomos de silício no centro, envoltos por átomos de oxigênio fazendo as conexões. Já na figura 5b é mostrada sílica amorfa, susceptível a ataques químicos pelos álcalis presentes no cimento e com contribuição de álcalis e cálcio formando conexões. Por fim, tem-se na figura 5c uma representação do gel de álcali-sílica, composto por uma aglomeração de partículas de sílica coloidal em meio à solução porosa do gel. A estrutura da sílica se mostra altamente degradada (RAJABIPOUR et al., 2015). 

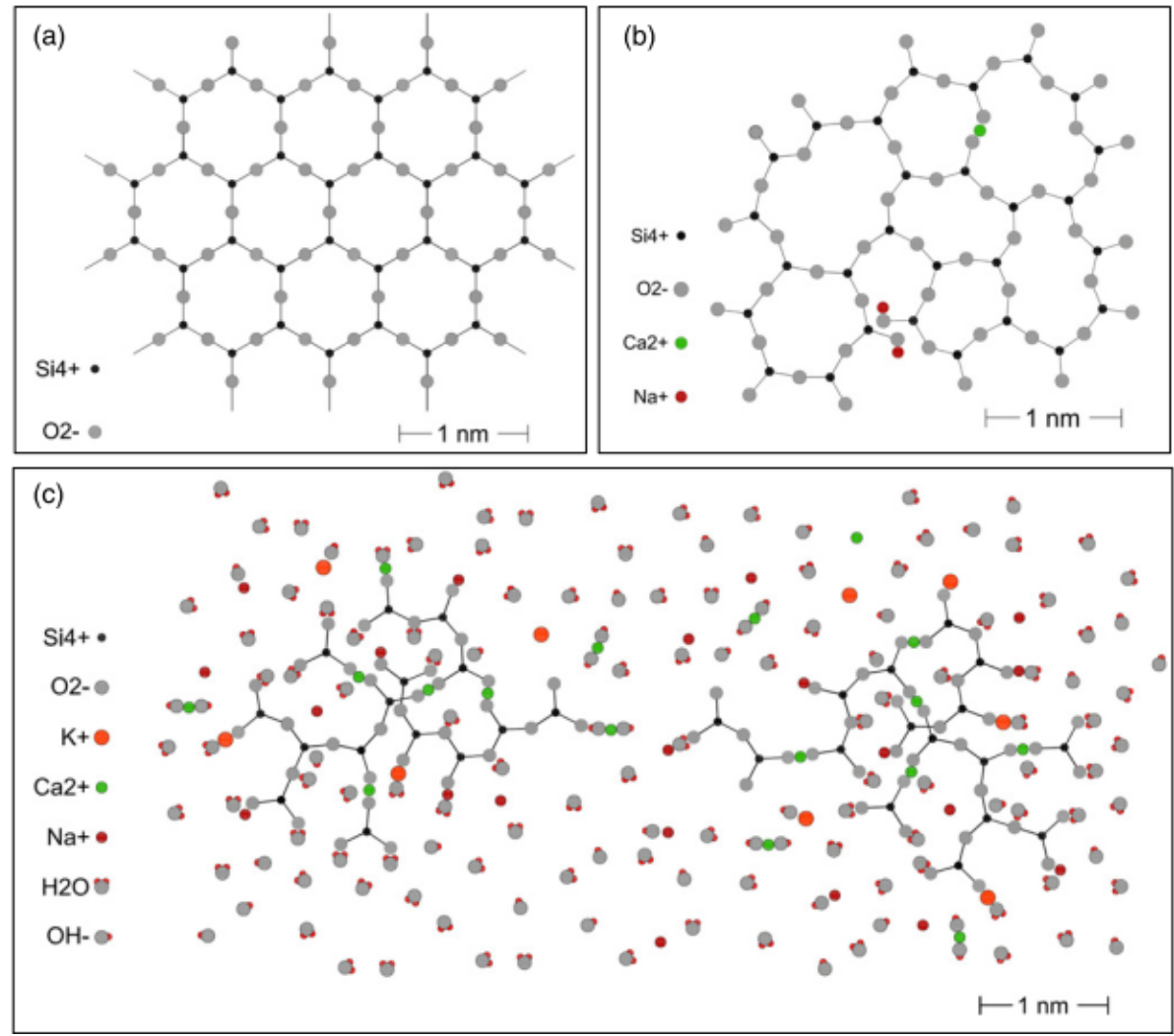

Figura 5 - Diversos tipos de arranjo estrutural para sílica.

Fonte: Rajabipour et al. (2015)

Após a dissolução da sílica em uma solução coloidal, o cálcio começa a agir realizando diversas ligações crosslink, fazendo surgir assim o gel expansivo.

\subsection{Inchamento do Gel}

Após a formação do gel, este absorve qualquer quantidade de umidade presente ao redor e sofre expansão volumétrica. O mecanismo de expansão não está completamente compreendido, entretanto há algumas hipóteses comumente aceitas.

O gel de sílica é poroso, possui alta superfície específica e muitos grupos hidrofílicos $(-\mathrm{OH},-\mathrm{O}, \ldots, \mathrm{Na})$, resultando assim em pressão osmótica, absorção d'água e inchamento. A pressão osmótica adicional poderia ser gerada por meio do efeito Gibbs-Donnan, no qual o gel age como membrana semipermeável, permitindo a entrada de pequenos álcalis e hidroxilas para difusão no gel, enquanto é impedida a saída de íons maiores de sílica para a solução de concreto, criando assim pressão osmótica e movimentação da água adjacente para o interior do gel. O inchamento do gel também está relacionado com a viscosidade do gel, que é função do grau de conectividade entre as partículas coloidais (RAJABIPOUR et al., 2015). 
A mobilidade do gel também influencia a absorção da água. Com o gel fluindo para o interior do agregado e para outros pontos do concreto, este pode absorver mais água e criar fissuras. O processo químico é resumido por Chatterji, Thaulow e Jensen (1989) pela equação 2.3:

$$
\mathrm{SiO}_{2}+2 \mathrm{Na}^{+}+2 \mathrm{Cl}^{-}+\mathrm{Ca}^{++}+2 \mathrm{OH}^{-} \rightarrow \text { Complexo de Sílica/Sódio }+\mathrm{Ca}^{++}+2 \mathrm{Cl}^{-}
$$

Outro mecanismo proposto em Chatterji et al. (1986) diz que a expansão ocorre quando a taxa de penetração de íons hidroxila (sódio e potássio) nos cristais de sílica for superior a taxa de saída dos íons de sílica do agregado para o concreto.

Este processo de inchamento provoca mudança de volume e forma que pode se tornar significativa, afetando a estrutura e seu desempenho. Podem ocorrer desaprumos, desalinhamentos, interferência nos equipamentos e instalações (pontes rolantes e turbinas, por exemplo), interrupção do funcionamento de determinados componentes, agravamento de outras manifestações patológicas e danos estruturais.

\subsection{Fatores que influenciam a reação álcali-sílica}

Existem diversos fatores que podem influenciar na reação álcali-sílica. Segue-se uma explicação dos fatores mais importantes para a RAS e formação do gel.

\subsubsection{Quantidade de álcalis no concreto}

A principal fonte de álcalis no concreto provém do cimento portland. Segundo Collins e Bareham (1987), cimentos com teor de álcalis superior a 0,6\% de $\mathrm{Na}_{2} \mathrm{O}$ equivalente $\left(\mathrm{Na}_{2} \mathrm{O}+0,658 \mathrm{~K}_{2} \mathrm{O}\right)$ quando expostos a agregado reativo, são capazes de gerar gel expansivo por meio da reação álcali-sílica e álcali-silicato.

Vale notar que podem existir outras fontes de álcalis encontrados em aditivos, adições minerais, agregados contaminados e água do mar. (BÉRUBÉ et al., 2002). Também existem agregados que liberam álcalis na solução dos poros do concreto, podendo provocar a RAA até em cimentos de baixa alcalinidade. (CONSTANTINER; DIAMOND, 2003). A figura 6 mostra as regiões de ocorrência ou não de RAA dependendo da concentração de álcalis no cimento e quantidade de cimento.

O teor de álcalis apenas afetará as reações álcali-sílica e álcali-silicato, formando em ambos os casos o gel expansivo. Para a reação álcali-carbonato, os álcalis servem como catalisadores da reação de desdolomitização, sendo regenerados durante o processo. 


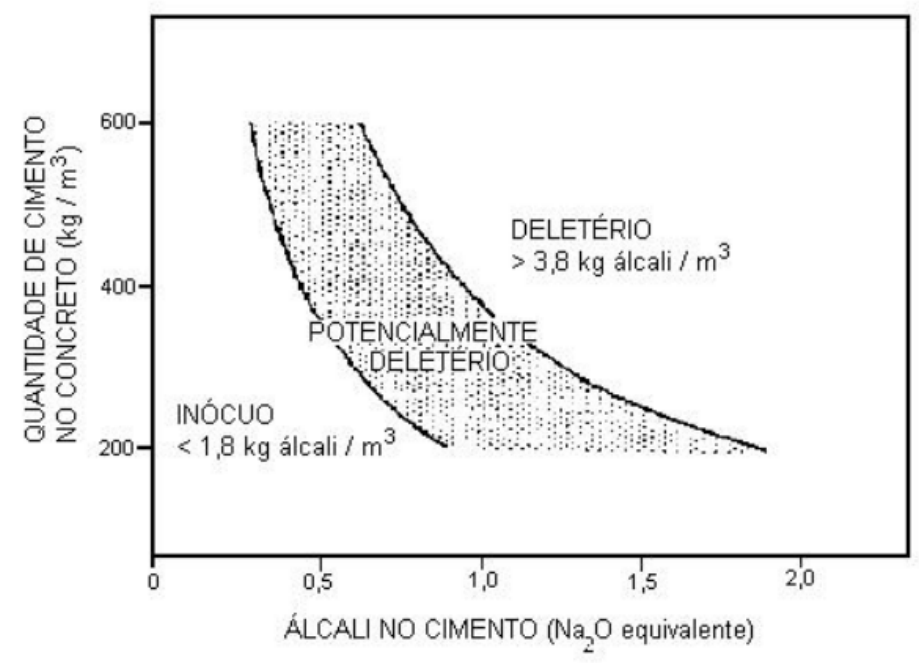

Figura 6 - Regiões de ocorrência ou não de RAA de acordo com quantidade de álcalis no cimento e quantidade de cimento.

Fonte: Adaptado de Wigum (1995)

\subsubsection{Temperatura}

De acordo com Collins e Bareham (1987), o aumento da temperatura aumenta a solubilidade da sílica e reduz a do $\mathrm{Ca}(\mathrm{OH})_{2}$. Com isto tem-se um aumento na velocidade de expansão por tornar a sílica mais propensa a reagir e redução da taxa de combinação do hidróxido de cálcio com o gel, que poderia diminuir sua expansibilidade.

Ademais, em Chatterji e Christensen (1990), com o decréscimo da temperatura, há um aumento no período inicial de expansão, provavelmente devido à lenta penetração de sais de sódio e redução na taxa de expansão da RAS.

Guthrie e Carey (2015) também indicam que mudanças nas condições de temperatura e umidade do concreto podem alterar as condições químicas em favor da formação do gel de álcali-sílica.

\subsubsection{Granulometria e Mineralogia do Agregado}

A reação álcali-sílica é complexa no sentido de que muitos fatores podem interferir. Dentre eles é possível destacar a granulometria e composição mineralógica do agregado utilizado. Existem agregados em que a sílica metaestável se encontra igualmente distribuída ao longo do agregado, propiciando assim um ataque pelos álcalis de fora para dentro, formando inicialmente gel em sua superfície. Outros tipos de agregados possuem maior concentração de sílica amorfa em seu interior e a formação de gel se dá de dentro para fora, que com o processo de expansão é capaz de partir o agregado ao meio. 
De acordo com Saouma et al. (2015), agregados de granulometria maior tendem a reter maiores concentraçoes de $\mathrm{OH}^{-}$and íons alcalinos em seu interior e, portanto, a formação do gel expansivo se inicia de dentro para fora, ao invés da superfície, onde há maior concentração de cálcio proveniente do cimento. Isto explica a severa fissuração destes agregados e o fim prematuro da reação em agregados mais finos.

Anteriormente, em Sanchez et al. (2014), foi feito um estudo sobre a influência da variação da granulometria do agregado sobre a RAS. Foi percebido que, para agregados de menor granulometria, a expansão se deu quase que linear e mais rapidamente, enquanto que com agregados maiores, a curva possui um formato côncavo e mais lento. Em ambos os casos, quanto maior a resistência característica do concreto e conteúdo de álcalis, mais rápido é o desenvolvimento da RAS.

Ademais, não há sempre uma relação linear entre a quantidade de constituintes potencialmente reativos e a expansão por RAS. O valor máximo de expansão pode ocorrer num determinado ponto de concentração, o qual é denominado de pessimum. Acima e abaixo deste ponto, são registradas expansões de menor magnitude. O ponto de pessimum varia de acordo com o tipo de agregado constituinte utilizado e portanto, diferentes misturas de concreto com diferentes quantidades de agregados devem ser realizadas para obter o ponto de pessimum (LINDGARD et al., 2014).

\subsubsection{Porosidade}

Para a reação álcali-sílica e álcali-silicato há duas maneiras em que a porosidade pode interferir. Primeiramente, é impedindo a circulação de água e do gel em seu interior e, por conseguinte, dificultando sua mobilidade. Em segundo lugar, um concreto com alta porosidade possuiria poros em quantidade e tamanhos suficientes para que, por mais que o gel se expanda, este não cause pressões internas e fissuras, por haver espaço suficiente para expansão.

De acordo com Jensen, Chatterji e Thaulow (1984), a incorporação de ar na mistura é capaz de reduzir a expansão máxima provocada pela RAS. Para a introdução de $4 \%$ de ar, há uma redução média de $40 \%$ na expansão final. Entretanto, em locais em que se faz uso de incorporação de ar para evitar o desgaste do concreto pelos ciclos de gelo e degelo, pode ocorrer do gel de álcali-sílica ocupar os poros e diminuir sua eficácia.

Para o caso da reação álcali-carbonato, de acordo com Liang e Mingshu (1999), a água não influencia na formação de cristais e portanto a baixa porosidade só reduziria o espaço para a expansão, gerando pressões internas e fraturas. No caso de alta porosidade, haveria espaço suficiente para a expansão e portanto nenhum efeito danoso no concreto. 


\subsubsection{Tensões Confinantes}

Tensões confinantes são um fator importante a se levar em consideração no caso da RAS. Estas podem alterar o grau de expansão do concreto, podendo até suprimí-lo (CAPRA; BOURNAZEL, 1998). Em Multon e Toutlemonde (2006) fica evidenciado o conceito de "transferência de expansão" em que nos casos de estruturas de concreto submetidas a carregamentos ou restrições, as expansões oriundas da RAS são transferidas para as direções menos comprimidas.

A figura 7 mostra corpos de prova submetidos a vários estados de confinamento na direção 1. À medida que a tensão é aumentada, passando de compressão para tração, também percebe-se aumento no grau de expansão do concreto na direção 1, principalmente.

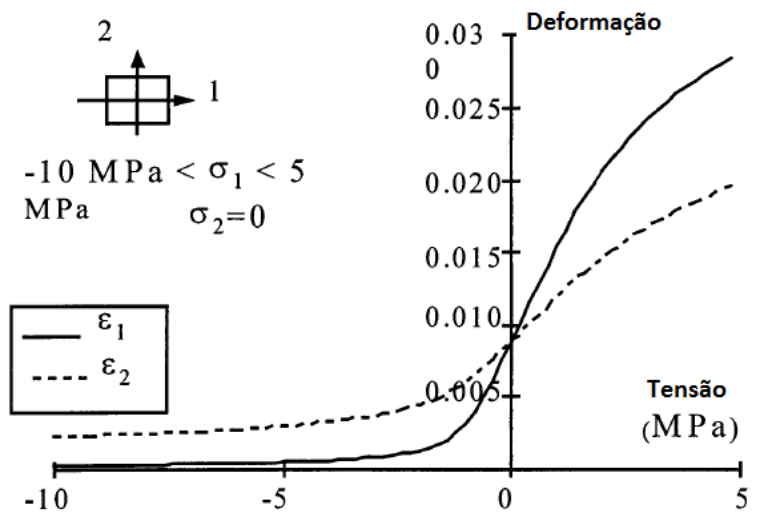

Figura 7 - Vários estados de confinamento em corpo de prova e respectivas expansões. Fonte: Capra e Bournazel (1998)

A figura 8 mostra a expansão de um corpo de prova de concreto submetido a estado uniaxial de compressão. Há redução de expansão na direção do carregamento. Entretanto, na direção ortogonal, a redução é menos significativa.

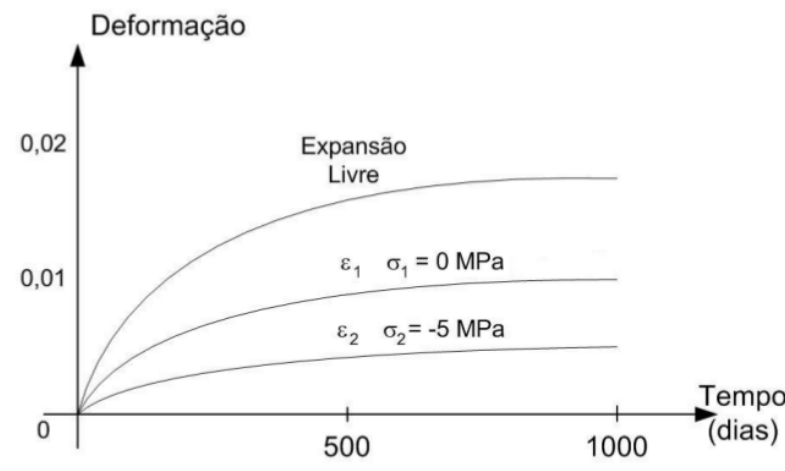

Figura 8 - Expansão em corpo de prova submetido a estado uniaxial de compressão. Fonte: Capra e Bournazel (1998) 


\subsubsection{Grau de Umidade}

A água é necessária tanto para a ocorrência da reação como para o processo de expansão por RAS. É indispensável a presença de água diluída nos poros do concreto para a solubilização dos íons alcalinos, tanto para a reação álcali-sílica, álcali-silicato como para a álcali-carbonato também. Por fim, após a formação do gel que possui propriedades higroscópicas, é necessário mais água para ser absorvida e provocar o processo de inchamento do gel. No caso da reação álcali-carbonato, acredita-se que a expansão se dê pela absorção da água por argilo-minerais resultantes da reação de desdolomitização.

Segundo Bazant e Steffens (2000), é preciso no mínimo uma umidade relativa de 85\% para que ocorra a reação. Para Léger, Coté e Tinawi (1996) este número decai para $75 \%$.

Entretanto, na grande maioria dos ensaios e resultados laboratoriais, o regime de umidade é mantido constante ao longo de todo o período de tempo, o que pode não refletir a realidade das obras correntes. Há poucos dados sobre o provimento não uniforme de umidade e sua influência na curva de expansão da RAS.

Segundo Multon e Toutlemonde (2010) e seu experimento (melhor detalhado na seção 6.2), é possível perceber que ao retardar o abastecimento de água à um corpo de concreto susceptível à RAS, seu processo de expansão é diferente se submetido integralmente em contato com água.

Os autores concluem que ao retardar o abastecimento de água por tempo suficiente, no momento que este entrar em contato com umidade necessária para que ocorra a reação álcali-sílica e expansão, o valor máximo da expansão será menor, e esta ocorrerá de forma mais abrupta. Portanto, desejando-se representar com maior fidelidade a expansão para casos gerais, faz-se-á necessário levar em consideração o tempo em que a estrutura ficou privada de umidade mínima necessária para ocorrência da RAS.

Ademais, quando durante o processo de expansão o concreto sofrer interrupção no fornecimento de umidade, este pode parar de expandir e mantém seu volume atual, ou seja, a expansão por RAS não regride ao se cortar o suprimento de água. Ao voltar a entrar em contato com água, o concreto retorna a expandir, da forma discutida anteriormente. 


\section{Modelagem da Reação Álcali-Sílica}

De acordo com Saouma et al. (2015), pode-se entender a evolução da RAS a partir de exames petrográficos ou de um ponto de vista evolucionário.

A partir de exames petrográficos, tem-se os seguintes estágios:

1. Formação da borda de reação;

2. Continuação da formação da borda e exsudação da solução/gel no agregado contaminado, preenchendo parcialmente os microporos da pasta de cimento;

3. Fissuração dentro do agregado reagente acompanhado de preenchimento por gel;

4. Propagação de fissuras radiais preenchidas por gel do agregado contaminado em direção à pasta de cimento adjacente e

5. Precipitação do gel de álcali-sílica dentro de vazios de ar ao longo de fissuras distantes do agregado reativo.

Do ponto de vista evolucionário, existem 4 fases distintas:

1. Na fase de micro-nucleação, a reação começa da periferia do agregado, sem produzir expansões;

2. O processo de expansão começa dentro do agregado, onde o gel da reação álcali-sílica, rico em álcalis, é confinado dentro de micro-texturas do agregado reativo. Esta fase marca o desenvolvimento da reação;

3. Na aceleração da reação e deterioração do concreto, ocorre a fissuração, com o aumento na largura e densidade das fissuras e

4. Por fim, ocorre a fissuração severa depois que ocorre a expansão do concreto, incluindo falhas estruturais (ruptura da armadura, deformações, perda de integridade estrutural).

Na figura 9 estão representadas as fases explicadas, em que $\varepsilon^{\infty}$ é a expansão máxima, $\tau_{l}$ é o tempo de latência e $\tau_{C}$ é o tempo característico. Estas são as mesmas variáveis empregadas no modelo de Larive (1997). 


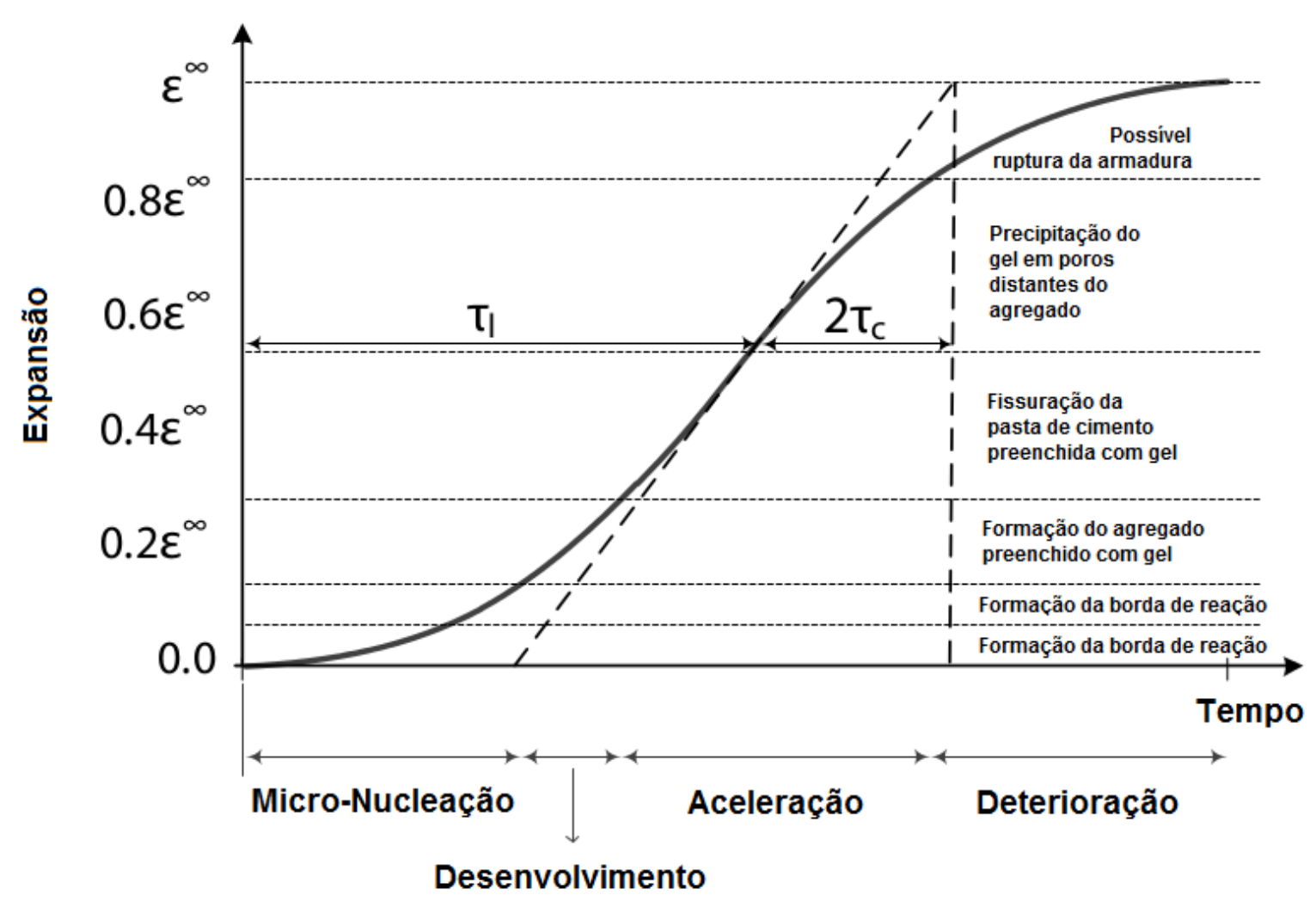

Figura 9 - Interpretação petrográfica e evolucionária da reação álcali-agregado.

Fonte: Saouma et al. (2015)

Sobre a classificação dos modelos existentes, Wu, Temizer e Wriggers (2014) fazem a classificação em basicamente três grupos:

- Modelos Macroscópicos;

- Modelos Mesoscópicos e

- Modelos Microscópicos.

Os modelos macroscópicos tratam a estrutura do material como homogênea. Nos modelos mesoscópicos há o discernimento da matriz cimentícia, agregados e poros com distribuição uniforme, além de também contemplar a zona de transicão entre agregados e matriz. Por fim, os modelos microscópicos levam em consideração a microestrutura da pasta de cimento, contendo produtos resultantes da hidratação, resíduos não hidratados do clínker e microporos.

Embora esta classificação ajude na compreensão dos modelos, recentemente novos modelos multiescala vêm sendo desenvolvidos para analisar a falha do concreto quando submetido a várias frentes de ataque. 


\subsection{Modelos Microscópicos}

\subsubsection{Modelo matemático para a cinética da reação álcali-sílica}

A partir da cadeia de três reações químicas que caracterizam a RAS, Saouma et al. (2015) buscam o desenvolvimento de um modelo matemático para melhor entender a cinética da reação. Por não encontrarem solução analítica, fazem uso de solução numérica para a simulação de diferentes concentrações de álcalis e sílica.

As três equações de formação do gel são reescritas da seguinte forma nas equações $3.1,3.2$ e 3.3 :

$$
\begin{gathered}
\underbrace{S i-O-S i}_{A}+\underbrace{R^{+}+O H^{-}}_{B} \stackrel{k_{3}}{\rightarrow} \underbrace{S i-O-R}_{C}+\underbrace{H-O-S i}_{D} \\
\underbrace{H-O-S i}_{D}+\underbrace{R^{+}+O H^{-}}_{B} \stackrel{k_{2}}{\rightarrow} \underbrace{S i-O-R}_{C}+\underbrace{H_{2} O}_{E} \\
\underbrace{S i-O-R}_{C}+\underbrace{n H_{2} O}_{E} \stackrel{k_{3}}{S i-O^{-}+\left(H_{2} O\right)_{n}+N a^{+}}
\end{gathered}
$$

em que $k_{i}$ é a taxa de reação, com $i=1,2,3$. $A$ é o Siloxano, $B$ é um íon hidroxila, $C$ é o gel de álcali-sílica, $D$ é o ácido silícico, $E$ é a água e $F$ é o gel de álcali-sílica expandido. $R$ é um íon alcalino encontrado no cimento, podendo ser tanto sódio $(N a)$ como potássio $(K)$. O objetivo do estudo foi determinar um único termo cinético que caracterize a reação:

$$
k_{A S R}=f\left(k_{1}, k_{2}, k_{3}\right)
$$

Para tanto foram escritas as taxas de mudança de concentração dos seis constituintes $(\mathrm{A}, \mathrm{B}, \mathrm{C}, \mathrm{D}, \mathrm{E}, \mathrm{F})$ :

$$
\begin{gathered}
\frac{d A}{d t}=-k_{1} A(t) B(t) \\
\frac{d B}{d t}=-k_{1} A(t) B(t)-k_{2} D(t) B(t) \\
\frac{d C}{d t}=k_{1} A(t) B(t)+k_{2} D(t) B(t)-k_{3} C(t) E(t) \\
\frac{d D}{d t}=k_{1} A(t) B(t)-k_{2} D(t) B(t) \\
\frac{d E}{d t}=k_{2} D(t) B(t)-k_{3} C(t) E(t)
\end{gathered}
$$




$$
\frac{d F}{d t}=k_{3} C(t) E(t)
$$

Como não foi possível obter uma relação analítica com estas equações, fez-se uso de solução numérica para comparação com outros modelos. Por fim, foram obtidas três leis de conservação expressas nas equações a seguir:

$$
\begin{gathered}
2[\text { Siloxano }]-[\text { íons Hidroxila }]+[\text { ácido Silícico }]=\text { Constante } \\
{[\text { Siloxano }]+[\text { Álcali }- \text { Silicato }]-[\text { Água }(\text { gerada })]=\text { Constante }}
\end{gathered}
$$

$[$ íons Hidroxila $]-[a ́ l c a l i-$ Silicato $]+[$ Álcali-Silicato Expandido $]=$ Constante

Embora o estudo de Saouma et al. (2015) não tenha gerado um modelo para a expansão da RAS, alguns pontos interessantes foram obtidos, como as três leis de conservação (equações 3.11, 3.12 e 3.13). Também foi confirmada a importância da concentração inicial de água na formação do gel, similaridades qualitativas entre a concentração de gel e expansão do concreto por RAS, e que quantidades relativas de concentração de álcalis, sílica e água podem produzir quatro estimativas finais possíveis de concentração de gel de álcali-sílica.

Ainda de acordo com Saouma et al. (2015), de forma geral, existem dois grandes grupos de modelos microestruturais e esta diferença reside no tipo de agregado reativo, ou seja, na expansão precoce com borda de reação e expansão tardia sem formação de borda de reação, mas com pontos interiores de reação. Seu estudo serve como "teoria unificadora", pois cobre tanto casos com expansão precoce como tardia.

\subsubsection{Modelo Químico-Mecânico}

Em Multon, Sellier e Cyr (2009) foi proposto um modelo químico-mecânico para prever a expansão por reação álcali-agregado. Trata-se de um modelo microscópico para analisar o desenvolvimento da RAS em misturas com agregados de diferentes tamanhos. $\mathrm{O}$ ataque da sílica reativa pelos álcalis foi feito pela equação de balanço de massa, controlando o mecanismo de difusão no agregado e fixação dos álcalis no gel. Para o modelo mecânico, foi utilizado a teoria do dano para representar o decaimento do módulo de elasticidade devido à fissuração pela RAS e calcular a expansão de um Volume Elementar Representativo (VER). 


\subsubsection{Modelo Poro-Mecânico}

O modelo poro-mecânico desenvolvido por Pignatelli, Comi e Monteiro (2013) é um modelo que leva em consideração duas variáveis isotrópicas internas: o dano químico e o mecânico. O dano químico provém da pressão causada pela expansão do gel de RAA, enquanto a dano mecânico descreve a degradação da resistência e rigidez pelas cargas externas.

Este modelo faz uso da teoria de camada dupla para simular a pressão oriunda do gel. Tal camada é formada pelo ataque da sílica amorfa pelos álcalis do cimento e a formação de uma dupla camada de partículas carregadas, negativas e positivas, na superfície do agregado.

Com a equação 3.14 é possível obter a pressão oriunda da expansão do gel de álcali-sílica, sendo que $C_{0}$ é a concentração eletrolítica, $R$ é a constante molar de gás, $T$ é a temperatura absoluta, $p$ é a pressão resultante, $\nu_{D}$ é o fator potencial de escada $(25.69 \mathrm{mV}$ a $298 K), Z$ é o parâmetro de valência e $\nu$ é o potencial elétrico.

$$
p=C_{0} R T\left[e^{\left(Z \frac{\nu}{\nu_{D}}\right)}+e^{\left(-Z \frac{\nu}{\nu_{D}}\right)}-2\right]
$$

Também é definida a expansão da reação álcali-agregado (equação 3.15) como função do grau de saturação $\left(S_{W}\right)$, com os parâmetros $\epsilon_{A S R}^{\infty}, b_{1}$ e $b_{2}$ definindo a expansão máxima volumétrica em diferentes condições de umidade e obtidos por meio de ensaios experimentais.

$$
\epsilon\left(S_{W}\right)=\epsilon_{A S R}^{\infty} \frac{1+b_{1} e^{-b_{2}}}{1+b_{1} e^{-b_{2} S_{W}}}
$$

Por fim, foi mostrada a possibilidade de modelar a expansão da RAA com fornecimento de umidade tardio, corroborando com os dados obtidos por Multon e Toutlemonde (2010).

\subsection{Modelos Mesoscópicos}

\subsubsection{Modelo Elasto-Plástico Mecânico}

Em Qian, Zhuang e Huang (2016) foi proposto um modelo numérico para prever a expansão por RAA a partir de fatores como tamanho do agregado, propriedades mecânicas dos materiais compostos e concentração inicial de álcalis. As reações químicas foram descritas a partir da teoria de reação de estado sólido. O concreto foi considerado contendo agregados, com regiões fissuradas e íntegras. O gel de álcali-sílica foi considerado a principal fonte de expansão e o volume de gel foi calculado com a utilização de reações de álcali-sílica. 
A mecânica elasto-plástica foi usada para modelar o comportamento do concreto e para determinação do raio da zona de fissuração foi utilizado o critério de Mohr-Coulomb. O processo de controle da expansão da RAS foi a difusão de íons de sódio para o agregado.

\subsection{Modelos Macroscópicos}

\subsubsection{Modelo Constitutivo Mecânico}

Pietruszczak (1996) faz uso dos campos de reatividade e do estado de tensões para elaborar uma equação constitutiva que modele a taxa de expansão da RAA $\left(\dot{\varepsilon}_{R A A}\right)$ :

$$
\dot{\varepsilon}_{R A A}=\frac{\varepsilon_{v o l}^{\max } A_{1}}{\left(A_{1}+t\right)^{2}} e^{\frac{A_{2} \delta^{T} \sigma}{f_{c}}}
$$

em que $\varepsilon_{V o l}^{\max }$ é o valor assintótico de deformação livre da RAA, $A_{1}$ e $A_{2}$ são constantes do material relacionadas com a reatividade dos componentes do concreto, $f_{c}$ é a resistência à compressão uniaxial inicial, $\delta^{T} \sigma$ são as tensões hidrostáticas e $t$ é o valor do instante de tempo.

A sua formulação é baseada numa perspectiva fenomenológica em que o processo de expansão devido a RAA é acoplado com a degradação das propriedades mecânicas do concreto.

\subsubsection{Modelo Paramétrico}

Este modelo foi desenvolvido por Léger, Coté e Tinawi (1996) e consiste na utilização de fatores normalizados de expansão representando parâmetros que influenciam na reação álcali-agregado. Para a simulação da distribuição não uniforme da expansão foram utilizados 4 parâmetros:

- Confinamento - C

- Temperatura - T

- Umidade - M

- Reatividade - $\mathrm{R}$

Na figura 10 estão representados os fatores de normalização e as suas relações com seus respectivos fatores de influência na RAA. Para Léger, Coté e Tinawi (1996), $\mathrm{RH}_{\text {min }}$ e $\mathrm{RH}^{\max }$ são $75 \%$ e $100 \%$ respectivamente. $\mathrm{T}_{L}$ e $\mathrm{T}_{\max }$ são $18{ }^{\circ} \mathrm{C}$ e $36{ }^{\circ} \mathrm{C}$ respectivamente. Por fim a tensão mínima, $\sigma_{L}$, é -0,3 MPa e a máxima, $\sigma_{m a x}$, é de -8,0 MPa. 


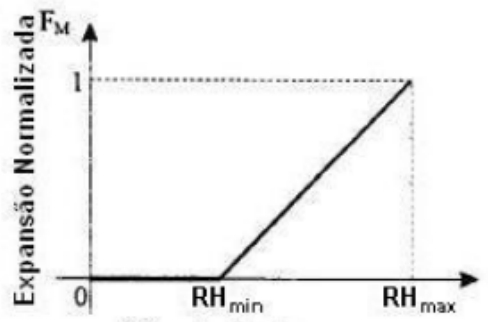

(a) Umidade

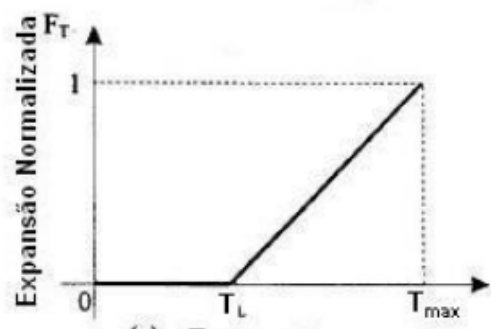

(c) Temperatura

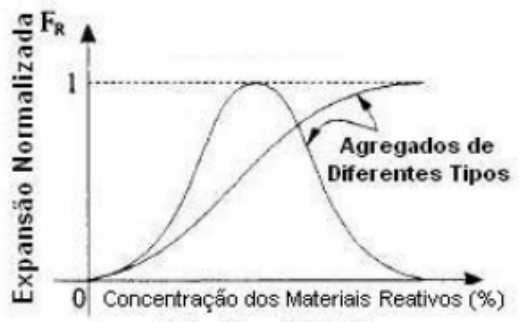

(b) Reatividade dos Materiais

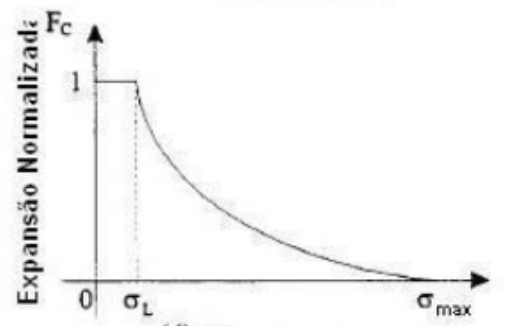

(d) $\sigma_{\text {Tensäo de Compressão }}$

Figura 10 - Fatores de normalização dos parâmetros que influenciam na RAA. Fonte: Adaptado de Léger, Coté e Tinawi (1996)

Os fatores normalizados de umidade e temperatura $\left(F_{M}\right.$ e $\left.F_{T}\right)$ seguem leis lineares. Assumem valor unitário quando a umidade relativa e temperatura estão nos seus valores máximos $\left(\mathrm{RH}_{\max }\right.$ e $\left.\mathrm{T}_{\max }\right)$ e valor nulo quando a umidade e temperatura estão nos valores mínimos $\left(\mathrm{RH}_{\text {min }}\right.$ e $\left.\mathrm{T}_{L}\right)$. O fator de tensões confinantes $\left(F_{C}\right)$ possui uma lei exponencial decrescente com o aumento das tensões aplicadas no sólido e o fator de reatividade $\left(F_{R}\right)$ segue uma lei que varia de acordo com o tipo de agregado empregado e seu percentual no traço do concreto. Certos tipos de agregados apresentam o efeito pessimum, refletindo assim numa curva com formato de sino para $F_{R}$.

Por fim, têm-se uma distribuição espacial da expansão que posteriormente é calibrada com dados em campo. Com isso é obtida a seguinte equação:

$$
\varepsilon_{R A A}=\beta(t)\left[F_{C}(\sigma, t) F_{T}(t) F_{M}(t) F_{R}(t)\right]
$$

No qual $\beta$ é parâmetro de calibração, $F_{C}$ é fator de confinamento, $F_{T}$ é o fator de temperatura, $F_{M}$ é fator de umidade e $F_{R}$ é o fator de reatividade ao longo do tempo $(t)$. Todos esses fatores são dados pela figura 10. Os fatores podem ser considerados transientes, assim como é possível considerar alterações nas propriedades do concreto ao longo do desenvolvimento da RAA. 
Pappalardo Jr. (1998) se baseou no modelo de Léger, Coté e Tinawi (1996) para criar mais um modelo paramétrico com normalização dos campos de influência e uma nova equação constitutiva que agora assume a seguinte forma:

$$
\dot{\varepsilon}_{R A A}=\frac{\varepsilon_{v o l}^{\max } A_{1} F_{T}}{\left(A_{1} F_{T}+t-t_{p} F_{P}\right)^{2}} \sqrt{F_{C} F_{M}}
$$

em que $t_{p}$ é o parâmetro correspondente ao tempo de preenchimento dos poros do concreto, $F_{P}$ o fator normalizado da porosidade, $A_{1}$ se torna o índice de reatividade e $F_{C}, F_{M}$ e $F_{T}$ continuam sendo os fatores de influência das tensões confinantes, umidade e temperatura, respectivamente.

A figura 11 mostra os respectivos fatores de influência $\left(F_{M}, F_{P}, F_{C}, F_{T}\right)$ e de calibração do modelo $\left(k_{p}, k_{c}, k_{m}, k_{t}\right)$.

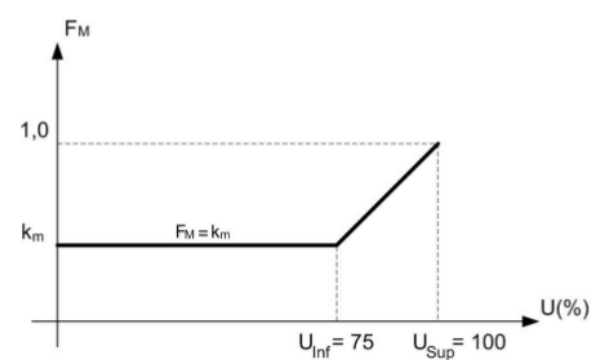

(a) - Umidade

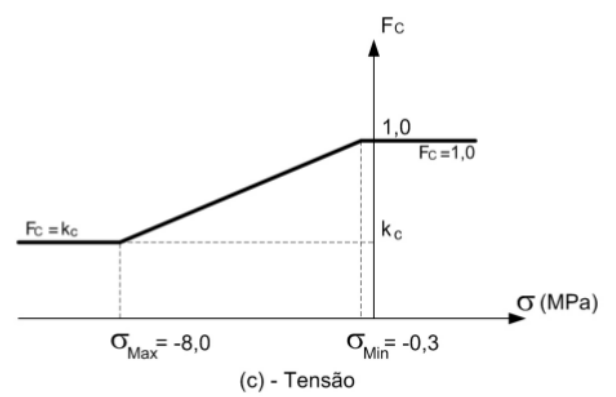

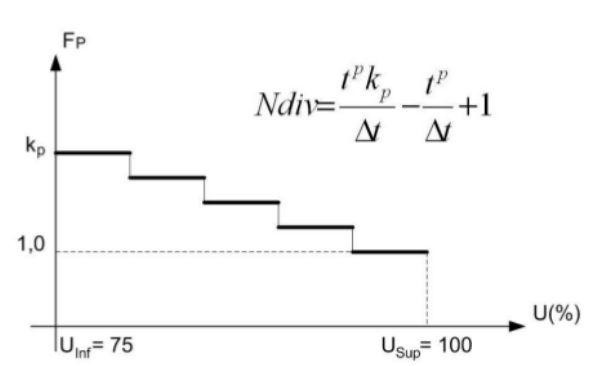

(b) - Porosidade

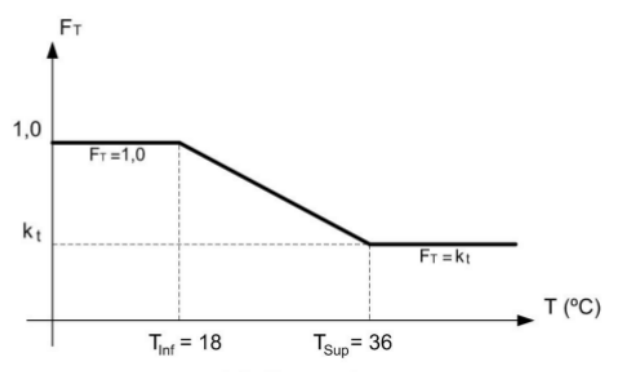

(d) - Temperatura

Figura 11 - Fatores de influência e de calibração do modelo paramétrico. Fonte: Carrazedo (2004) e Pappalardo Jr. (1998).

Os fatores de influência de umidade, tensão confinante e temperatura $\left(F_{M}, F_{C}\right.$ e $F_{T}$ ) seguem leis lineares entre os seus respectivos limites superiores e inferiores de umidade, tensão e temperatura. Adicionalmente, seus respectivos parâmetros de calibração $\left(k_{m}, k_{c}\right.$ e $k_{t}$ ) regulam os valores mínimos dos fatores de influência quando os dados de umidade, tensão ou temperatura estiverem abaixo dos seus limites inferiores. O fator de porosidade $\left(F_{P}\right)$ segue uma lei dependente do tempo de preenchimento dos poros e do parâmetro de calibração $k_{p}$, que regula o valor máximo que $F_{P}$ pode atingir. 
Em Carrazedo (2004) é proposta a seguinte equação para a taxa de expansão por RAA, baseada no trabalho de Pappalardo Jr. (1998) e Pietruszczak (1996):

$$
\dot{\varepsilon}_{R A A}=\mathrm{H}\left(t-t_{p} F_{P}\right) \varepsilon^{\max }\left[\frac{e^{\frac{-\left(t-t_{p} F_{P}\right)}{A_{2} F_{T}}}}{A_{2} F_{T}}\right] \sqrt{F_{C} F_{M}}
$$

em que é empregado uma função Heaviside (H) para que não haja processo de expansão para valores de tempo $t$ menores que $t_{p} F_{P}$. A função $\mathrm{H}$ também impede que ocorra uma singularidade no momento em que $A_{1} F_{T}+t=t_{p} F_{P}$ na equação 3.18. Com isso a taxa de expansão é apenas calculada após o preenchimento completo dos poros. (CARRAZEDO, 2004). $\varepsilon^{\text {max }}$ é a expansão máxima esperada pela manifestação patológica, $A_{2}$ corresponde à taxa de expansão e $F_{P}, F_{C}, F_{M}$ e $F_{T}$ são os parâmetros de influência de porosidade, tensões confinantes, umidade e temperatura, respectivamente.

\subsection{Modelo Adotado}

O modelo adotado é o modelo desenvolvido em Carrazedo (2004), em que a modelagem da RAS é realizada pela utilização de parâmetros que atuam sobre a estrutura. Ademais, como o foco do estudo está na interferência do campo higrométrico no desenvolvimento da manifestação patológica, foi realizada uma alteração na forma em que a expansão máxima $\varepsilon^{\text {max }}$ e o parâmetro de reação $A_{2}$ se comportam, fazendo-os agora função do tempo de privação de umidade.

A solução do campo mecânico é dada pelo método dos elementos finitos posicional e a solução do campo higrométrico é obtida pelo método dos elementos finitos convencional sem movimentação de malha. Os capítulos seguintes elucidam as formulações utilizadas sobre os campos mecânico e higrométrico. Depois, é explicado o acoplamento higromecânico e a consideração de regimes não uniformes de umidade no modelo de expansão da RAS. 


\section{Campo Mecânico}

Em relação ao campo mecânico, neste trabalho é utilizado o método dos elementos finitos posicional (MEFP). Tal formulação é realizada com o uso das posições nodais do corpo, ao invés dos deslocamentos, como em outros métodos mais convencionais. Foi primeiramente apresentado por Bonet et al. (2000), com conceitos observados em Ogden (1984) e Ciarlet (1993). Posteriormente foi apresentado por Coda (2003) e maior parte dos conceitos apresentados adiante seguem o referido trabalho.

\subsection{Função Mudança de Configuração}

Diz-se mudança de forma ou configuração quando um sólido deformável, sujeito à forças externas e em equilíbrio estável, se deforma e muda de formato. Pode-se imaginar uma função $\vec{f}$ que descreva a mudança de configuração de um sólido de um estado inicial $B_{0}$ para uma configuração atual $B$, tal como apresentado na figura 12 .

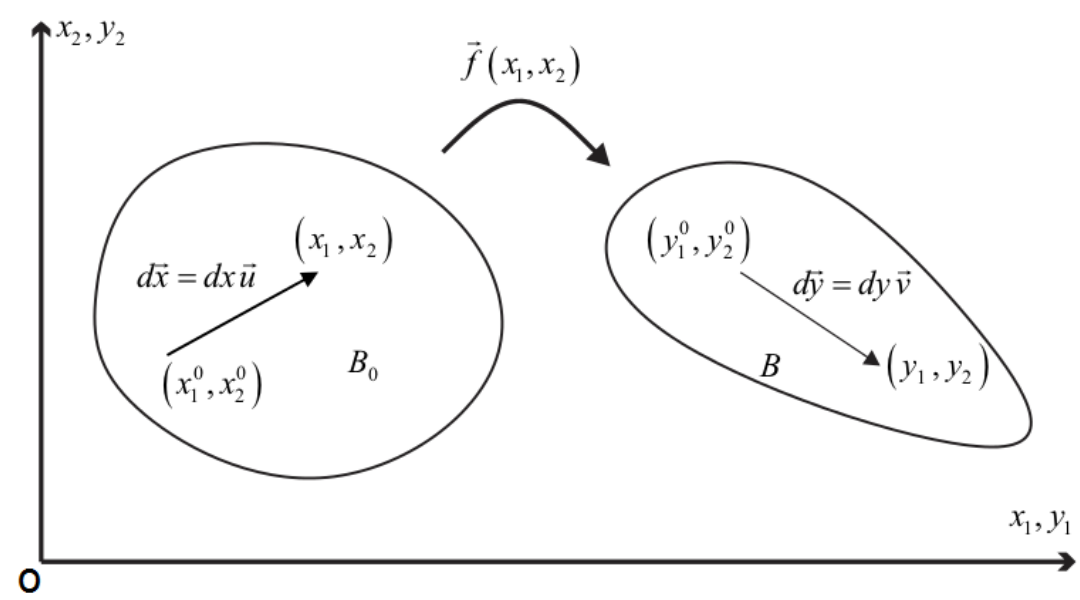

Figura 12 - Representação da função mudança de configuração e dois estados de configuração de um sólido deformável.

Na figura 12, o sistema de coordenadas é único e cartesiano, com origem em $o$. As letras $x$ e $y$ denotam as coordenadas nos estados inicial e atual, respectivamente. Os eixos coordenados estão nas direções 1 e 2 . Com $x_{0}$ e $x$ pertencendo à $B_{0}$ e $d \vec{x}$ o vetor dado pela diferença desses dois pontos, é possível escrever a imagem de $x$ em $B$ da seguinte forma:

$$
y=f(x)=f\left(x_{0}\right)+\left.\frac{\partial f}{\partial x}\right|_{x_{0}} \Delta \vec{x}+O^{2}
$$

O estado de deformação do corpo é definido pelo gradiente da função mudança de 
configuração, ou seja, tomando as derivadas de $\vec{f}$ obtêm-se:

$$
y-y_{0}=d y=\left.\frac{\partial f}{\partial x}\right|_{x_{0}} d x
$$

ou

$$
\overrightarrow{d y}=\mathbf{A} \overrightarrow{d x}
$$

Com A sendo a matriz que representa o gradiente da função mudança de configuração em qualquer ponto do domínio $B_{0}$.

\subsubsection{Mudança ou Variação de Volume}

Uma informação que se pode obter de $\mathbf{A}$ é sobre a variação de volume entre as configurações inicial e atual. Assumindo $d V_{0}$ e $d V$ como volumes infinitesimais na configuração inicial e atual, respectivamente:

$$
d V_{0}=\left(d \overrightarrow{x_{1}} \otimes d \overrightarrow{x_{2}}\right) \bullet d \overrightarrow{x_{3}}
$$

e

$$
d V=\left(d \overrightarrow{y_{1}} \otimes d \overrightarrow{y_{2}}\right) \bullet d \overrightarrow{y_{3}}
$$

Lembrando que $d \vec{y}=\mathbf{A} d \vec{x}$ é possível reescrever o volume atual como:

$$
d V=\left(\mathbf{A} d \overrightarrow{x_{1}} \otimes \mathbf{A} d \overrightarrow{x_{2}}\right) \bullet \mathbf{A} d \overrightarrow{x_{3}}
$$

Tomando a derivada do volume atual em relação ao volume inicial é possível obter a seguinte relação:

$$
\frac{d V}{d V_{0}}=\operatorname{det}(\mathbf{A})=J=\operatorname{det}(\mathbf{A})\left(d \overrightarrow{x_{1}} \otimes d \overrightarrow{x_{2}}\right) \bullet d \overrightarrow{x_{3}}
$$

E por fim

$$
J=\operatorname{det}(\mathbf{A})
$$

em que $J$ é conhecido como Jacobiano e representa a variação de volume entre as configurações. 


\subsubsection{Mudança de Área}

Outra informação igualmente importante é com relação a mudança de área durante a mudança de configuração, representada na figura 13. Tomando-se uma área infinitesimal:
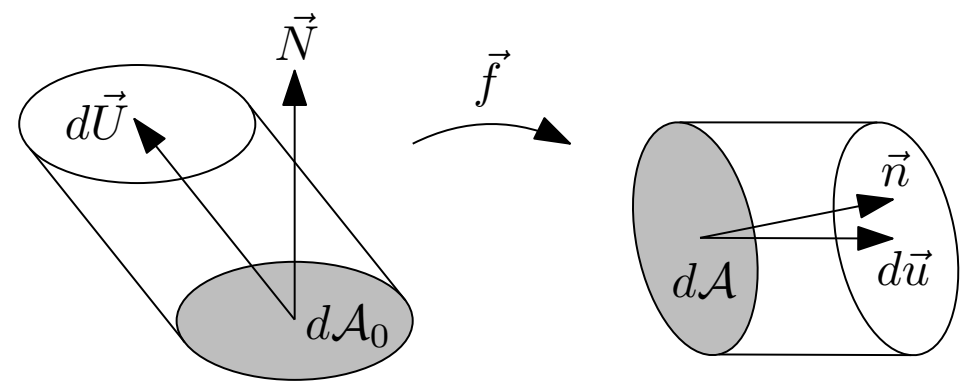

Figura 13 - Representação da função mudança de configuração e mudança de área.

Representando as áreas iniciais $\left(d \mathcal{A}_{0}\right)$ e atuais $(d \mathcal{A})$ por:

$$
\begin{gathered}
d \overrightarrow{\mathcal{A}_{0}}=\vec{N} d \mathcal{A}_{0} \\
d \overrightarrow{\mathcal{A}}=\vec{n} d \mathcal{A}
\end{gathered}
$$

com $\vec{N}$ e $\vec{n}$ sendo vetores normais às áreas nas configurações inicial e atual, respectivamente. Partindo de um vetor $d \vec{U}$ e $d \vec{u}$ para o cálculo do volume:

$$
\begin{gathered}
d V_{0}=d \vec{U}^{T} \bullet \vec{N} d \mathcal{A}_{0} \\
d V=d \vec{u}^{T} \bullet \vec{n} d \mathcal{A}
\end{gathered}
$$

Fazendo uso do fato de que:

$$
d V=J d V_{0}
$$

$\mathrm{e}$

$$
d \vec{u}=\mathbf{A} d \vec{U}
$$

é possível obter a relação de áreas entre as configurações:

$$
d \vec{u}^{T} \bullet \vec{n} d \mathcal{A}=J d \vec{U}^{T} \bullet \vec{N} d \mathcal{A}_{0}
$$




$$
d \vec{U}^{T} \mathbf{A}^{T} \bullet \vec{n} d \mathcal{A}=J d \vec{U}^{T} \bullet \vec{N} d \mathcal{A}_{0}
$$

$$
\mathbf{A}^{T} \bullet \vec{n} d \mathcal{A}=J \vec{N} d \mathcal{A}_{0}
$$

que por fim, resulta na equação 4.18 que é conhecida como fórmula de Namson:

$$
\vec{n} d \mathcal{A}=J \mathbf{B} \vec{N} d \mathcal{A}_{0}
$$

$\mathrm{Ou}$

$$
d \overrightarrow{\mathcal{A}}=J \mathbf{B} d \overrightarrow{\mathcal{A}_{0}}
$$

$\operatorname{com} \mathbf{B}=\left(\mathbf{A}^{T}\right)^{-1}=\left(\mathbf{A}^{-1}\right)^{T}$

\subsection{Tensor de Deformação de Green-Lagrange}

Neste trabalho foi utilizado o tensor de deformação de Green-Lagrange, definido na seguinte expressão:

$$
\mathbf{E}=\frac{1}{2}\left(\mathbf{A}^{T} \mathbf{A}-\mathbf{I}\right)
$$

em que A é o gradiente da função mudança de configuração $(f)$ e I é a matriz identidade. O termo $\mathbf{A}^{T} \mathbf{A}$ também pode ser representado por $\mathbf{C}$, que é chamado de tensor de alongamento à direita de Cauchy-Green. Os termos de sua diagonal refletem uma medida precisa dos deslocamentos de fibras inicialmente dispostas nos eixos coordenados e os seus termos fora da diagonal estão relacionados com a distorção ocorrida. Vale notar que por não se admitir degeneração do material, o tensor $\mathbf{C}$ é sempre positivo definido e o determinante do gradiente da função mudança de configuração será sempre maior que zero.

Pode-se reescrever o tensor de deformação de Green-Lagrange como:

$$
\mathbf{E}=\frac{1}{2}(\mathbf{C}-\mathbf{I})
$$

A incorporação das deformações provenientes pela RAS é feita de forma aditiva, como expresso na equação 4.22. Entende-se que os valores de deformação são suficientemente pequenos para que a composição aditiva tenha boa acurácia.

$$
\mathbf{E}_{\text {total }}=\mathbf{E}_{\text {elástico }}+\mathbf{E}_{R A S}
$$




\subsection{Lei Constitutiva de Saint-Venant-Kirchhoff}

A lei constitutiva utilizada neste trabalho é a de Saint-Venant-Kirchhoff e fazendo uso da medida de deformação de Green-Lagrange, a equação da energia específica $\left(u_{e}\right)$ é expressa por:

$$
u_{e}=\frac{1}{2} \mathbf{E}: \mathbf{D}: \mathbf{E}
$$

com $\mathbf{E}$ sendo o tensor de deformação de Green-Lagrange e $\mathbf{D}$ o tensor de quarta ordem chamado de tensor constitutivo elástico tangente.

Tomando a derivada de $u_{e}$ em relação ao tensor de deformações de Green-Lagrange obtém-se o tensor de tensão de Piola-Kirchhoff de segunda espécie $(\mathbf{S})$ :

$$
\mathbf{S}=\frac{E \nu}{(1+\nu)(1-2 \nu)}[\operatorname{tr}(\mathbf{E})] I+2 G \mathbf{E}
$$

com $E, G$ e $\nu$ sendo o módulo de elasticidade, módulo de elasticidade transversal e o coeficiente de Poisson, respectivamente. Para a dedução da equação 4.24, considerou-se material isotrópico.

A lei de Saint-Venant-Kirchhoff é linear pois o tensor constitutivo elástico (D) é constante independentemente do nível de tensão aplicado.

É possível estabelecer uma relação entre o segundo tensor de Piola-Kirchhoff e o tensor de tensão de Cauchy, que é dada pela equação:

$$
\sigma=\frac{1}{J} \mathbf{A S A}^{T}
$$

em que $J=\operatorname{det}(\mathbf{A})$, sendo $\mathbf{A}$ o gradiente da função mudança de configuração.

\subsection{Princípio da Energia Potencial Total Estacionária}

Segundo o princípio da energia potencial total estacionária, o corpo irá se encontrar em equilíbrio estável quando ele atingir o patamar mínimo de sua energia total. A equação de energia de um corpo para o caso estático é:

$$
\Pi=U_{e}+\mathbf{P}
$$

em que $\Pi$ é a energia total, $U_{e}$ e $\mathbf{P}$ são a energia interna de deformação do corpo e o trabalho das forças externas aplicadas respectivamente. 
Ao se tomar a derivada da energia em relação ao vetor de posições nodais e igualar a zero, é possível saber a posição de equilíbrio da estrutura e sua configuração atual deformada:

$$
\frac{\partial \Pi}{\partial \vec{Y}}=\vec{F}_{i n t}-\vec{F}_{e x t}=0
$$

Levando-se em conta a discretização por elementos finitos, a energia de deformação do sólido passa a ser o somatório da energia de deformação dos $n f$ elementos finitos e portanto:

$$
\frac{\partial U_{e}}{\partial \vec{Y}}=\sum_{f=1}^{n f} \frac{\partial U_{e}}{\partial \vec{Y}}=\sum_{f=1}^{n f} \vec{F}_{i n t}
$$

\subsection{Método Iterativo de Newton Raphson}

Encontrar a configuração de equilíbrio da estrutura acaba se tornando um problema de natureza não linear e para tanto é utilizado o método iterativo de Newton-Raphson. Faz-se uso de dois vetores de força aplicados aos nós $F_{\text {ext }}$ e $F_{\text {int }}$ para as forças externas e forcas internas, respectivamente. Para o caso de forças externas conservativas, é dito que uma estrutura se encontra em equilíbrio quando:

$$
F_{\text {ext }}-F_{\text {int }}=0
$$

Entretanto, como o vetor de forças internas depende das posições de maneira não linear, haverá uma diferença, chamada de vetor de desbalanceamento e para a correção a equação passa a ser:

$$
F_{\text {ext }}-F_{\text {int }}\left(y^{i}\right)=\Delta F\left(y^{i}\right)
$$

em que $F_{\text {int }}\left(y^{i}\right)$ e $\Delta F\left(y^{i}\right)$ representam os vetores de força interna e desbalanceamento que dependem das posições do passo atual num processo iterativo.

Ao fazer a expansão de $\Delta F\left(y^{i}\right)$ em uma série de Taylor:

$$
\Delta F\left(y^{i}\right)=\Delta F\left(y^{i-1}\right)+\left.\frac{\partial \Delta F}{\partial y}\right|_{y^{i-1}}\left(y^{i}-y^{i-1}\right)+\text { termos de maior ordem }
$$

O termo $\left.\frac{\partial \Delta F}{\partial y}\right|_{y^{i-1}}$ é referenciado como Hessiana e no método clássico de NewtonRaphson é como se fosse o módulo tangente à curva. Desprezando os termos de ordem 
maior, o acréscimo ou resíduo $\left(\Delta y^{i}\right)$ é calculado da seguinte forma:

$$
\left.\frac{\partial \Delta F}{\partial y}\right|_{y^{i-1}} \Delta y^{i}=F_{\text {ext }}-F_{\text {int }}\left(y^{i-1}\right)
$$

Diz-se que há convergência do processo quando $\Delta y^{i}$ é suficientemente pequeno. Para tanto pode-se fazer a seguinte verificação:

$$
\frac{\left\|\Delta y^{i}\right\|}{\left\|y_{0}\right\|} \leq \text { Tolerância }
$$

A figura 14a é a representação gráfica do método e como ocorre sua convergência. A Hessiana aqui é representada por $K$, sendo a inclinação da reta. $g, q$ e $f$ são os vetores de desbalanceamento, forças externas e forças internas, respectivamente. $\Delta u_{i}$ são os resíduos calculados para cada passo de iteração. É mostrado na figura 14b que este método também pode ser usado de forma incremental. Para cada incremento de carga $\Delta f$ é atingido um estado de equilíbrio e assim vai-se caminhando sucessivamente até a solução final.

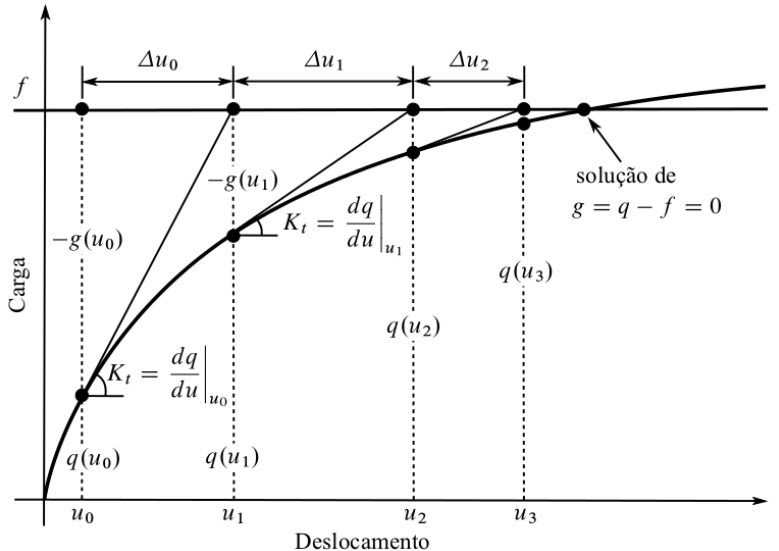

(a) Método de Newton-Raphson para resolver a (b) equação de equilíbrio.

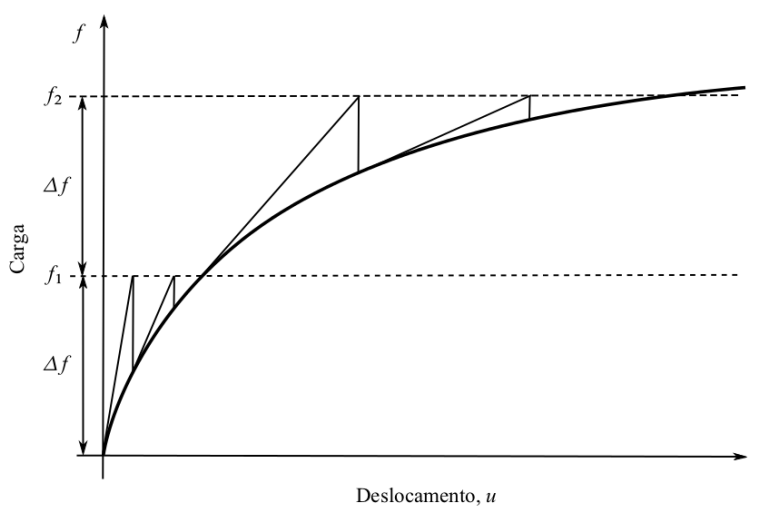

(b) Procedimento incremental-iterativo para o método de Newton-Raphson.

Figura 14 - Representação gráfica do método de Newton-Raphson e procedimento incremental para convergência e obtenção da solução.

Fonte: Lacerda (2014)

\subsection{Método dos Elementos Finitos Posicional Estático}

O método dos elementos finitos posicional (MEFP) pretende encontrar a configuração de equilíbrio de um sólido deformável. Lembrando-se a equação da energia do sistema, para o caso estático:

$$
\Pi=U_{e}+\mathbf{P}=\underbrace{\int_{A} u_{e} d A}_{\text {Energia de Deformação Trabalho das Forças Externas }} \underbrace{-\int_{A} \vec{F} \vec{Y} d A-\oint_{\Gamma} \vec{f} \vec{Y} d \Gamma}_{\Gamma}
$$


com $\vec{F}$ sendo o vetor de forças de volume aplicado e $\vec{f}$ o vetor de forças externas aplicado sobre uma superfície $\Gamma$ do sólido 2D. Derivando-se em relação às posições nodais do sólido:

$$
\frac{\partial \Pi}{\partial \vec{Y}}=\int_{A} \frac{\partial u_{e}}{\partial E} \frac{\partial E}{\partial \vec{Y}} d A-\int_{A} \vec{F} d A-\oint_{\Gamma} \vec{f} d \Gamma
$$

A soma dos dois últimos termos resulta justamente no vetor de forças externas que atua sobre o sólido. Já o primeiro termo representa o vetor de forças internas da estrutura. A variação da energia de deformação em relação ao tensor de Green representa a própria tensão interna, ou seja, o segundo tensor de Piola-Kirchhoff de acordo com 4.24. O termo $\frac{\partial E}{\partial \vec{Y}}$, que representa a derivada parcial do tensor de Green-Lagrange em relação às posições nodais, é dado por:

$$
\frac{\mathbf{E}}{\partial \vec{Y}}=\frac{1}{2} \frac{\partial(\mathbf{C}-\mathbf{I})}{\partial \vec{Y}}=\mathbf{A} \frac{\partial \mathbf{A}}{\partial \vec{Y}}
$$

Neste trabalho são utilizados elementos bidimensionais triangulares de 10 nós, com aproximação cúbica, para análise de estado plano de deformação. Para tanto, pode-se fazer uma distinção entre a função mudança de configuração e o seu gradiente, transformando-os em duas funções cada de duas etapas, como mostrado na figura 15:

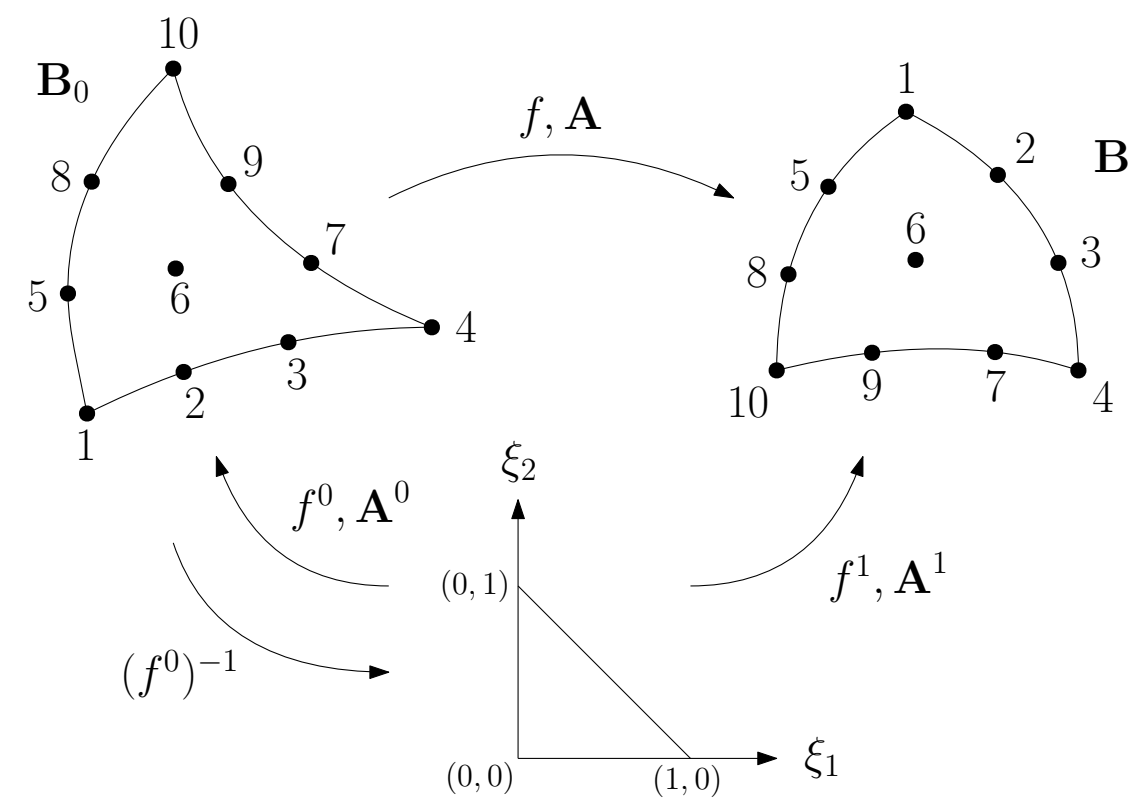

Figura 15 - Mapeamento do elemento bidimensional nas configurações inicial e final. 
É possível definir $\vec{f}^{0}$ e $\vec{f}^{1}$ da seguinte forma:

$$
f_{i}^{0}\left(\xi_{1}, \xi_{2}\right)=X_{i}\left(\xi_{1}, \xi_{2}\right)=\phi_{l}\left(\xi_{1}, \xi_{2}\right) X_{i}^{l}
$$

e

$$
f_{i}^{1}\left(\xi_{1}, \xi_{2}\right)=Y_{i}\left(\xi_{1}, \xi_{2}\right)=\phi_{l}\left(\xi_{1}, \xi_{2}\right) Y_{i}^{l}
$$

em que o índice $i$ denota a direção (1 ou 2 para o caso 2D), $\phi$ é a função de forma no ponto, $\xi_{1}$ e $\xi_{2}$ são as coordenadas paramétricas do elemento finito e por fim o índice $l$ denota o ponto do elemento finito em que a função está sendo avaliada.

A função $\vec{f}$ e seu gradiente são agora compostos da seguinte forma:

$$
\vec{f}=\vec{f}^{1} \circ\left(\vec{f}^{0}\right)^{-1}
$$

e

$$
\mathbf{A}=\mathbf{A}^{1} \circ\left(\mathbf{A}^{0}\right)^{-1}
$$

Particularizando para o estado plano de deformação, a energia específica de deformação se torna:

$$
u_{e}^{S V K}=\frac{1}{2}\left[(1-\nu) K\left(E_{11}^{2}+E_{22}^{2}\right)+2 \nu K\left(E_{11} E_{22}\right)+2 G\left(E_{12}^{2}+E_{21}^{2}\right)\right]
$$

$\operatorname{com} K=\frac{E}{(1+\nu)(1-2 \nu)}$ e $G=\frac{E}{2(1+\nu)}$.

Voltando atenção às derivadas parciais da energia específica de deformação em relação ao tensor de deformações de Green-Lagrange, obtém-se:

$$
\begin{gathered}
\frac{\partial u_{e}}{\partial E_{11}}=K\left[(1-\nu) E_{11}+\nu E_{22}\right] \\
\frac{\partial u_{e}}{\partial E_{22}}=K\left[(1-\nu) E_{22}+\nu E_{11}\right] \\
\frac{\partial u_{e}}{\partial E_{12}}=2 G E_{12} \\
\frac{\partial u_{e}}{\partial E_{21}}=2 G E_{21}
\end{gathered}
$$


Retomando agora à equação 4.36, é possível chegar na seguinte expressão:

$$
\frac{\partial E}{\partial Y_{\alpha}^{\beta}}=\frac{1}{2}\left(\left(A^{0}\right)^{-t}\left(\frac{\partial A^{1}}{\partial Y_{\alpha}^{\beta}}\right)^{t} A^{1}\left(A^{0}\right)^{-1}+\left(A^{0}\right)^{-t}\left(A^{1}\right)^{t}\left(\frac{\partial A^{1}}{\partial Y_{\alpha}^{\beta}}\right)\left(A^{0}\right)^{-1}\right)
$$

em que $\alpha$ indica a direção (1 ou 2) e $\beta$ indica o nó em que está sendo avaliada a variação. A partir disto é possível obter o vetor de forças internas do elemento e por consequência o vetor de forças internas do sólido 2D por meio de integração numérica:

$$
f_{\alpha}^{\beta}=\frac{\partial E}{\partial Y_{\alpha}^{\beta}}: S
$$

e

$$
\left(F_{\alpha}^{\beta}\right)^{i n t}=\sum_{i h=1}^{n h} f_{\alpha}^{\beta} w_{i h} J\left(\xi_{1}(i h), \xi_{2}(i h)\right)
$$

em que $i h$ é o ponto de integração de Hammer, nh é o número de pontos de integração, $w_{i h}$ é o peso associado ao ponto de Hammer e $J\left(\xi_{1}(i h), \xi_{2}(i h)\right)$ é o jacobiano calculado no ponto de Hammer e equivale ao determinante de $A^{0}$.

Ao recordar a equação 4.31, percebe-se a existência da derivada do vetor de forças internas em relação às posições nodais, que originará uma matriz chamada de Hessiana:

$$
\frac{\partial\left(F_{\alpha}^{\beta}\right)^{i n t}}{\partial Y_{\gamma}^{z}}=\int_{V_{0}} \frac{\partial f_{\alpha}^{\beta}}{\partial Y_{\gamma}^{z}} d V_{0}
$$

com $\gamma$ sendo a direção e $z$ o nó, em que:

$$
\begin{aligned}
\frac{\partial f_{\alpha}^{\beta}}{\partial Y_{\gamma}^{z}}= & \frac{1}{2}\left[\left(A^{0}\right)^{-t}\left(\frac{\partial A^{1}}{\partial Y_{\alpha}^{\beta}}\right)^{t}\left(\frac{\partial A^{1}}{\partial Y_{\gamma}^{z}}\right)\left(A^{0}\right)^{-1}+\left(A^{0}\right)^{-t}\left(\frac{\partial A^{1}}{\partial Y_{\alpha}^{\beta}}\right)\left(\frac{\partial A^{1}}{\partial Y_{\gamma}^{z}}\right)\left(A^{0}\right)^{-1}\right]: S \\
& +\left[\frac{1}{2}\left(\left(A^{0}\right)^{-t}\left(\frac{\partial A^{1}}{\partial Y_{\alpha}^{\beta}}\right)^{t} A^{1}\left(A^{0}\right)^{-1}+\left(A^{0}\right)^{-t}\left(A^{1}\right)^{t}\left(\frac{\partial A^{1}}{\partial Y_{\alpha}^{\beta}}\right)\left(A^{0}\right)^{-1}\right)\right]: \frac{\partial S}{\partial Y_{\gamma}^{z}}
\end{aligned}
$$

Por fim, procede-se com integração numérica da mesma maneira que com o vetor de forças internas e aplica-se o método de Newton-Raphson para a resolução do problema. 


\section{Campo Higrométrico}

A modelagem do campo higrométrico foi feita de duas maneiras distintas, por meio da percolação d'água em meios porosos e da difusão de umidade governada pela segunda lei de Fick. A explicação do campo higrométrico nas seções 5.1 a 5.5 segue Wang e Anderson (1982).

\subsection{Potencial Hidráulico Total}

Potencial de um fluído é o trabalho necessário para transformar uma unidade de massa de um fluído de um estado arbitrário para um estado a ser considerado. Entende-se que o potencial total hidráulico é composto por três parcelas potenciais: pressão, elevação e cinética. Estes potenciais são mostrados nas três equações à seguir:

$$
\begin{aligned}
& \text { Potencial de Pressão }=\frac{1}{m} \int_{0}^{P} V d P=\frac{1}{m} \int_{0}^{P} \frac{m}{\rho_{w}} d P=\frac{P}{\rho_{w}} \\
& \text { Potencial de Elevação }=\frac{1}{m} \int_{0}^{z} m g d z=g z \\
& \text { Potencial Cinético }=\frac{1}{m} \int_{0}^{z} m a d z=\frac{1}{m} \int_{0}^{z} m \frac{d v}{d t} d z=\int_{0}^{v} v d v=\frac{v^{2}}{2}
\end{aligned}
$$

em que $m$ é a massa, $V$ é o volume, $P$ é a pressão, $\rho_{w}$ é a densidade do fluído, $g$ é a aceleração da gravidade, $z$ é a altura a partir do ponto de referência (datum), a é a aceleração no instante de tempo $t$ e $v$ é a velocidade.

O potencial hidráulico total $(\phi)$ é composto pelo somatório de todas as suas parcelas e assume a forma da equação 5.2 .

$$
\phi=\frac{P}{\rho_{w}}+g z+\frac{v^{2}}{2}
$$

Dividindo-se o potencial total hidráulico pela gravidade $g$ é obtida a seguinte equação:

$$
\Phi=\frac{P}{\rho_{w} g}+z+\frac{v^{2}}{2 g}
$$

Pode-se reescrever a pressão $P$ de um ponto em um fluído como:

$$
P=\frac{F}{A}=\frac{m g}{A}=\frac{H A \rho_{w} g}{A}=\rho_{w} g H
$$


em que $F$ é a força exercida num ponto imerso em um fluído qualquer, $A$ é a área de atuação da força e $H$ é a altura da coluna de fluído acima do ponto em questão.

Finalmente, substituindo a equação 5.4 na equação 5.3, e desconsiderando a parcela de potencial cinético (devido ao fato da velocidade em problemas de percolação ser muito pequena), é obtida a seguinte expressão:

$$
\Phi=\frac{\phi}{g}=H+z
$$

ou ainda

$$
\Phi=z+\frac{p}{\gamma}
$$

em que z é a altura do ponto analisado em relação à um datum, $p$ é a altura da coluna de fluído acima e $\gamma$ é a densidade do fluído.

\subsection{Lei de Darcy}

A lei de Darcy é uma relação empírica que relaciona a taxa de descarga d'água com a permeabilidade e variação da pressão de coluna d'água. A lei de Darcy é dada pela seguinte função:

$$
Q=-K A \frac{\phi_{2}-\phi_{1}}{l_{2}-l_{1}}
$$

Na equação 5.7, $Q$ é a taxa de descarga d'água, $K$ é a permeabilidade, $\phi_{2}-\phi_{1}$ é a mudança no potencial hidráulico, $A$ é a área transversal e $l_{2}-l_{1}$ é a diferença de comprimento. O sinal negativo diz que o fluxo da água vai na direção da perda de pressão.

\subsection{Lei de Darcy nas Três Direções}

Para generalizar o potencial nas três direções do espaço, ou seja, com $\phi=\phi(x, y, z)$ e generalizar $d \phi / d l$ podemos definir $q=\frac{Q}{A}$ como a taxa de volume por unidade de área. A quantidade $q$ é chamada de descarga específica. No limite, fazendo os intervalos $\phi_{2}-\phi_{1} \mathrm{e}$ $l_{2}-l_{1}$ se tornarem cada vez menores, obtêm-se a forma diferencial representada na equação 5.8, também conhecida como velocidade de Darcy.

$$
q=-K \frac{d \phi}{d l}
$$


A generalização tridimensional da lei de Darcy assume então a forma da equação 5.9

$$
\begin{aligned}
& q_{x}=-K \frac{d \phi}{d x} \\
& q_{y}=-K \frac{d \phi}{d y} \\
& q_{z}=-K \frac{d \phi}{d z}
\end{aligned}
$$

Nota-se que as derivadas no espaço são derivadas parciais, pois a pressão é função das três direções. Pode-se reescrever a equação 5.9 na forma da equação $5.10 \mathrm{com} q$ sendo o vetor composto pelas componentes $q_{x}, q_{y}, q_{z}$

$$
q=-K \nabla \phi
$$

\subsection{Equação de Continuidade para o Fluxo Estacionário}

Para o caso de fluxo estacionário, primeiro assume-se que a pressão d'água é independente do tempo, o fluído é incompressível, a quantidade de água que entra é a mesma quantidade que sai, e que em um volume elementar não há fontes nem sumidouros. A partir destas premissas chega-se na equação 5.11:

$$
\frac{\partial q_{x}}{\partial x}+\frac{\partial q_{y}}{\partial y}+\frac{\partial q_{z}}{\partial z}=\operatorname{div} \mathbf{q}=0
$$

\subsection{Equação de Laplace}

Combinando as equações de Darcy e a equação de Continuidade, obtém-se a equação 5.12:

$$
\frac{\partial}{\partial x}\left(-K \frac{\partial \phi}{\partial x}\right)+\frac{\partial}{\partial y}\left(-K \frac{\partial \phi}{\partial y}\right)+\frac{\partial}{\partial z}\left(-K \frac{\partial \phi}{\partial z}\right)=0
$$

com $K$, coeficiente de permeabilidade, sendo considerado isótropo e portanto independente de $x, y, z$. O aquífero é considerado homogêneo sob condições estacionárias e a equação 5.12 assume a forma da equação 5.13 que é a equação de Laplace.

$$
\frac{\partial^{2} \phi}{\partial x^{2}}+\frac{\partial^{2} \phi}{\partial y^{2}}+\frac{\partial^{2} \phi}{\partial z^{2}}=0
$$




\subsection{Modelagem da Percolação}

A modelagem do processo de percolação d'água através da estrutura porosa do concreto foi realizada por duas abordagens distintas. Após, foi realizado o acoplamento de cada uma com o algoritmo de expansão pela RAS e por fim com o problema mecânico.

A descrição e formulação de cada uma das abordagens é feita nas seções seguintes. Numa delas foi realizada a implementação da segunda lei de Fick para o transporte de umidade através do domínio ao longo do tempo decorrido do ensaio. Noutra, foi efetuada a implementação do algoritmo de percolação de água em meios porosos, simulando o caso de estruturas hidráulicas, como barragens, por exemplo. Neste segundo modelo, o problema é considerado estando num regime de fluxo estacionário dentro de cada intervalo de tempo.

\subsubsection{Modelagem de acordo com a segunda Lei de Fick}

Para a modelagem do processo de difusão d'água ao longo do tempo e em meio poroso foi utilizada a segunda lei de Fick, descrita na equação 5.14. Considerando-se transferência conservativa de massa, a segunda lei de Fick descreve a concentração de umidade no domínio ao longo do tempo.

$$
\frac{\partial s}{\partial t}=D_{s} \nabla^{2} s
$$

em que $s$ é o grau de umidade e $D_{s}$ é o coeficiente de percolação. Percebe-se que o caso estacionário é um caso particular, quando $\frac{\partial s}{\partial t}=0$, resultando em $D_{s} \nabla^{2} s=0$. Portanto, o caso estacionário remete à lei de Darcy ou primeira lei de Fick.

Foi utilizado o esquema da equação 5.15 para realizar a integração temporal. É assumido que $\theta=\frac{1}{2}$, correspondendo ao método de Crank-Nicholson.

$$
(\mathbf{M}+\Delta t \mathbf{K} \theta) s^{n+1}=(\mathbf{M}-\Delta t \mathbf{K}(1-\theta)) s^{n}
$$

em que $\mathbf{M}$ é a matriz de massa, $\mathbf{K}$ é a matriz de permeabilidade, $\Delta t$ é o passo de tempo adotado e $s$ é o grau de saturação no instante $t$.

\subsubsection{Modelagem da Percolação em Meio Poroso}

No que concerne o cálculo da superfície freática em meios porosos pelo método dos elementos finitos, pode-se separar basicamente em dois grandes grupos. Os métodos de malha variável e os métodos com malha fixa. Este trabalho se concentra em fazer uso de um dos métodos de malha fixa por apresentar vantagens quando for necessário efetuar a expansão por álcali-sílica. 
O cálculo da superfície freática da percolação é feito utilizando o método desenvolvido por Bathe e Khoshgoftaar (1979) por se tratar de fácil implementação e entendimento. A seguir é feita a explanação do método de acordo com seu artigo.

Partindo da equação de Laplace e assumindo que:

$$
\phi=z+\frac{p}{\gamma}
$$

em que $z$ é a coordenada responsável pela altura, $p$ é a pressão exercida pela água e $\gamma$ é a densidade específica da água, obtém-se as seguintes condições de contorno para o problema da figura 16.

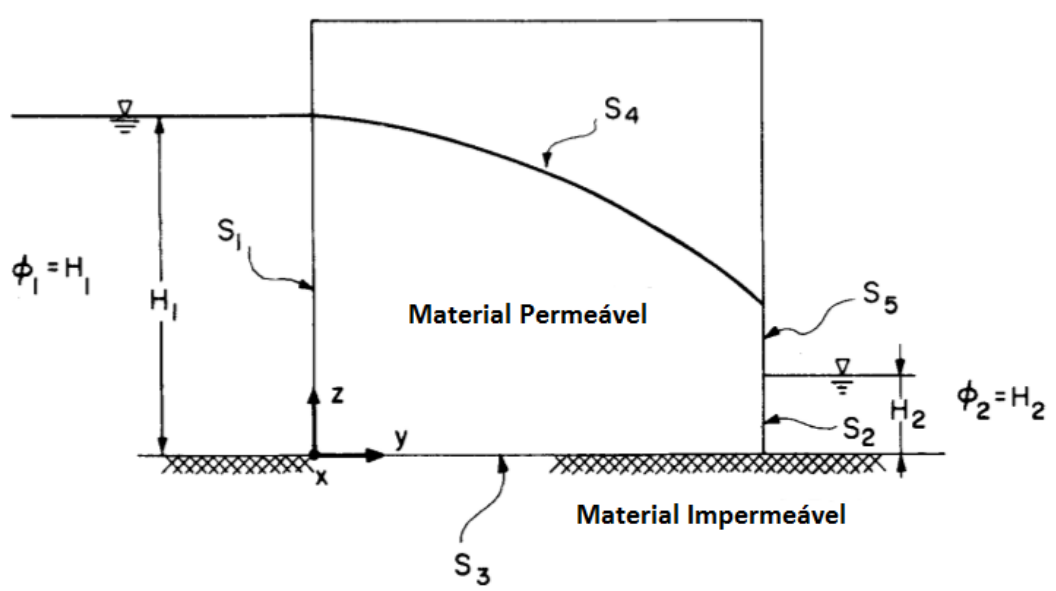

Figura 16 - Fluxo d'água estacionário de superfície livre em meio poroso. Fonte: Adaptado de Bathe e Khoshgoftaar (1979)

em que:

$$
\begin{aligned}
& \phi=\phi_{1} \mathrm{em} S_{1} \\
& \phi=\phi_{2} \mathrm{em} S_{2}
\end{aligned}
$$

A condição de contorno para a base impermeável é:

$$
\frac{\partial \phi}{\partial n}=0 \mathrm{em} S_{3}
$$

em que $n$ denota a normal em relação a superfície. 
Para a superfície livre têm-se:

$$
\left.\begin{array}{rl}
\phi & =z \\
\frac{\partial \phi}{\partial n} & =0
\end{array}\right\} e m S_{4}
$$

E por fim, na face de percolação:

$$
\phi=z e m S_{5}
$$

Uma equação variacional é empregada, no qual as condições de contorno essenciais são explicitamente impostas e as condições de contorno naturais são implicitamente satisfeitas. O princípio do trabalho virtual que governa a percolação em fluxo estacionário é:

$$
\int_{V} \delta \phi^{\prime} \Gamma k \phi^{\prime} d V=0
$$

$\delta$ denota a "variação em", k é a matrix de permeabilidade nas direções principais, por exemplo:

$$
\mathbf{k}=\left[\begin{array}{ccc}
k_{x} & 0 & 0 \\
0 & k_{y} & 0 \\
0 & 0 & k_{z}
\end{array}\right]
$$

e

$$
\phi^{\prime}=\left[\begin{array}{c}
\frac{\partial \phi}{\partial x} \\
\frac{\partial \phi}{\partial y} \\
\frac{\partial \phi}{\partial z}
\end{array}\right]
$$

\subsubsection{Formulação por Elementos Finitos}

Fazendo uso de elementos isoparamétricos de número $N$ de nós,

$$
x=\sum_{i=1}^{N} h_{i} x_{i}, y=\sum_{i=1}^{N} h_{i} y_{i}, z=\sum_{i=1}^{N} h_{i} z_{i} \text { e } \phi=\sum_{i=1}^{N} h_{i} \phi_{i}
$$

com $x_{i}, y_{i}, z_{i}$ sendo as coordenadas dos nós, $h_{i}$ os valores das funções de forma naqueles nós e $\phi_{i}$ o valor do potencial de água naquele nó. Substituindo na equação 5.22 e incluindo as superfícies de contorno têm-se:

$$
\mathbf{K}^{k} \phi=0
$$


em que

$$
\mathbf{K}^{k}=\sum_{m} \int_{V^{(m)}} \mathbf{B}^{(m) T} \mathbf{k}^{(m)} \mathbf{B}^{(m)} d V^{(m)}
$$

com $\mathbf{K}^{k}$ é a matriz de permeabilidade global resultante da junção de todos os elementos, $\phi$ é o vetor correspondente a todos os potenciais hidráulicos nodais, $\mathbf{B}^{(m)}$ é a matriz do gradiente das funções de forma do elemento $m$ e $\mathbf{k}^{(m)}$ é a matriz de permeabilidade do elemento $m$, de acordo com a equação 5.23.

Para impor os potenciais hidráulicos das condições de contorno, são adicionados coeficientes de alta permeabilidade dos elementos que compõem a diagonal de $\mathbf{K}^{\mathbf{k}}$ correspondentes aos nós do contorno. Portanto, pode-se modificar a equação 5.26 para ficar no seguinte formato:

$$
\left(\mathbf{K}^{k}+\mathbf{K}^{b}\right) \phi=\mathbf{Q}^{b}
$$

no qual $\mathbf{K}^{b}$ é uma matriz diagonal. O iésimo elemento da diagonal de $\mathbf{K}^{b}$ é igual a zero se $\phi_{i}$ não for prescrito e igual a $k$ se for, onde $k>>k_{i i}^{k}$. Analogamente, o mesmo elemento $i$ no vetor $\mathbf{Q}^{b}$ será zero se $\phi_{i}$ não for especificado e do contrário será $k \phi_{i}$. Pelo fato de $k$ ser apenas adicionado na diagonal de $\mathbf{K}^{b}$, este procedimento não cria problemas numéricos, independentemente do valor de $k$.

Levando-se em consideração as condições de contorno naturais, a condição de $\frac{\partial \phi}{\partial n}=0 \mathrm{em} S_{3}$ e $S_{4}$ é imposta não prescrevendo fluxo normal à superfície nas equações 5.22 e 5.26 .

Neste momento, poderia-se obter a solução do problema se a superfície $S_{4}$ fosse conhecida. Entretanto, pelo fato desta ser também desconhecida, é necessário reescrever o problema de forma não-linear em que a superfície de percolação deverá ser encontrada por meio de um processo iterativo, sempre satisfazendo as condições estabelecidas na equação 5.20. Assumindo uma estrutura completamente discretizada e representada por elementos finitos, faz-se a permeabilidade dos elementos ser:

$$
\text { permeabilidade do material }=\left\{\begin{array}{l}
k \text { para } \phi \geq z \\
0 \text { para } \phi<z
\end{array}\right.
$$

Então, os elementos acima da linha freática são efetivamente removidos ao atribuirlhes permeabilidade 0 e os que estão abaixo continuam ativos, com suas respectivas permeabilidades. A equação 5.29 é representada na figura 17.

Por questão de estabilidade numérica, é necessário inserir um valor significativamente pequeno $(\varepsilon)$ ao invés de 0 . Neste trabalho foi usado o valor de $\frac{k}{1000}$ como sugerido por Bathe e Khoshgoftaar (1979). 


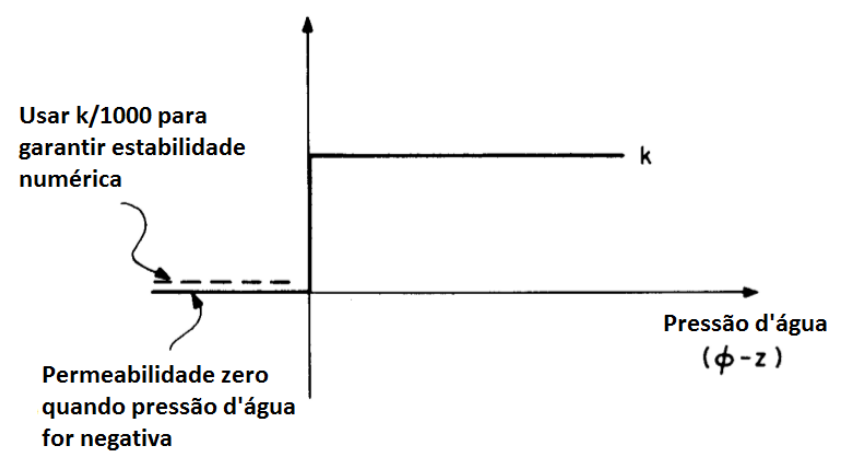

Figura 17 - Função de permeabilidade não-linear do elemento.

Fonte: Adaptado de Bathe e Khoshgoftaar (1979)

A equação 5.29 é basicamente uma função Heaviside e pode ser reescrita da seguinte forma na equação 5.30:

$$
H_{\varepsilon}(x)=\left\{\begin{array}{l}
1 \text { para } x \geq 0 \\
\varepsilon \text { para } x<0
\end{array}\right.
$$

Entretanto, fazendo uso apenas da equação 5.30 não foi suficiente para conseguir a convergência no exemplo da subseção 7.1.1 para validação do algoritmo. Segundo Zheng, Dai e Liu (2009) este método, da forma que é apresentado no artigo, possui determinadas limitações, principalmente no que diz respeito à dependência de malha. A função heaviside descontínua pode causar oscilações na integração numérica quando a superfície freática (SF) corta o elemento finito. As figuras 18a e 18b representam o caso da superfície freática passar acima e abaixo do ponto $g$, respectivamente. De acordo com $H_{\varepsilon}(x)$ na equação 5.30, não importa o quão próximos estiverem os pontos de integração, aquele que estiver abaixo da SF contribuirá com $100 \%$ da permeabilidade para a integração numérica, enquanto que, aquele que estiver acima contribuirá apenas $\operatorname{com} \varepsilon$. Portanto esta descontinuidade causará oscilações, que dependerão da configuração da malha.
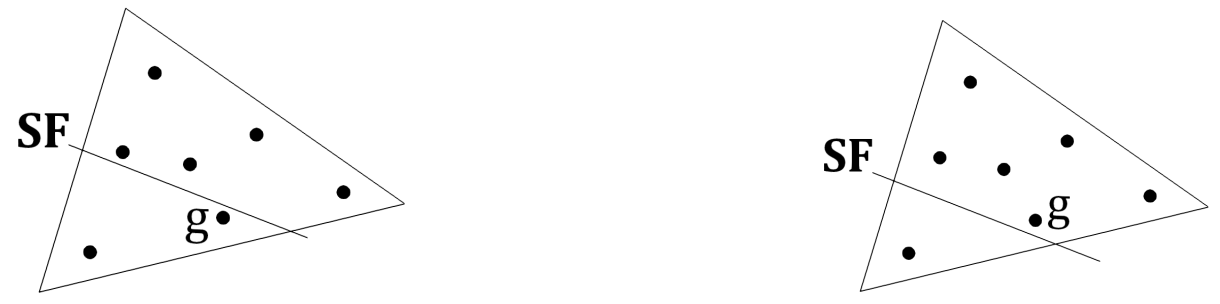

(a) $100 \%$ de contribuição quando a $\mathbf{S F}$ passa (b) $\varepsilon$ de contribuição quando a $\mathbf{S F}$ passa abaixo acima do ponto g. do ponto g.

Figura 18 - Posição da Superfície Freática em relação aos pontos de integração. 
No trabalho de Zheng, Dai e Liu (2009) é feito uso de uma função quasi-Heaviside, em que há um trecho linear de transição entre o valor mínimo $(\varepsilon)$ e o valor máximo $(k)$, de acordo com a equação 5.31.

$$
H_{\varepsilon}^{\lambda}(x)=\left\{\begin{array}{r}
1 \text { para } x \geq 0 \\
\frac{1-\varepsilon}{\lambda} x+1 \text { para }-\lambda<x<0 \\
\varepsilon \text { para } x \leq-\lambda
\end{array}\right.
$$

As figuras 19a e 19b mostram o comportamento das funções quasi-Heaviside de Bathe e Khoshgoftaar (1979) e Zheng, Dai e Liu (2009), respectivamente. De acordo com Zheng, Dai e Liu (2009) a função quasi-Heaviside contínua garante que haja continuidade na integração numérica mesmo com a SF passando sobre o ponto de integração. Vale mencionar que o formato de $H_{\varepsilon}^{\lambda}(x)$ é similar à curva característica de solo não saturado e portanto é possível substituir a função quasi-Heaviside contínua por esta curva e resolver problemas de percolação em solos não saturados sem demais alterações.

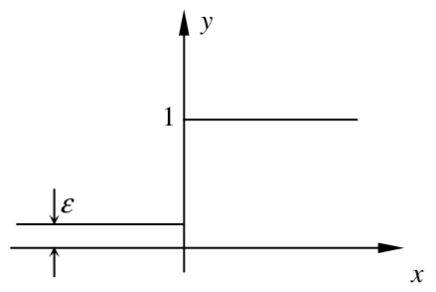

(a) Função Heaviside $H_{\varepsilon}$.

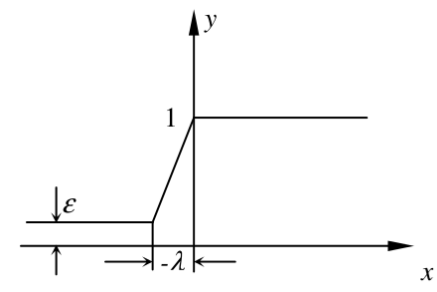

(b) Função quasi-Heaviside contínua $H_{\varepsilon}^{\lambda}$.

Figura 19 - Comparação entre as funções Heaviside e quasi-Heaviside. Fonte: Adaptado de Zheng, Dai e Liu (2009)

Fazendo uso do método de Newton-Raphson para resolução do problema não-linear de forma iterativa, reescreve-se a equação 5.28 da seguinte foma:

$$
\mathbf{F}^{k}+\mathbf{F}^{b}-\mathbf{Q}^{b}=0
$$

em que:

$$
\begin{gathered}
\mathbf{F}^{k}=\sum_{m} \int_{V^{(m)}} \mathbf{B}^{(m) T}\left(\mathbf{k}^{(m)} \mathbf{B}^{(m)} \phi\right) d V^{(m)} \\
\mathbf{F}^{b}=\mathbf{K}^{b} \phi
\end{gathered}
$$

e $k^{(m)}$ é a matriz de permeabilidade não-linear do elemento dependente do potencial hidráulico de acordo com 5.31. 
A iteração de Newton-Raphson para a solução da equação 5.32 é efetuada seguindo as seguintes equações:

$$
\begin{gathered}
\left(\mathbf{K}_{i-1}^{k}+\mathbf{K}^{b}\right) \Delta \phi_{i}=\mathbf{Q}^{b}-\mathbf{F}_{i-1}^{k}-\mathbf{F}_{i-1}^{b} ; i=1,2, \ldots \\
\mathbf{K}_{i-1}^{k}=\sum_{m=1}^{\text {nelem }} \int_{V^{(m)}} \mathbf{B}^{(m) T} \mathbf{k}_{i-1}^{m} \mathbf{B}^{m} d V^{m} \\
\mathbf{F}_{i-1}^{k}=\sum_{m=1}^{n e l e m} \int_{V^{m}} \mathbf{B}^{(m) T}\left[\mathbf{k}_{i-1}^{m} \mathbf{B}^{(m)} \phi_{i-1}\right] d V^{m} \\
\mathbf{F}_{i-1}^{b}=\mathbf{K}^{b} \phi_{i-1}
\end{gathered}
$$

e

$$
\phi_{i}=\phi_{i-1}+\Delta \phi_{i}
$$

Diz-se que se alcançou a convergência quando:

$$
\frac{\left\|\Delta \phi_{i}\right\|}{\left\|\phi_{i}\right\|} \leq \text { Tolerância }
$$

Neste trabalho foi utilizado o valor de $10^{-3}$ como parâmetro de tolerância para convergência.

Ressalta-se que a atribuição de valor suficientemente pequeno para a permeabilidade do elemento ao invés de 0 é necessário para manter um coeficiente positivo definido na matriz da equação 5.35 .

Por se tratar de uma análise não-linear por elementos finitos isoparamétricos, na integração numérica a permeabilidade apropriada do material é avaliada nos pontos de integração, principalmente quando a superfície freática atravessa o elemento finito.

Do método de Newton-Raphson, a condição inicial de iteração é especificada como o potencial hidráulico máximo das condições de contorno do problema. Ademais, os elementos não zerados da matriz $\mathbf{K}^{b}$ da equação 5.35 precisam corresponder apenas às condições de contorno das superfícies $S_{1}$ e $S_{2}$ na figura 16. 


\section{Acoplamento Higromecânico}

Sobre o acoplamento entre os campos mecânico e higrométrico, o campo higrométrico servirá apenas para suprir dados ao campo mecânico, indicando quais pontos de integração estão sob efeito da umidade de acordo com a configuração do problema. Após a solução do problema higrométrico, é efetuada a resolução do problema mecânico, levando-se em consideração a expansão promovida pelo modelo de RAS. A solução do problema mecânico, devido a natureza do problema e das estruturas comumente analisadas, não interferirá no campo higrométrico.

Como já dito na seção 3.4, o modelo de expansão da RAS é o modelo paramétrico utilizado em Carrazedo (2004). Este modelo, demonstrado pela equação 3.19, considera que a presença de água ocorre desde o tempo inicial, o que é um caso particular, dado o fato de que o provimento de água pode se dar em data posterior da moldagem do concreto.

Estruturas que nunca entraram em contato com a água, podem muito bem ter desenvolvido o gel da RAS e se forem submetidas a regime de umidade ao longo de sua vida, apresentarão deformações significativas provindas da patologia. Todavia, o desenvolvimento das deformações será diferente em comparação com uma estrutura que esteve em contato com a água desde o início, assim como evidenciado por Multon e Toutlemonde (2010).

Portanto, é necessário alterar a equação 3.19 para contemplar a situação em que a estrutura tenha desenvolvido a patologia, mas não tenha ainda entrado em contato com a água. Também é necessário contemplar casos em que há regimes não constantes de umidade, onde pode haver a interrupção temporária do contato com a água.

\subsection{Expansão da RAA Levando em Consideração o Regime de Umi- dade.}

Diante do exposto anteriormente, é proposta uma alteração na equação de expansão da RAS para levar em consideração o tempo em que a estrutura não esteve submetida à condição de umidade necessária para que ocorra o processo de inchamento do gel, mas ainda assim contabilizar o tempo de formação do gel.

Na equação 6.1 as alterações envolvem as variáveis $A_{2}$ e $\varepsilon$ que, para representar a alteração destes valores quando há privação de umidade durante o tempo de formação do gel, são funções de $t_{a}$. $t_{a}$ é uma variável que é apenas incrementada quando o concreto está em situação de umidade insuficiente para causar expansão, ou seja, com umidade relativa inferior a $85 \%$ ou $75 \%$, dependendo da adoção. A variável $t_{a}$ não é incrementada 
quando se está no período de preenchimento dos poros, ou seja, quando $t$ for menor que $t_{p}$ ou quando há água suficiente para a expansão da RAS e formação de mais gel.

$$
\dot{\varepsilon}_{R A A}=\mathrm{H}\left(t-t_{p} F_{p}\right) \varepsilon\left[\frac{e^{\frac{-\left(t-t_{p} F_{p}-t_{a}\right)}{A_{2} F_{T}}}}{A_{2} F_{T}}\right] \sqrt{F_{C} F_{M}}
$$

O fato de $\varepsilon$ e $A_{2}$ serem funções de $t_{a}$ implica que estes variam de acordo com o tempo de privação de água do concreto. Entretanto não há dados e bibliografia suficiente para a modelagem do seu comportamento. Neste trabalho foi adotado que ambos seguem leis lineares similares, representadas nas equações 6.2 e 6.3. Estas equações são dependentes de $t_{a}$, chamado de Tempo de Atraso do fornecimento de água, $t_{f}$ que é o Tempo Final de medição experimental destas reduções e $\Delta \varepsilon$ ou $\Delta A_{2}$ que representam a redução da expansão e reatividade, respectivamente, em percentual.

$$
\begin{gathered}
\varepsilon=\varepsilon^{\max }\left(1-\Delta \varepsilon \frac{t_{a}}{t_{f}}\right) \\
A_{2}=A_{2}^{\max }\left(1-\Delta A_{2} \frac{t_{a}}{t_{f}}\right)
\end{gathered}
$$

O comportamento destas funções está representado nas figuras 20a e 20b. Para um valor de $t_{a}$ maior que $t_{f}$, não há mais decaimento nos valores de $\varepsilon$ e $A_{2}$. Percebe-se que os valores mínimos para a expansão e reatividade são encontrados quando $t_{a} \geq t_{f}$. Como exemplificação, na figura 20 foram adotados para $\Delta \varepsilon$ e $\Delta A_{2}$ o valor de 0,40 e para $t_{f}$ o valor de 50 dias.

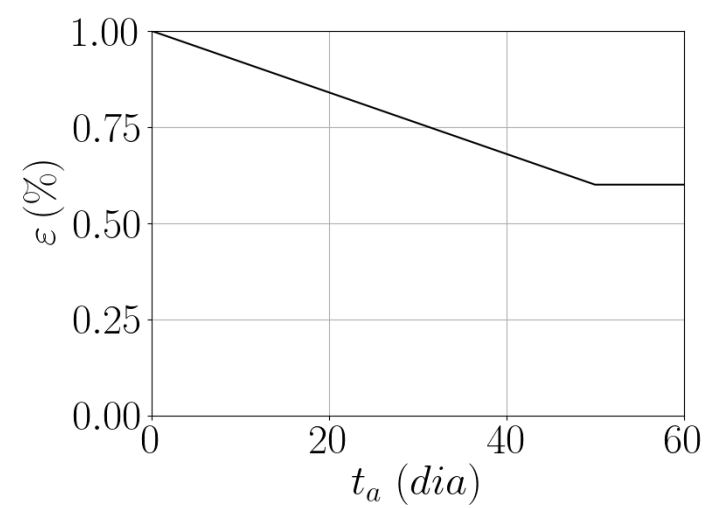

(a) Comportamento de $\varepsilon$ com a variação de $t_{a}$.

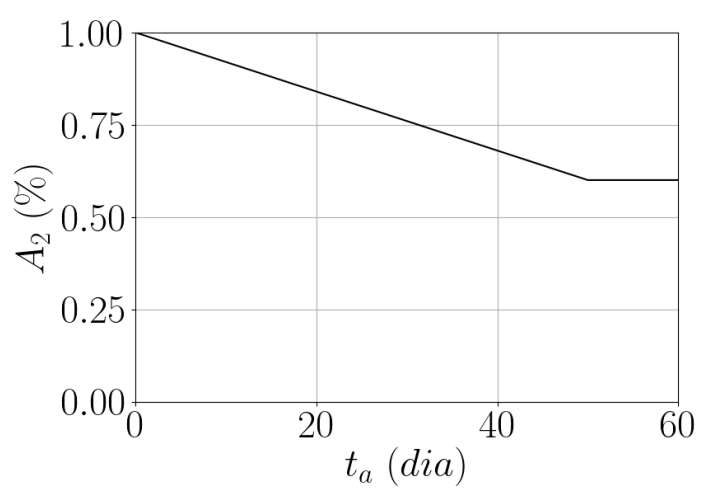

(b) Comportamento de $A_{2}$ com a variação de $t_{a}$.

Figura 20 - Comportamento e $\varepsilon$ e $A_{2}$ em função de $t_{a}$.

No que diz respeito aos ciclos de molhagem e secagem, Poyet et al. (2006) realizaram ensaios laboratoriais e concluíram que a presença de gel proveniente da RAS é capaz de provocar inchamento e retração adicionais em comparação com corpos de prova de concreto saudável. Eles argumentam que a retração excedente é causada pela perda de 
água do gel, o que reduziria seu volume e por consequência a pressão exercida nos poros do concreto. Tal retração adicional estaria na ordem de 0,04\%.

Entretanto, em Multon e Toutlemonde (2010), também foram realizados ensaios similares para averiguar o comportamento do concreto sob efeito da RAS quando submetido à ciclos de molhagem e secagem. A retração por secagem ficou na ordem de $0,05 \%$ e os resultados das amostras com RAS foram comparados com amostras sem a patologia. Dos resultados, a variação de massa e deformação entre as amostras foram da mesma magnitude. A cinética e amplitude da deformação por retração foi exatamente a mesma não importando a extensão do dano causado pela RAS e direção de tomada das medidas. A fissuração provocada pela RAS não alterou os valores últimos de retração e a deformação devida ao inchamento do gel permanece irreversível. Por fim, a deformação aparenta ser acumulativa e permanente com o fornecimento de água.

Neste trabalho foi adotado para o modelo os resultados e conclusões obtidos em Multon e Toutlemonde (2010). Portanto, não há retração e redução nos valores de deformação para o modelo de expansão para a RAS quando submetido à secagem. O fenômeno de retração é devido, exclusivamente, à pasta de cimento e agregados. A interrupção no fornecimento de água e secagem causam apenas uma interrupção no processo de expansão do gel.

A figura 21 mostra diferentes estados de expansão para diferentes regimes de umidade. Percebe-se que a curva cheia é a curva onde o corpo de prova se encontra em contato permanente com a água. É a situação típica dos ensaios e resultados laboratoriais. A curva tracejada representa um corpo de prova em que seu contato com a umidade foi postergado e portanto possui um comportamento de expansão mais brusco e um valor de expansão $\varepsilon^{\max }$ menor que a curva que representa a condição de umidade permanente. Por fim a curva que representa a condição de umidade intermitente mostra um corpo de prova que começou seu ciclo de vida imerso em água, entretanto passou por um período de secagem intermediário, afetando posteriormente sua taxa de expansão e valor de expansão máxima. 


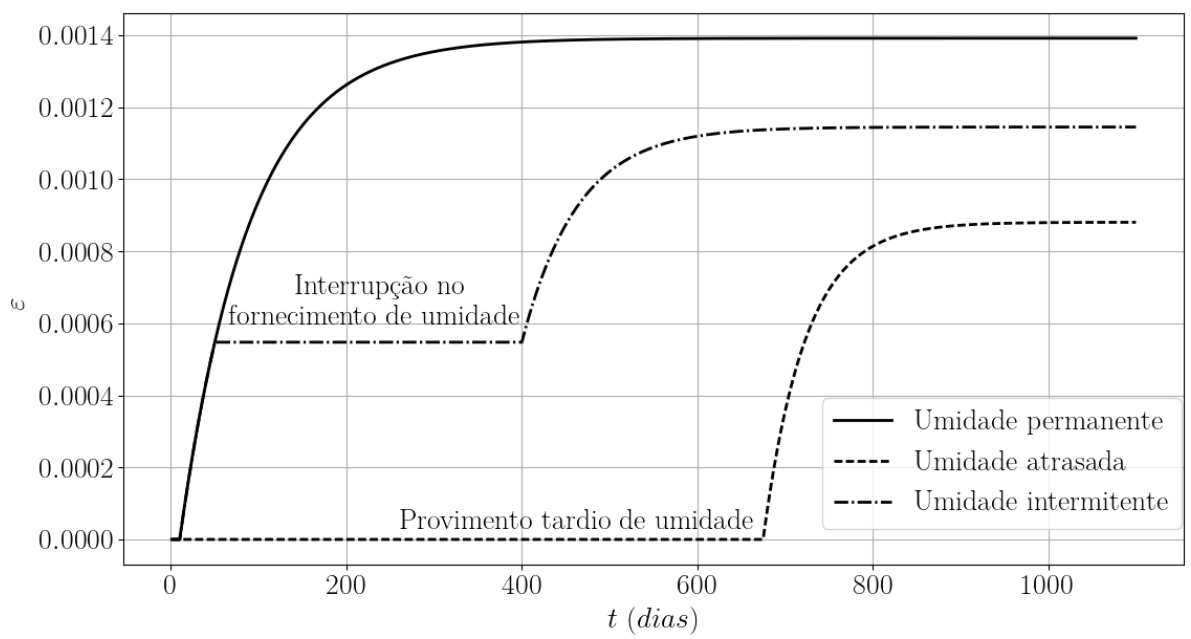

Figura 21 - Diferentes curvas de expansão para diferentes regimes de umidade.

\subsection{Ensaio Laboratorial da Viga Semi-Imersa}

O ensaio da viga semi-imersa descrito em Multon e Toutlemonde (2010) é importante pois nele fica mais claro o papel da umidade no processo de expansão da reação álcaliagregado.

Basicamente foram ensaiadas vigas de concreto armado biapoiadas de $3 \mathrm{~m}$ de comprimento e seção transversal de $25 \mathrm{~cm}$ por $50 \mathrm{~cm}$ de altura e corpos de prova cilíndricos de $14 \mathrm{~cm}$ de diâmetro por $28 \mathrm{~cm}$ de altura, sob regime não uniforme de umidade. Num primeiro momento, tanto as vigas como os corpos de prova foram mantidos com suas bordas inferiores em contato constante com a umidade, suas laterais seladas com papel alumínio e bordas superiores mantidas à 30\% de umidade relativa. Após 676 dias, foi adicionada água nas bordas superiores e tomadas medidas ao longo de todo o período de tempo. A figura 22 mostra as vigas de concreto armado e as condições de contorno de umidade do ensaio aplicadas nas vigas e nos corpos de prova.
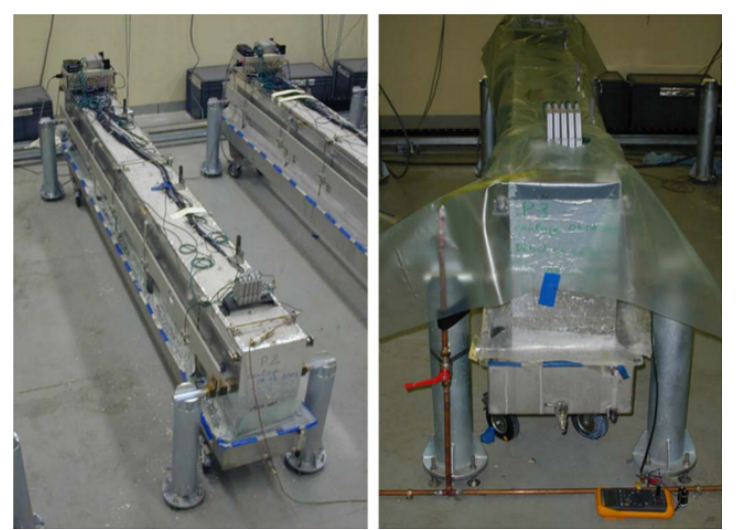

(a) Imagem das vigas de concreto armado ensaiadas.

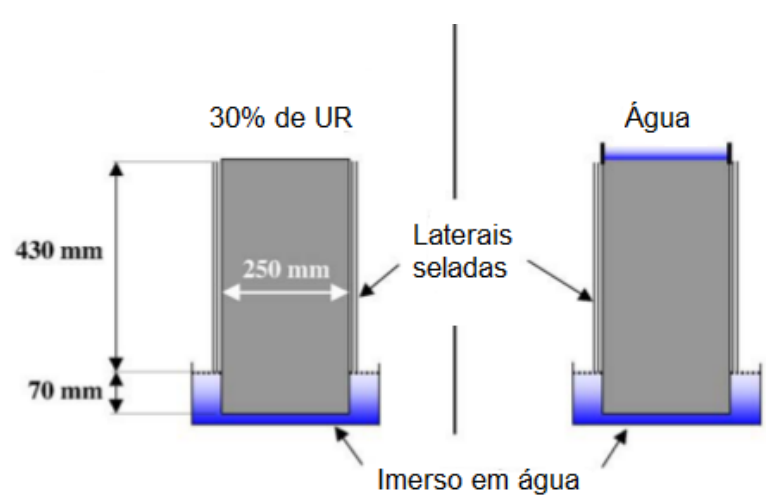

(b) Esquema das condições de contorno de umidade do ensaio.

Figura 22 - Imagem das vigas de concreto armado e do esquema das condições de contorno de umidade aplicadas ao longo do ensaio. 
Em paralelo, foram ensaiados dois grupos de corpos de prova cilíndricos de $16 \mathrm{~cm}$ de diâmetro por $32 \mathrm{~cm}$ de altura. O primeiro grupo foi submetido a $100 \%$ de umidade e $38{ }^{\circ} \mathrm{C}$ ao longo de todo o período de tempo. O segundo grupo é composto por corpos de prova que inicialmente foram selados e protegidos da umidade com papel alumínio e mantidos à $38^{\circ} \mathrm{C}$. Após 676 dias, foram submergidos em água e mantidos à $38^{\circ} \mathrm{C}$. Na figura 23 estão registradas deformações destes corpos de prova. Os pontos escuros são medidas na direção de moldagem e os pontos claros são medidas na direção perpendicular à moldagem. Os dados dos pontos quadrados são provenientes do primeiro grupo enquanto que os dados triangulares são do segundo grupo. Analisando apenas os pontos claros, percebe-se que o primeiro grupo (pontos quadrados) obteve comportamento de expansão contínuo, atingindo o valor máximo esperado. Entretanto, o segundo grupo (pontos triangulares) registrou basicamente nenhum valor de expansão até 676 dias. Após essa data, com a submersão dos corpos de prova, houve um súbito aumento na deformação e estabilização num valor final significativamente menor.

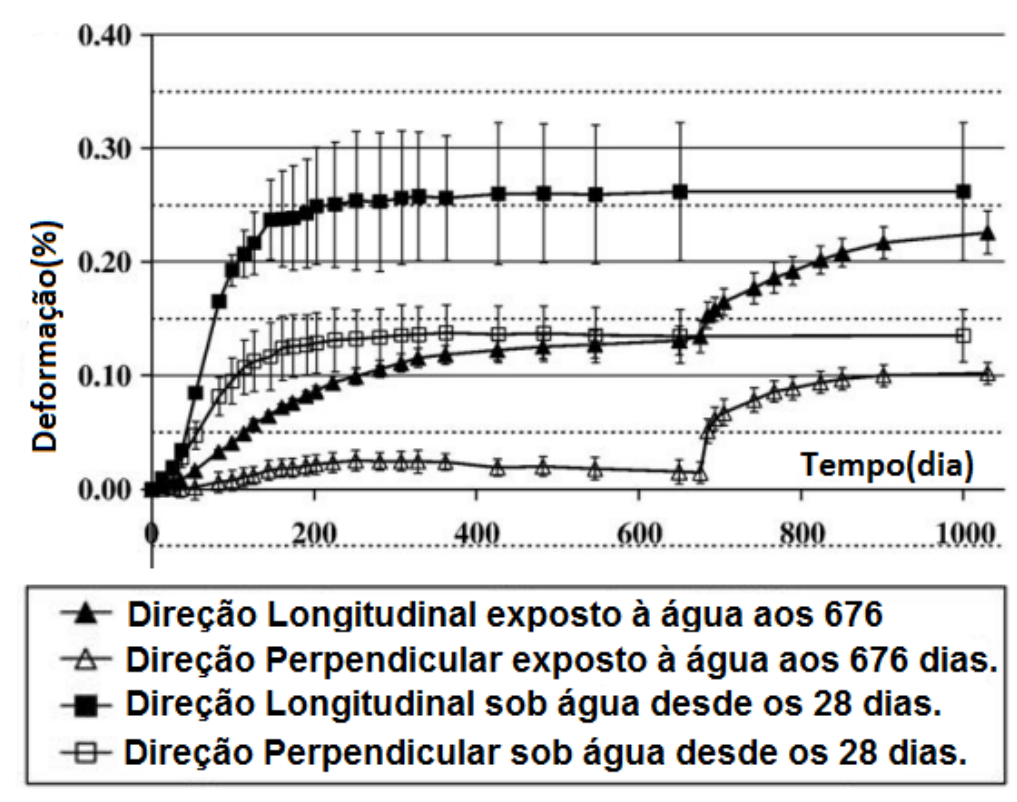

Figura 23 - Deformação x Tempo de corpos de prova cilíndricos submetidos à condições diferentes de umidade.

Fonte: Adaptado de Multon e Toutlemonde (2010) 


\section{Validação e Exemplos}

Neste capítulo são apresentados alguns exemplos numéricos com a finalidade de validação das diversas partes do algoritmo, e por fim, na validação do algoritmo final de resolução do problema da expansão da RAS levando em consideração os campos higrométrico e mecânico.

\subsection{Campo Higrométrico}

Aqui são apresentados os exemplos para a validação dos dois modelos de representação do campo higrométrico, o modelo de percolação em meio poroso de Bathe e Khoshgoftaar (1979) e o modelo da Lei de Fick.

\subsubsection{Barragem Retangular}

Para validar o campo higrométrico, foi reproduzido o exemplo de uma barragem retangular encontrada em Borja e Kishnani (1991). Trata-se de uma barragem de altura de $10 \mathrm{~m}$ e largura de $5 \mathrm{~m}$, com nível d'água a montante de $10 \mathrm{~m}$ e a jusante de $2 \mathrm{~m}$. Sua base é considerada impermeável e condições isotrópicas e constantes de permeabilidade foram assumidas. O coeficiente de permeabilidade utilizado foi unitário $\left(k=\left[\begin{array}{ll}1 & 0 \\ 0 & 1\end{array}\right]\right)$. A figura 24 mostra o esquema e a malha de elementos finitos para o exemplo. No total foram utilizados 218 elementos e 1036 nós.

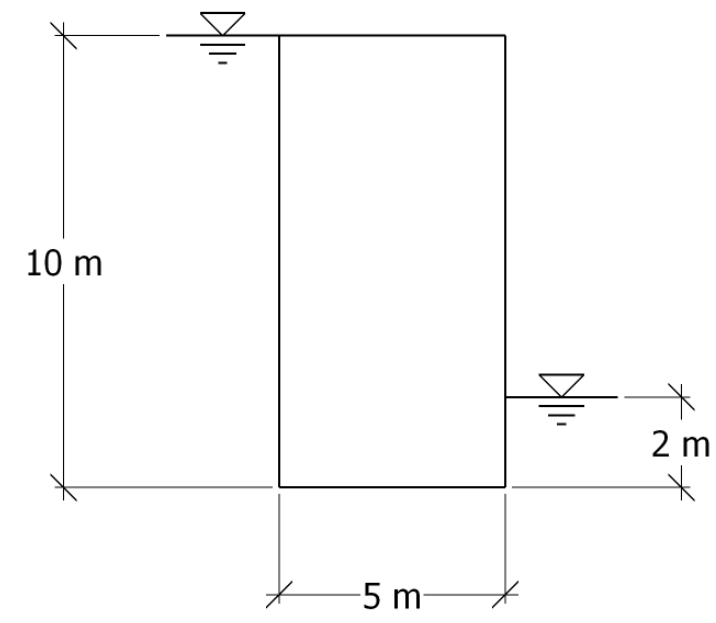

(a) Condições de contorno da barragem.

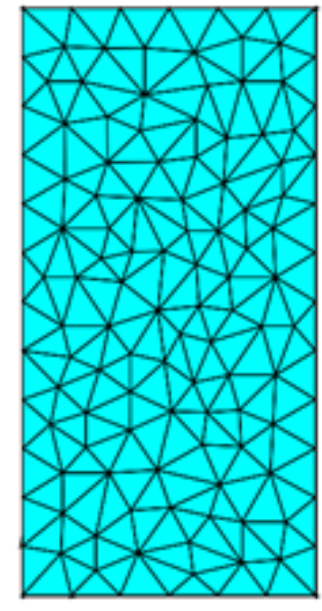

(b) Malha de elementos finitos.

Figura 24 - Esquema e malha empregados para o exemplo da barragem retangular. 
A figura 25 mostra a superfície freática de percolação calculada.

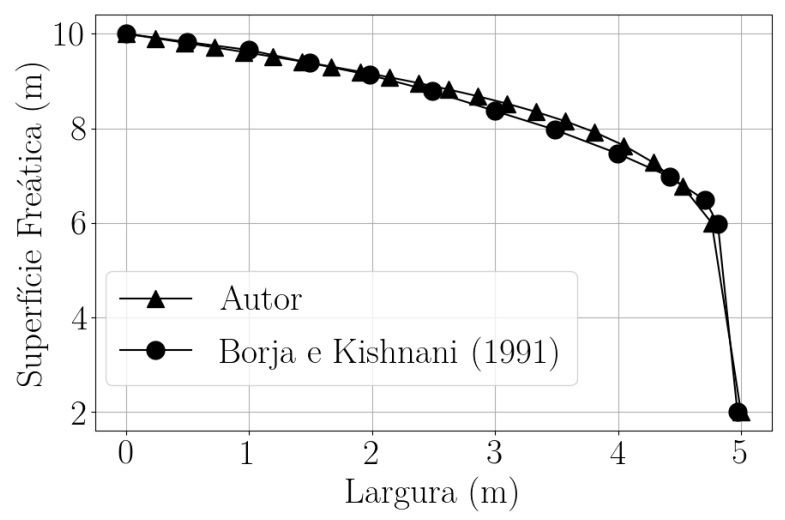

Figura 25 - Valores de $\phi$ ao longo da espessura da barragem.

Os resultados estão coerentes de acordo com o trabalho de Borja e Kishnani (1991). A queda brusca na superfície perto da face de percolação se deve ao fato de naquela face ser imposta a condição de contorno de $2 \mathrm{~m}$ a jusante e portanto o algoritmo deve obedecê-la. Borja e Kishnani (1991) também faz uso do método dos elementos finitos com malha fixa e uso de uma função quasi-Heaviside para calcular o valor da permeabilidade. Trata-se também de um algoritmo que encontra a superfície de percolação de forma iterativa.

\subsubsection{Segunda Lei de Fick}

Para validação do algoritmo para modelagem da segunda lei de Fick, comparou-se com a solução análitica encontrada em Crank (1975) e demonstrada na equação 7.1:

$$
C=C_{0} \operatorname{erfc}\left(\frac{x}{2 \sqrt{D t}}\right)
$$

em que $C$ é, neste caso, o grau de saturação num dado tempo e distância, $C_{0}$ é a condição de contorno numa das bordas, $D$ é o coeficiente de permeabilidade, $x$ é a distância da borda submetida a condição de contorno e $t$ é o tempo decorrido. A condição inicial de saturação no domínio é de 0,0 e erfc é a error function complementar.

Imaginou-se como exemplo uma barra com comprimento de 500,0 unidades, permeabilidade de 15000,0 unidades e condição de contorno $C_{0}$ de 1,0 unidade na borda esquerda. Na figura 26 estão plotados o resultado analítico e numérico para dois instantes de tempo $t$ ao longo da barra. É possível perceber que os valores numéricos estão suficientemente próximos dos analíticos. 


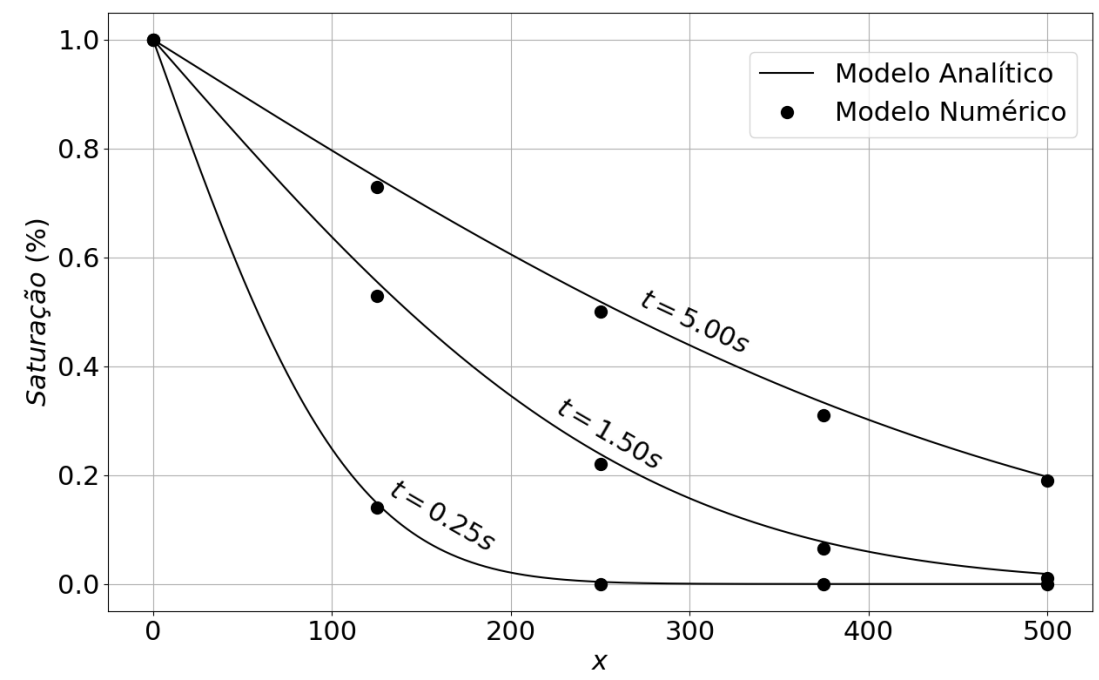

Figura 26 - Valores de saturação ao longo da barra em três instantes diferentes.

Na figura 27 nota-se o processo de difusão de umidade através da barra. Percebe-se que a umidade migra do ponto de maior concentração para o de menor.

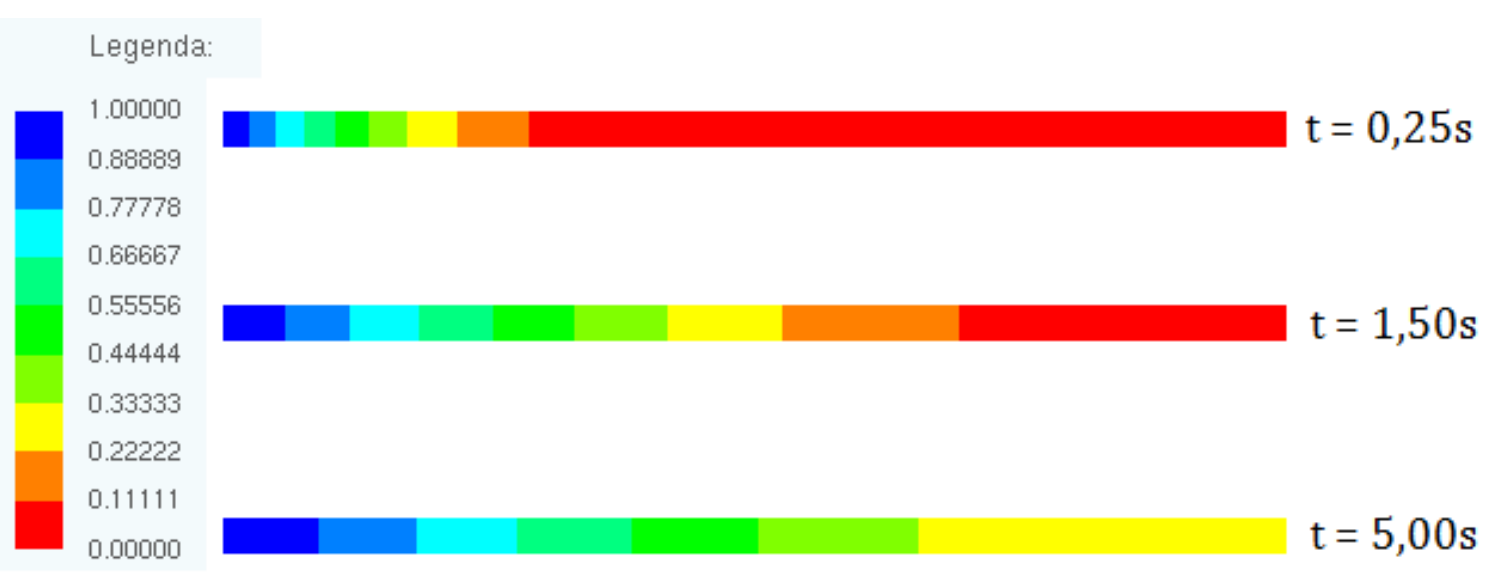

Figura 27 - Mapas de saturação ao longo da barra em três instantes de tempo.

\subsection{Campo Mecânico}

\subsubsection{Análise Não-Linear Geométrica de Viga Engastada}

Para a validação do programa de chapa não linear foi realizado o exemplo da viga engastada presente em Sampaio (2014). Para os dados do problema, têm-se uma viga engastada de comprimento $L=300 \mathrm{~cm}$, altura $h=10 \mathrm{~cm}$, largura $b=1 \mathrm{~cm}$, com módulo de elasticidade $E=21 \mathrm{GPa}$ e carregamento distribuído $q=50 \mathrm{~N} / \mathrm{cm}$.

A figura 28 mostra a deformada da estrutura com seu valor máximo de deformação na ponta livre. Sampaio (2014) reporta o valor de deformação de $\delta=-195,15175 \mathrm{~cm}$ enquanto para o algoritmo desenvolvido reporta $\delta=-195,208 \mathrm{~cm}$, o que significa uma diferença de 0,0288\% nos valores. 


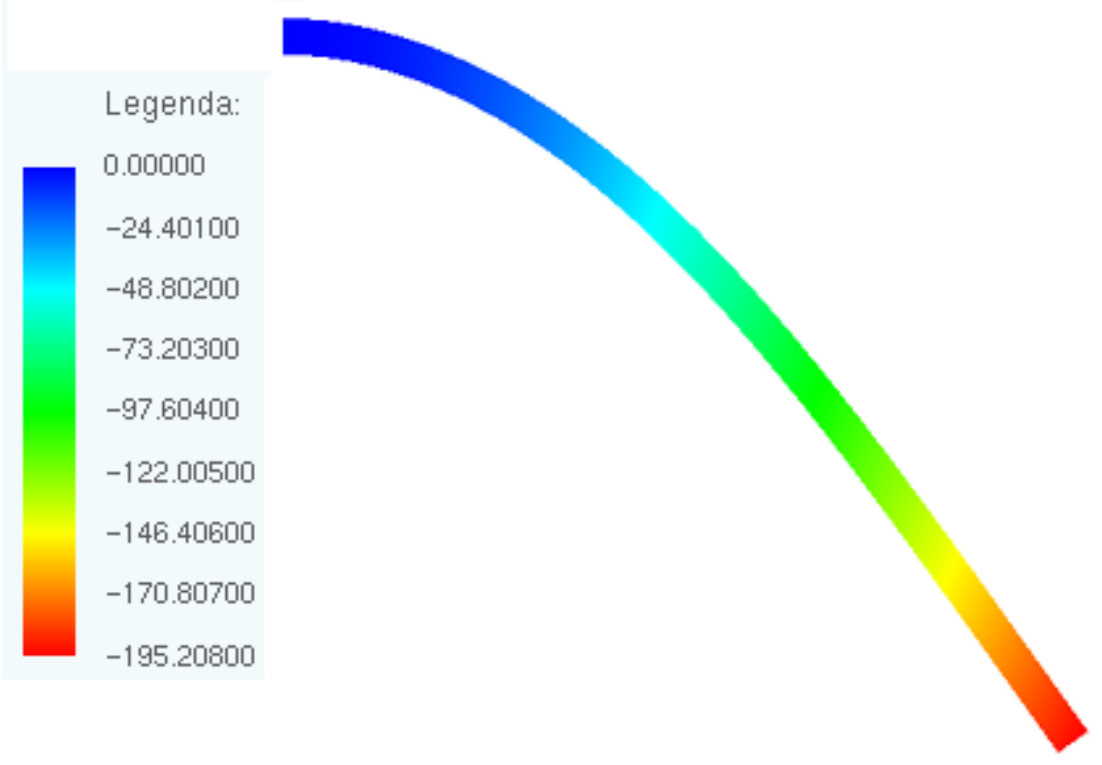

Figura 28 - Deformada da viga engastada em centímetros.

A figura 29 mostra a relação da Força $(N / \mathrm{cm})$ com o deslocamento vertical da extrema livre da viga $(\mathrm{cm})$. É possível perceber que, para valores altos de carga aplicada, o deslocamento segue um comportamento não linear.

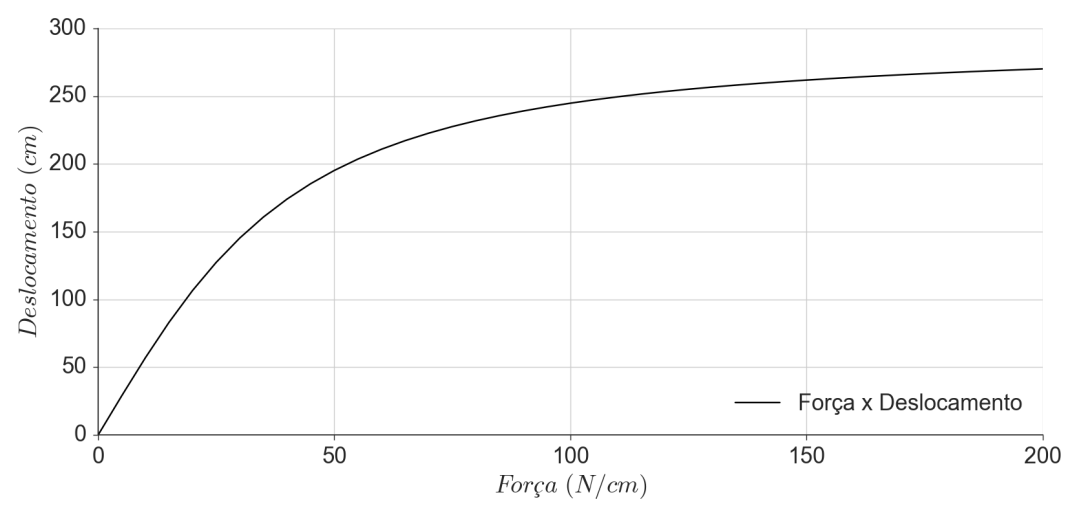

Figura 29 - Gráfico de Força x Deslocamento para a extremidade direita da viga.

\subsubsection{Barra Tracionada}

Comparando-se com o exemplo de uma barra de treliça tracionada em uma de suas extremidades encontrado em Carrazedo (2009). A barra possui 10,0 unidades de comprimento, área de 1,0 e módulo de elasticidade de 1,0. A força aplicada em sua extremidade vai até o valor de 1,0.

A figura 30 mostra os valores de deformação para a medida de deformação linear elástica e de Saint-Venant-Kirchhoff, tanto os resultados obtidos pelo algoritmo desenvolvido neste trabalho como os resultados encontrados em Carrazedo (2009). Percebe-se que para pequenos valores de deformação, tanto a medida linear como a não-linear se 
confundem. Entretanto, para valores altos de solicitação, há uma discrepância significativa nos valores de deformação em relação com a medida linear.

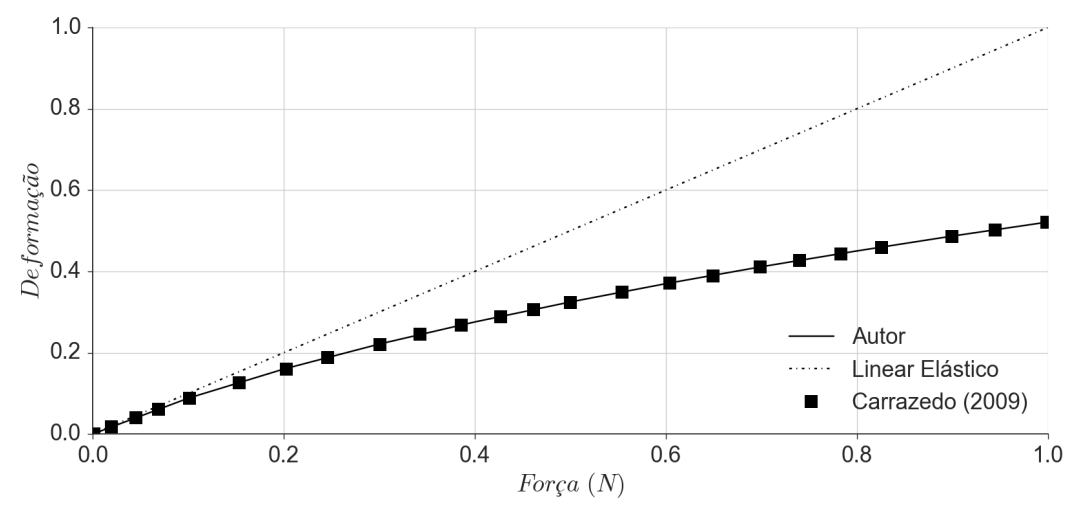

Figura 30 - Gráfico de Força x Deslocamento para a extremidade direita da barra tracionada.

\subsection{Campo Higromecânico}

São apresentados exemplos numéricos que demostram a interferência dos campos higrométrico e mecânico no processo de expansão por RAS.

\subsubsection{Viga Sob Regime Não Uniforme de Umidade}

Neste exemplo numérico é reproduzido o ensaio feito em Multon e Toutlemonde (2010). Neste ensaio, uma viga de concreto armado, com seção transversal de $50 \mathrm{~cm}$ de altura por $25 \mathrm{~cm}$ de largura foi submetida à condição de umidade variável. A sua borda inferior foi mantida à condição de umidade relativa de $100 \%$ durante todo o período de tempo, caracterizando assim o caso de umidade constante desde o tempo inicial. A borda superior foi mantida sob umidade de 30\% inicialmente e após 676 dias sua condição de umidade foi alterada para 100\%. Durante todo o ensaio as laterais da viga foram mantidas seladas com papel alumínio, fazendo com que apenas as bordas inferior e superior entrassem em contato com a umidade.

Neste trabalho foi simulado o mesmo ensaio e foram tomadas as medidas na altura das bordas superior e inferior do corpo de prova. Foi realizada a calibração manual do modelo paramétrico segundo as curvas de expansão apresentadas no trabalho de Multon e Toutlemonde (2010). As curvas de expansão experimental e do modelo paramétrico são dadas na Figura 31. Foi desconsiderada a deformação inicial para o caso do provimento tardio de umidade, pois não é garantia de que seja proveniente da RAS, ou ainda, que o isolamento por alumínio seja perfeito, permitido contato com a umidade. Percebe-se que o modelo atende suficientemente bem aos resultados experimentais, tanto no caso de umidade constante quanto no caso de provimento tardio. 


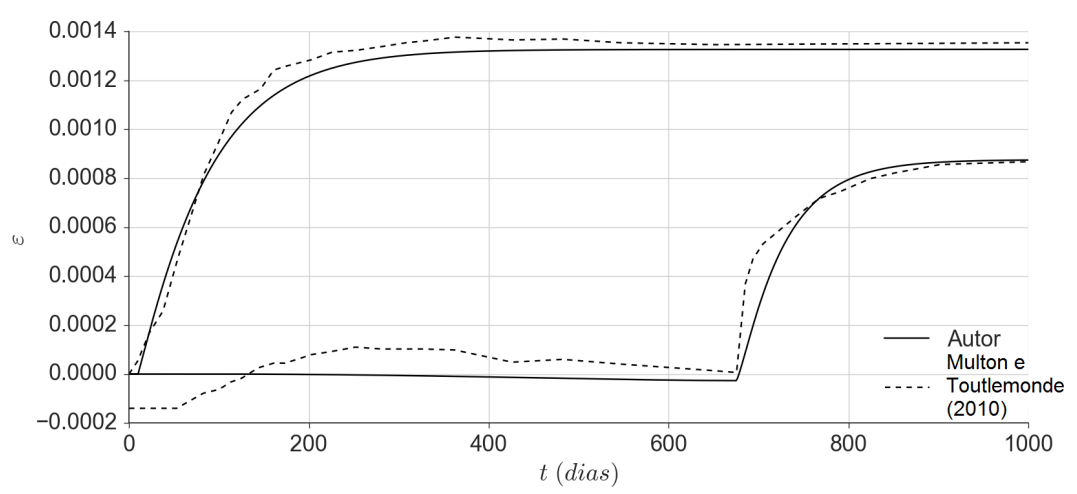

Figura 31 - Curvas de expansão calibradas do modelo paramétrico em comparação com as curvas experimentais de Multon e Toutlemonde (2010).

Para os dados obtidos pela calibração do modelo paramétrico de expansão, $\varepsilon^{\text {max }}=$ 0,0014, $\Delta \varepsilon=0,31, A_{2}^{\max }=400, \Delta A_{2}=0,4, t_{p}=10$ dias, $t_{f}=676$ dias, $k_{m}=0,0$ e $s_{\text {min }}$ $=0,80$, em que para valores inferiores de umidade não ocorre expansão por RAS e $t_{a}$ é incrementado. Foi utilizado um concreto com $E=20 \mathrm{GPa}$ e $\nu=0,20$.

A figura 32 apresenta o mapa de deformação da viga nas direções $X$ e $Y$. Na figura 32a é possível perceber que o bordo superior possui um grau menor de deformação que o bordo inferior.

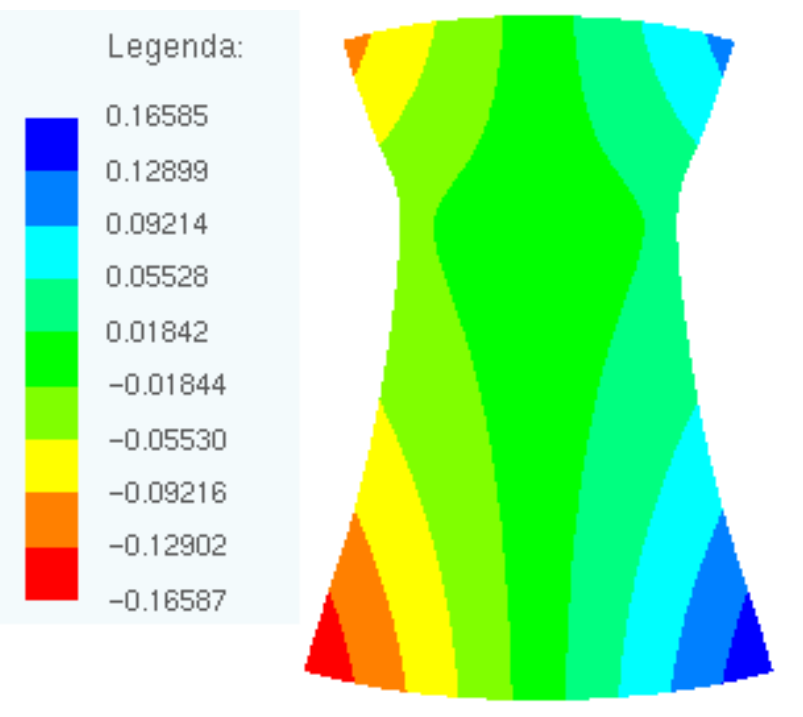

(a) Deformada da viga na direção $X$.

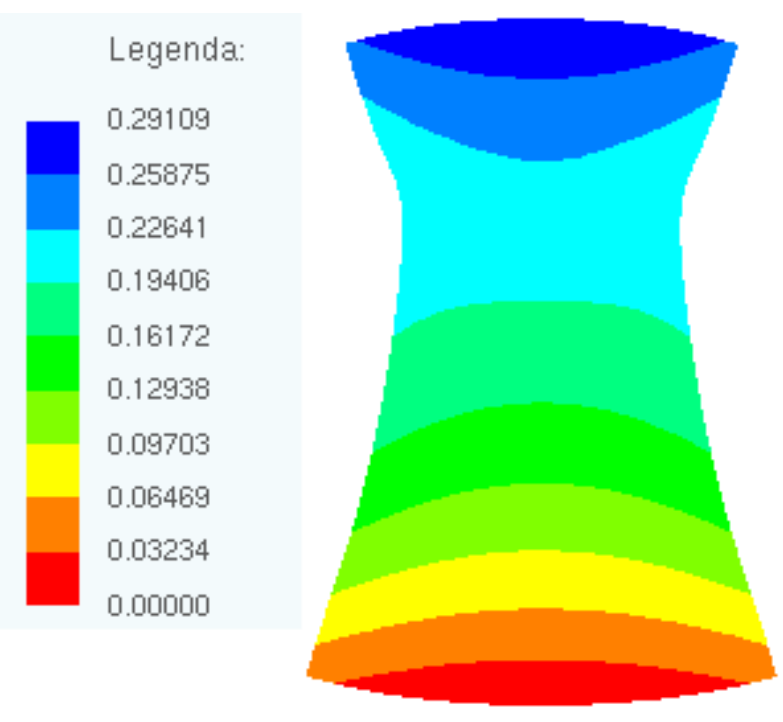

(b) Deformada da viga na direção $Y$.

Figura 32 - Mapas de deformação em milímetros. 


\subsubsection{Corpo de prova sob regime variável}

Pretende-se validar o modelo quanto aos casos de umidade variável e ciclos de molhagem e secagem. Para tanto foi realizado um exemplo que consiste num corpo de prova de concreto de $28 \mathrm{~cm}$ x $14 \mathrm{~cm}$ submetido a diversos níveis de umidade ao longo do tempo. Dividiu-se sua altura em 3 segmentos iguais e foram tomadas medidas transversais na meia altura de cada segmento.

Para a modelagem, foi empregado um concreto com módulo de elasticidade de $20 \mathrm{GPa}$ e $\nu=0,2$. Os dados do modelo de RAS foram obtidos por meio de calibração manual com os dados do trabalho de Multon e Toutlemonde (2010). Os valores do modelo paramétrico são $\varepsilon^{\max }=0,00137, \Delta \varepsilon=0,37, A_{2}^{\max }=400$ dias, $\Delta A_{2}=0,4, t_{f}=676$ dias, $t_{p}=10$ dias, $k_{c}=1,0, k_{t}=0,2, k_{m}=0,0$. Foram utilizados 216 elementos e 1027 nós. Na figura 33 é representada a posição dos extensômetros virtuais no sólido.

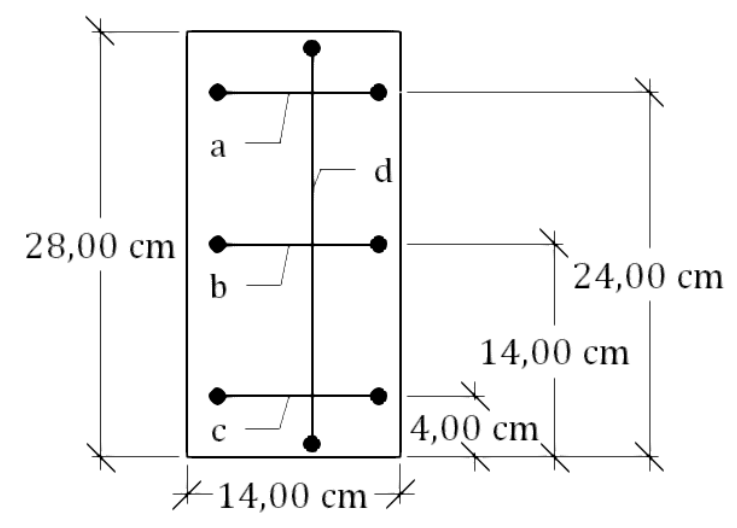

Figura 33 - Posicionamento e nomenclatura dos medidores virtuais.

Nas figuras 34 e 35 são mostrados os valores de expansão e respectivos graus de saturação para 3 casos típicos de regime não uniforme de umidade. Primeiramente têm-se a curva de umidade permanente, demonstrada pelo extensômetro (c), sendo a mesma curva de expansão encontrada em Multon e Toutlemonde (2010). A curva dada pelo extensômetro (a) representa o caso em que somente houve fornecimento de umidade após 676 dias. É possível perceber que a expansão final se deu num valor significantemente inferior à primeira curva e esta ocorreu de forma mais aguda. A curva do extensômetro (b), de umidade intermitente, representa a situação de ciclos de molhagem e secagem do concreto. O período de interrupção no fornecimento de umidade suficiente para a RAS provoca uma interrupção no processo de expansão, incrementa o valor de $t_{a}$ e provoca uma redução nos valores finais de $\varepsilon$ e $A_{2}$. A curva (d) mostra o valor da deformação vertical ao longo de todo o corpo de prova. É possível perceber que o valor final é inferior ao valor máximo da expansão livre, devido ao fato de parte do concreto não ter sido exposta à umidade permanentemente.

Na figura 35 é possível perceber as condições de contorno de umidade em cada intervalo de tempo. Entre $0<t \leq 50$ há um processo de expansão tanto da parte inferior 
quanto da parte média, enquanto a parte superior permanece inalterada. No intervalo de $50<t \leq 400$ há interrupção de fornecimento de umidade na parte média, o que causa interrupção no seu processo de expansão e incremento no valor de $t_{a}$ do modelo. Em $400<t \leq 676$ há o retorno de umidade para a condição inicial e o extensômetro (b) retorna a registrar deformações, entretanto, pelo fato de ter sido privado de umidade, este não chega a atingir o valor máximo de expansão. Por fim, para $t>676$, todo o corpo de concreto se encontra submerso e finalmente a parte superior começa a expandir. É justamente esta parte que registra o menor nível de deformação.

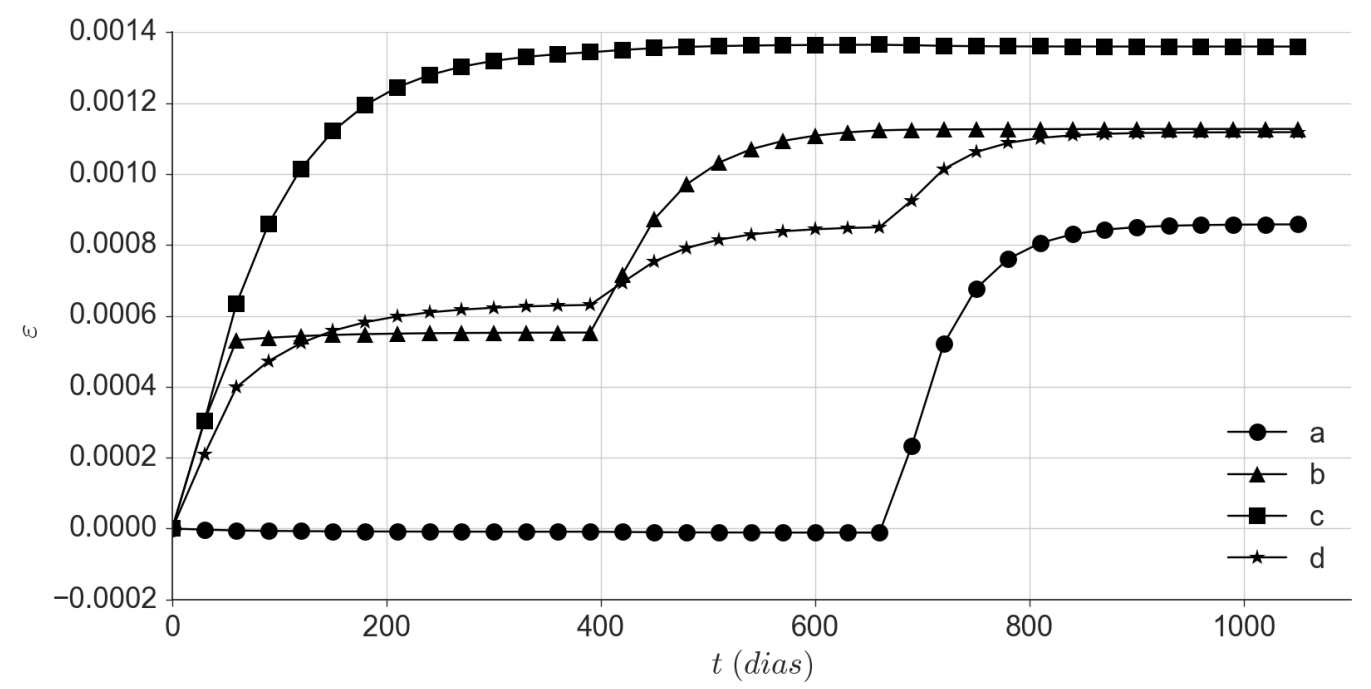

Figura 34 - Curvas de expansão do corpo de prova.
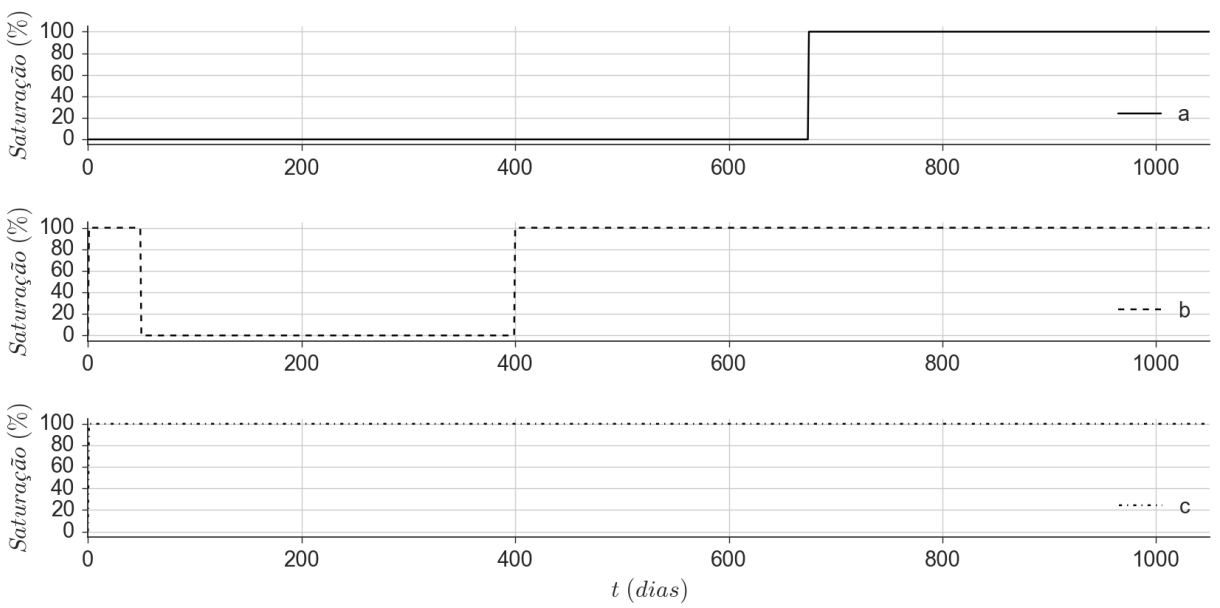

Figura 35 - Curvas do grau de saturação do extensômetro para o corpo de prova ao longo do tempo.

Na figura 36 está representada a deformada do corpo de prova ao longo do tempo. Percebe-se que o histórico de umidade ao qual o concreto é submetido altera significativamente a deformação da estrutura e seu comportamento. 


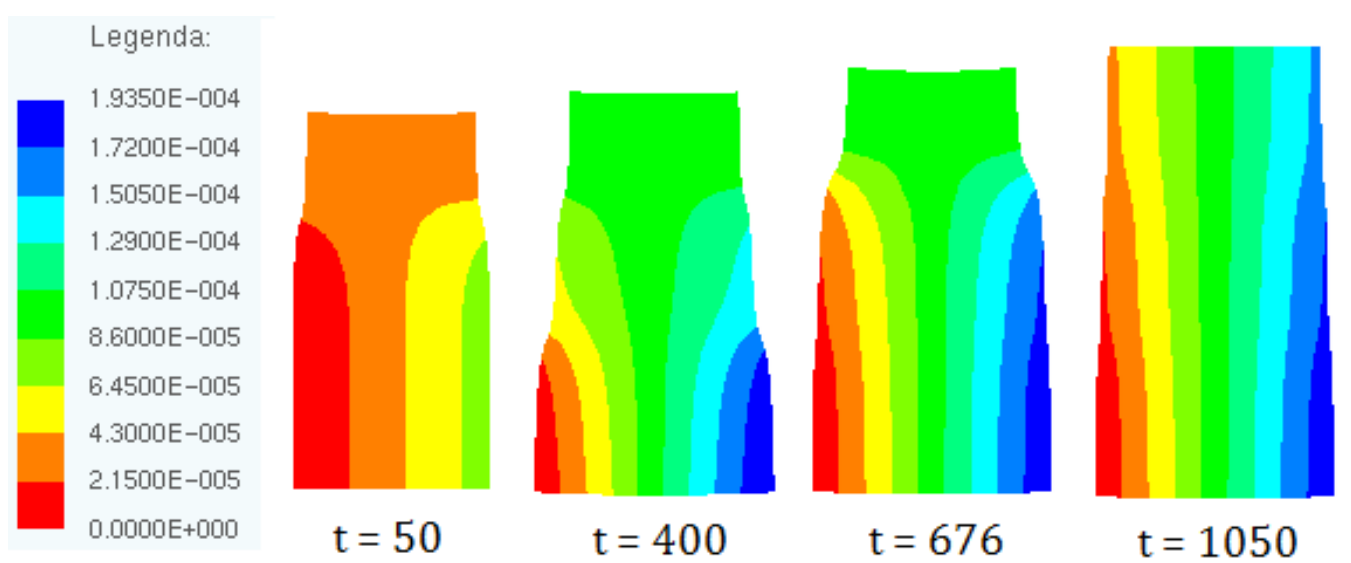

Figura 36 - Deformada do corpo de prova ao longo do tempo em metros.

\subsubsection{Corpo de prova sob regime variável sem a implementação do $t_{a}$}

Para demonstrar a mudança no comportamento da expansão por RAS com a implementação do parâmetro $t_{a}$, refez-se o exemplo da seção 7.3.2, mas sem a utilização do parâmetro $t_{a}$. Os parâmetros do modelo e condições de contorno são exatamente os mesmos.

A figura 37 mostra a alteração na curva de expansão. É possível perceber que o valor da expansão dos extensômetros vertical (d) e horizontal intermediário (b) deram bem abaixo que inicialmente, principalmente devido ao fato de que com o rebaixo do nível d'água, o modelo "continuou expandindo", mas com valor nulo, e por consequentemente, quando o nível d'água voltou a subir, não havia mais potencial de expansão naquela região.

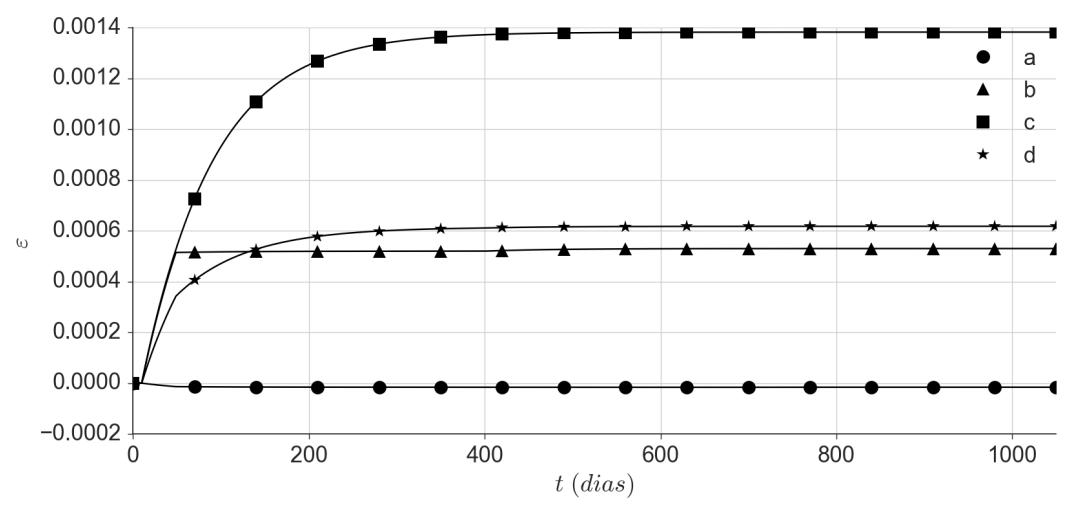

Figura 37 - Curvas de expansão do corpo de prova sob regime variável.

\subsubsection{Barra Prismática}

Para avaliar o comportamento do modelo de expansão com o modelo de umidade da Lei de Fick, foi feito o exemplo proveniente de Kawabata et al. (2016). Tal exemplo se constitui numa barra prismática de comprimento de $500 \mathrm{~mm}$, submetida à umidade constante de $100 \%$ na extremidade esquerda. Como condição inicial, a umidade da barra é 
equivalente à $80 \%$. Para os parâmetros do concreto, foram adotados $E=20 \mathrm{GPa}$ e $\nu=$ 0,20. Foram utilizados ao todo 110 elementos finitos e 664 nós.

Foi utilizado o modelo de Bazant e Najjar (1972) para calcular o coeficiente não-linear de difusão da água no concreto, dado pela equação 7.2.

$$
D_{s}=D_{0}\left(\alpha_{0}+\frac{1-\alpha_{0}}{1+\left(\frac{1-s}{1-s_{c}}\right)^{n}}\right)
$$

em que $D_{0}, \alpha_{0}$ e $s_{c}$ são constantes do material. Neste exemplo foram utilizados $D_{0}=75$, $\alpha_{0}=0,075, s_{c}=0,85$ e $n=6$.

Conjuntamente foi utilizado um modelo evolução da permeabilidade que representa o aumento da permeabilidade do concreto com o dano causado pela expansão da RAS, dado pela equação 7.3 .

$$
D_{s, 1}=D_{s, 0}\left(1+d_{\max }\left\{1-\exp \left(-\omega<\varepsilon_{f}-\varepsilon_{c r}>^{+}\right)\right\}\right)
$$

em que $D_{s, 0}$ é o coeficiente de expansão do concreto não expandido, $d_{\max }$ e $\omega$ são parâmetros do material representando o valor máximo da evolução e taxa do dano pela evolução, respectivamente. $\varepsilon_{c r}$ é o limite de expansão em que o processo de dano começa a ocorrer. Neste exemplo foram utilizados $d_{\max }=100, \omega=1,0$ e $\varepsilon_{c r}=0,0004$.

O exemplo numérico foi realizado ao longo de 1000 dias e foram tomadas medidas ao longo de três pontos, $10 \mathrm{~mm}, 100 \mathrm{~mm}$ e $200 \mathrm{~mm}$ da borda esquerda. Inicialmente foi realizado sem a consideração da lei de evolução, ou seja, sem a interferência da expansão da RAS na permeabilidade.

A figura 38 mostra o grau de saturação nos três pontos em comparação com o trabalho de Kawabata et al. (2016). É de se esperar concordância pois neste caso se está apenas avaliando a lei de Fick.

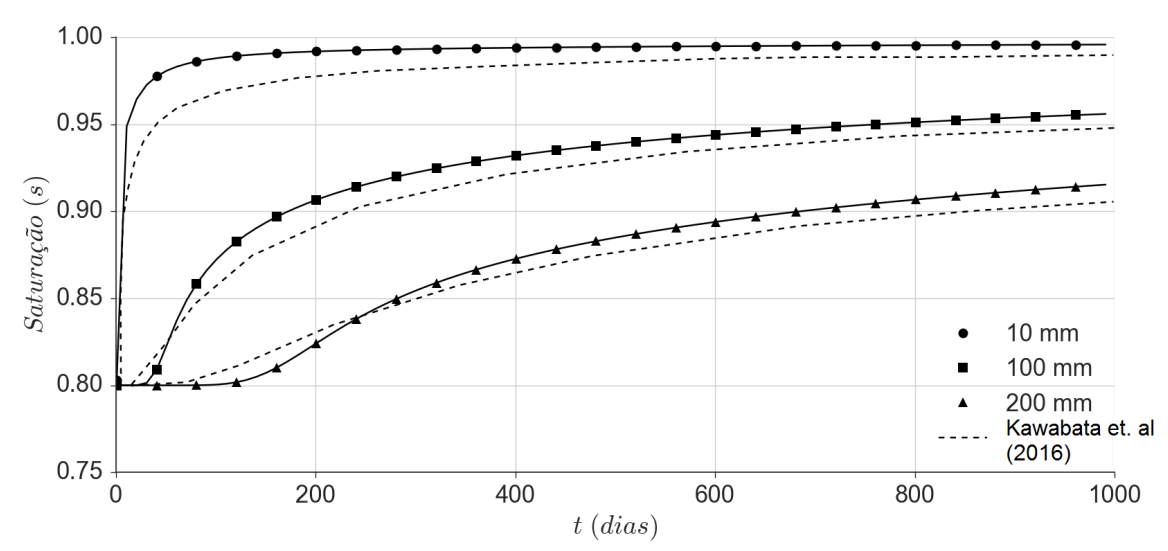

Figura 38 - Curvas de saturação sem a lei de evolução. 
Na figura 39 é apresentada a expansão pela RAS em comparação com o modelo adotado em Kawabata et al. (2016) e percebe-se que os valores finais estão de acordo. Entretanto o comportamento da expansão difere, dado o fato que são dois modelos de expansão distintos e portanto é de se esperar tal diferença. Para o modelo paramétrico, os parâmetros adotados foram $t_{p}=25$ dias, $s_{\text {min }}=85 \%$ (valor para o qual não há expansão e ocorre o incremento de $\left.t_{a}\right), k_{m}=0,4, k_{t}=0,2, k_{p}=1,0, k_{c}=1,0, \varepsilon^{\max }=0,01, \Delta \varepsilon=$ $0,4, A_{2}^{\max }=400, \Delta A_{2}=0,0$ e $t_{f}=400$ dias.

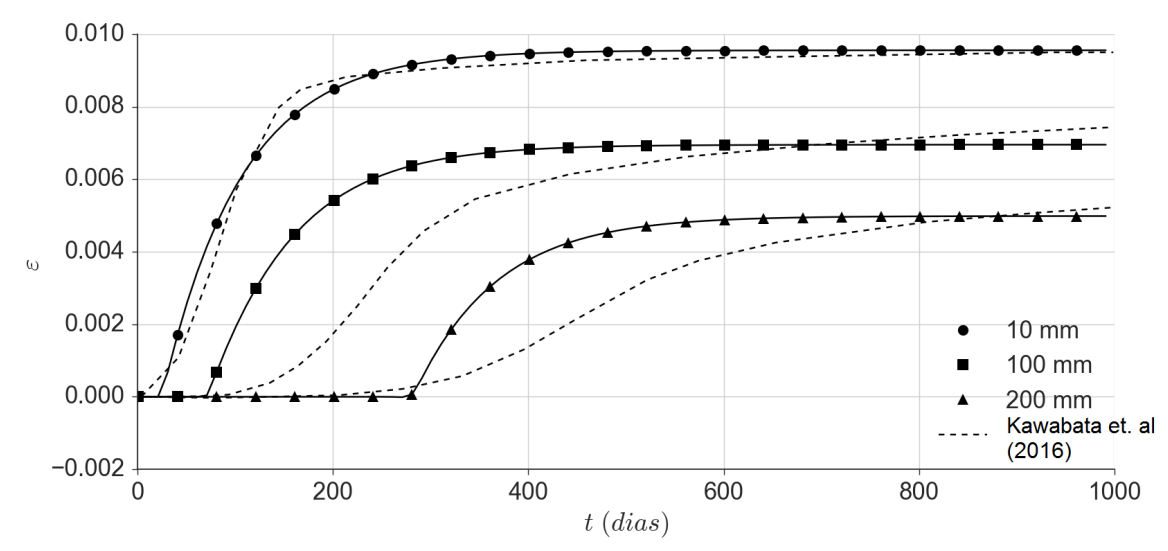

Figura 39 - Curvas de expansão sem a lei de evolução.

Posteriormente, aplicando a lei de evolução no algoritmo, na figura 40 é possível ver que as curvas de saturação estão coerentes. Percebe-se que embora os modelos de expansão sejam distintos, há boa concordância entre as curvas.

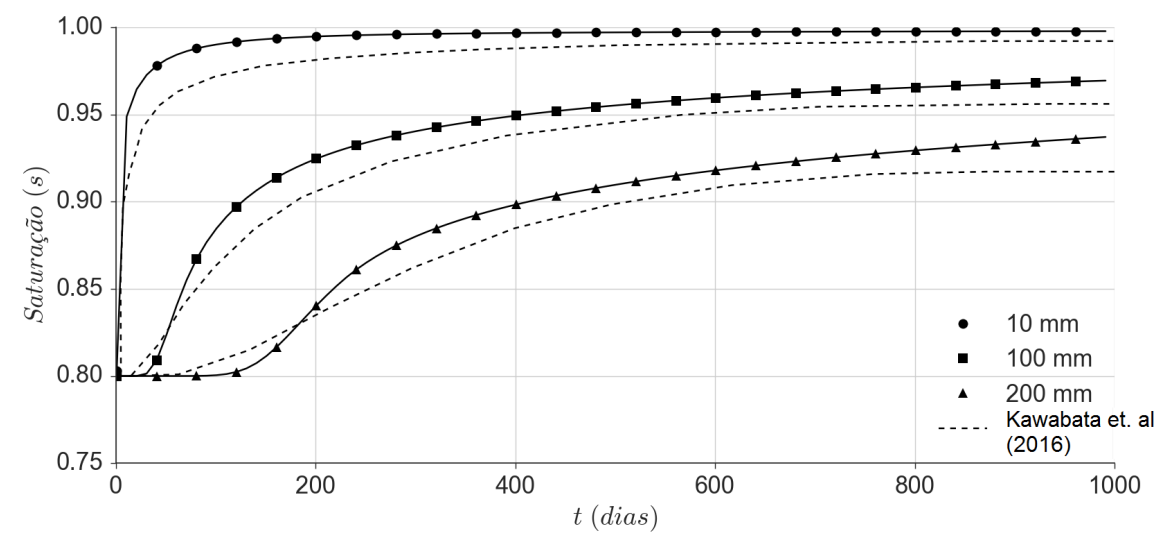

Figura 40 - Curvas de saturação com a lei de evolução.

De acordo com a figura 41, os valores finais da expansão de ambos modelos também são concordantes entre si, embora seus comportamentos também sejam diferentes. Na figura 42 é possível ver a deformada do prisma de concreto no tempo final. 


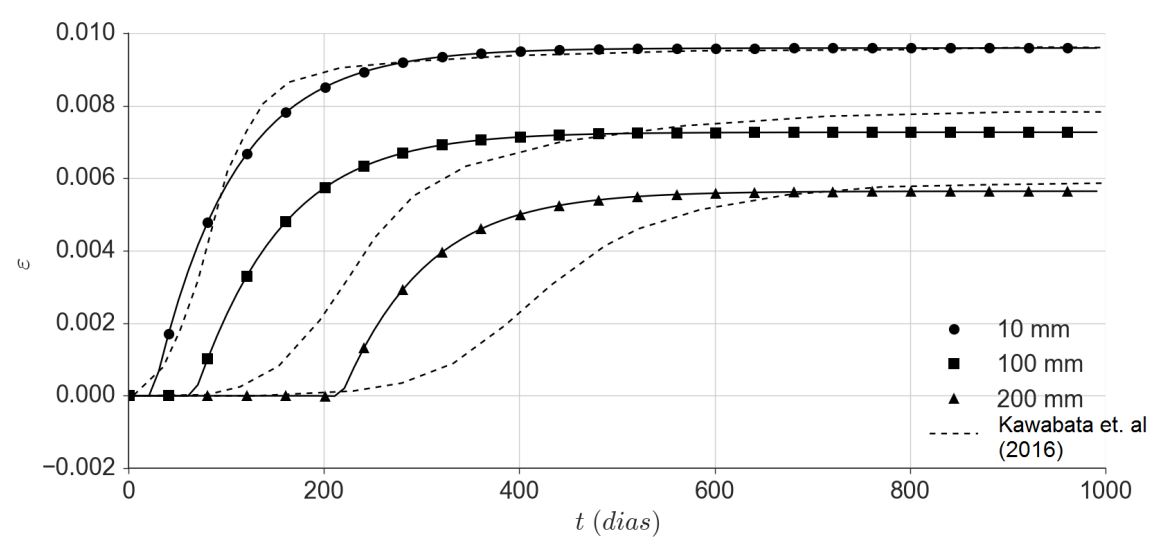

Figura 41 - Curvas de expansão com a lei de evolução.

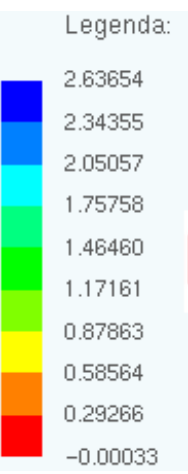

Figura 42 - Deformada da barra prismática com a lei de evolução da expansão em milímetros.

\subsubsection{Barragem do tipo Pine Flat com Variação do Nível d'água}

Usou-se como exemplo a barragem encontrada em Carrazedo, Sanches e Lacerda (2014), mas também levando em consideração a variação do nível d'água à montante. Na figura 43 está representada a geometria da barragem junto com o posicionamento dos medidores de deformação virtuais, totalizando 7. Foram usados 3 medidores horizontais ( $\mathrm{a}, \mathrm{b}$ e c) e mais 4 medidores verticais ( $\mathrm{d}$, e, f e g). A altura dos medidores horizontais a, b, e c é de $80 \mathrm{~m}, 42 \mathrm{~m}$ e $9 \mathrm{~m}$, respectivamente. O nível d'água máximo à montante é de $70 \mathrm{~m}$ e mínimo de $20 \mathrm{~m}$, enquanto o nível à jusante foi mantido constante em $10 \mathrm{~m}$. O concreto possui um módulo de elasticidade de 20 GPa e Poisson de 0,2. Para o modelo de RAS foram empregados os seguintes parâmetros: $\varepsilon^{\max }=0,001737, A_{2}^{\max }=250,989, t_{p}$ $=52$ dias, $t_{f}=200, \Delta \varepsilon=0,4, \Delta A_{2}=0,4, k_{m}=0,0, k_{c}=1,0, k_{t}=0,2$ e $k_{p}=1,0$. Foi considerada sua base como engastada e tempo máximo de 500 dias. Foram utilizados 285 elementos e 1366 nós. 


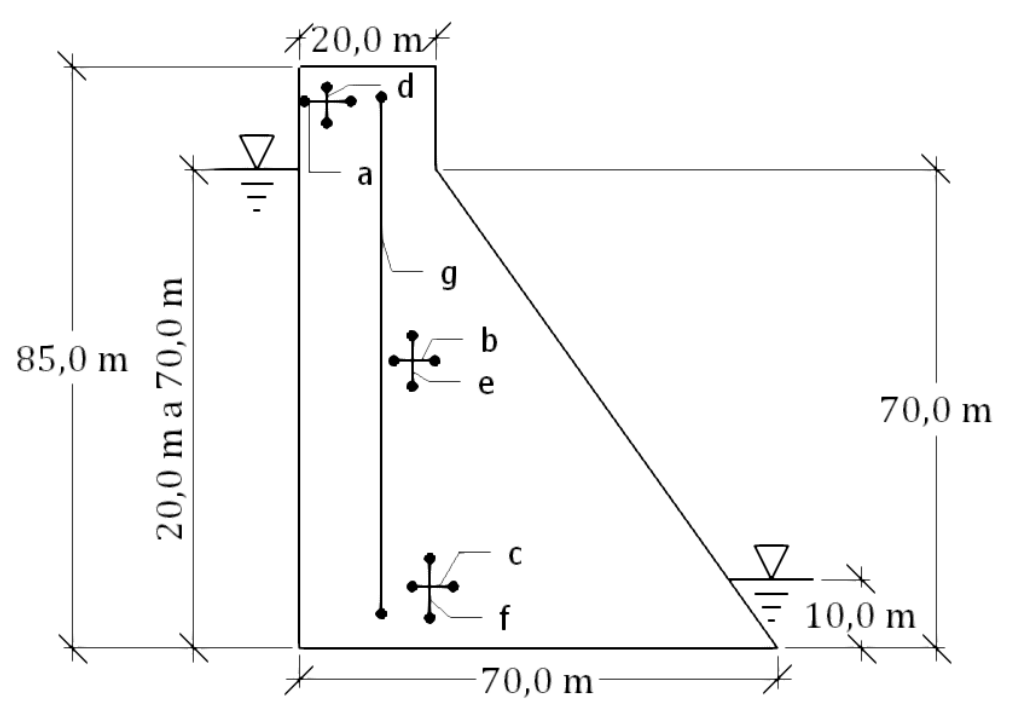

(a) Representação da barragem e posição dos extensômetros virtuais.

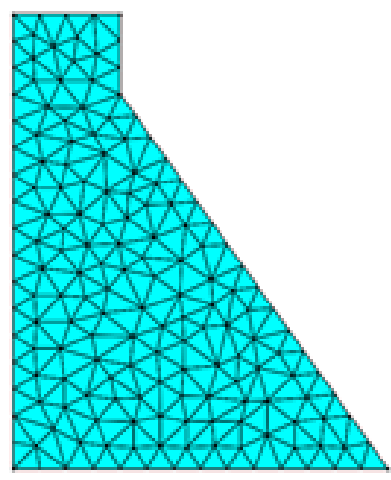

(b) Malha de elementos finitos empregada.

Figura 43 - Representação e malha utilizados para o exemplo da barragem.

O regime de umidade variável é dado pela variação do nível d'água à montante que obedece a curva dada pela figura 44, e a figura 45 mostra o grau de saturação nos respectivos extensômetros.

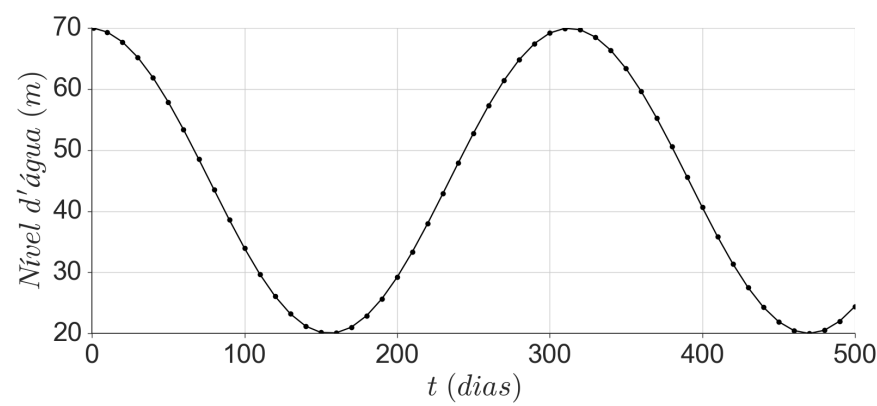

Figura 44 - Nível do reservatório ao longo do tempo.
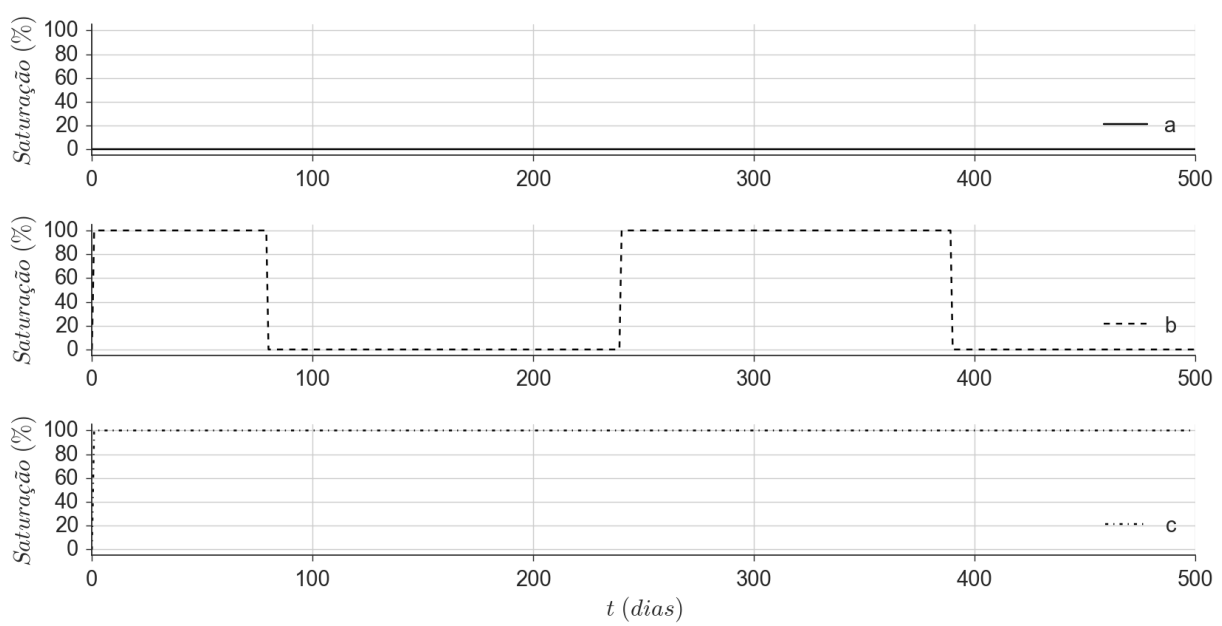

Figura 45 - Grau de saturação na altura dos extensômetros verticais. 
É possível perceber pelas figuras 46 e 47 que a influência da variação do nível d'água afeta não apenas o valor final de expansão por RAS, mas também o seu comportamento ao longo do tempo. Em períodos de baixo nível, há uma redução na taxa de expansão, que volta a subir com a subida do nível de água do reservatório. Dos medidores, percebe-se que os medidores (a) e (d), que estiveram sempre acima da superfície freática, não registraram deformações, enquanto que os medidores (c) e (f), por estarem sempre submersos, registraram contínua expansão. Atribui-se o fato de (c) não registrar a maior expansão dentre os medidores horizontais por estar localizado próximo da base engastada. Maior diferença no comportamento é perceptível nos medidores à meia altura, região em que há mudança frequente no nível de água.

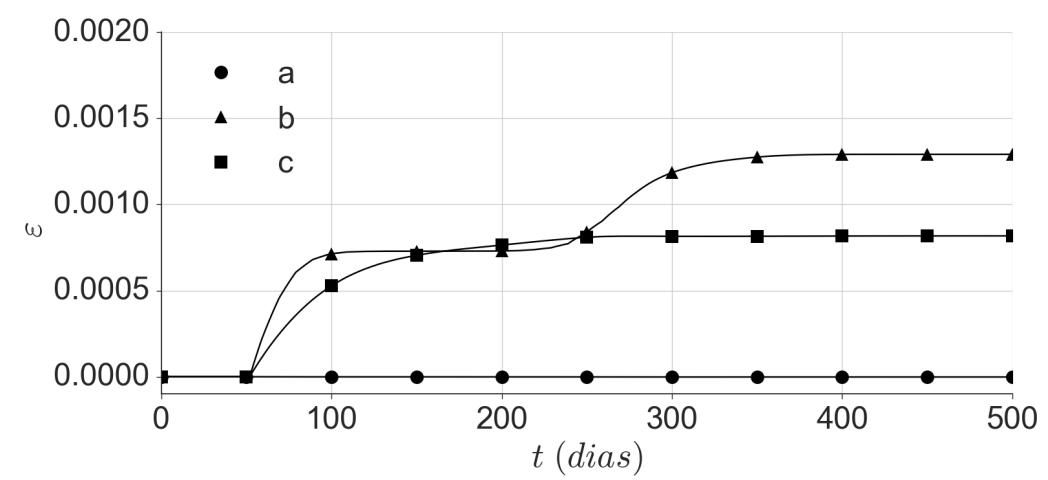

Figura 46 - Curvas de expansão dos extensômetros horizontais.

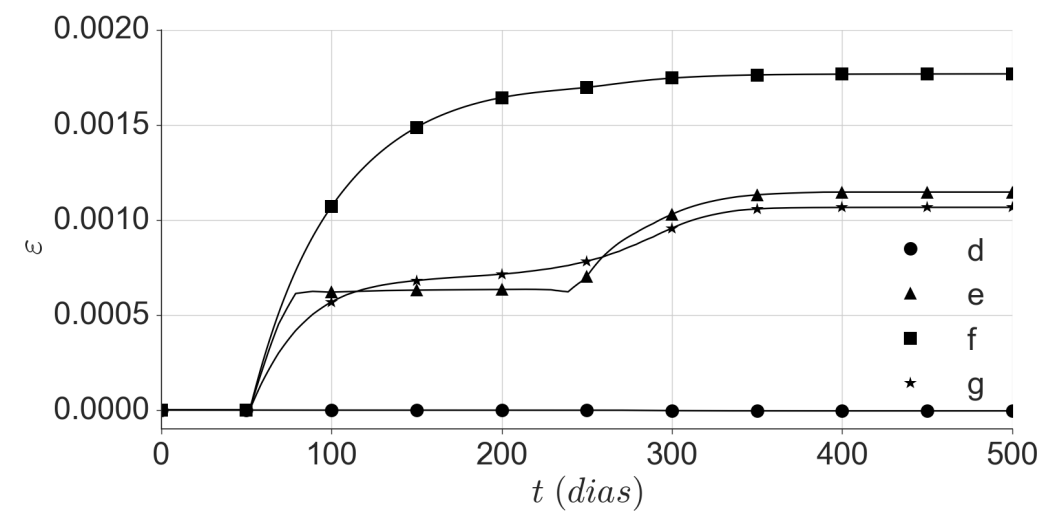

Figura 47 - Curvas de expansão dos extensômetros verticais. 
A deformada da estrutura é dada pela figura 48.

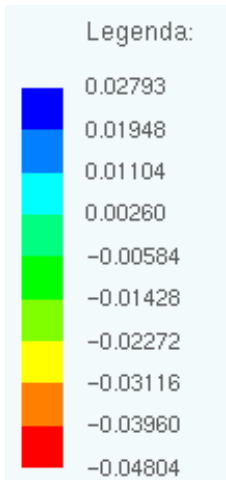

(a) Deformada da estrutura na direção X.

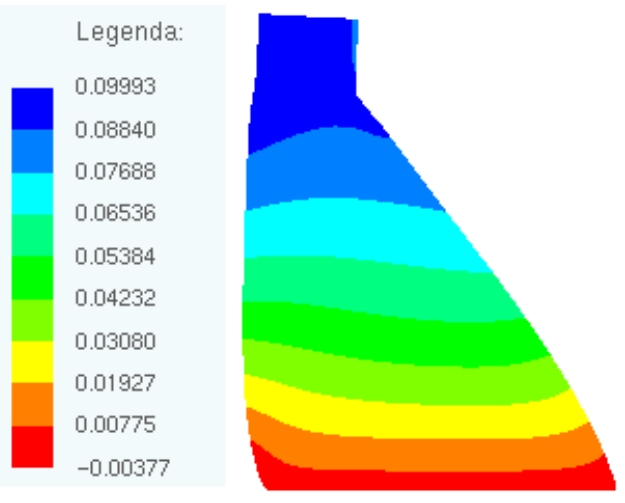

(b) Deformada da estrutura na direção Y.

Figura 48 - Mapa de cores da deformação sofrida pela barragem em metros.

Por fim, refez-se o exemplo da Barragem mas sem a utilização do parâmetro $t_{a}$. Os valores para o modelo de expansão, condições de contorno e regime de umidade são os mesmos.

As figuras 49 e 50 mostram a expansão dos extensômetros horizontais e verticais respectivamente. Percebe-se que a privação de água na zona intermediária das datas iniciais levou a um valor significantemente menor que o registrado anteriormente.

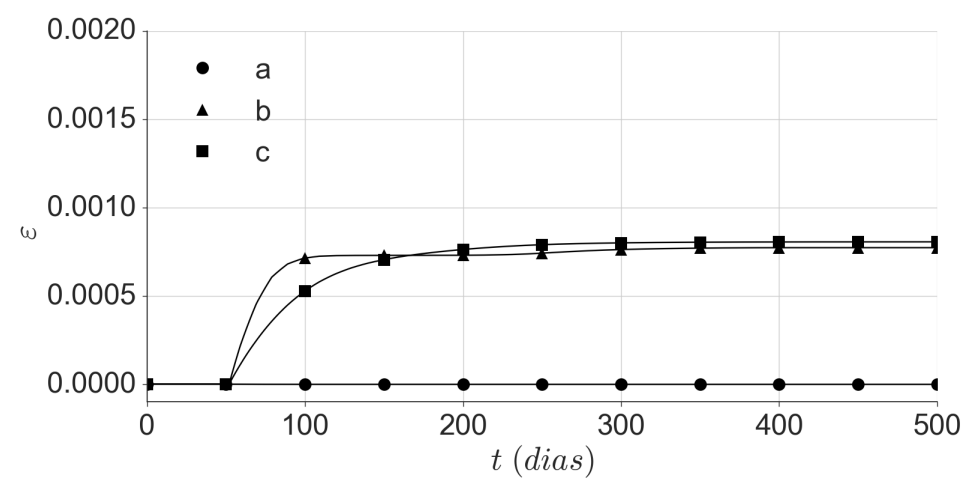

Figura 49 - Curvas de expansão dos extensômetros horizontais.

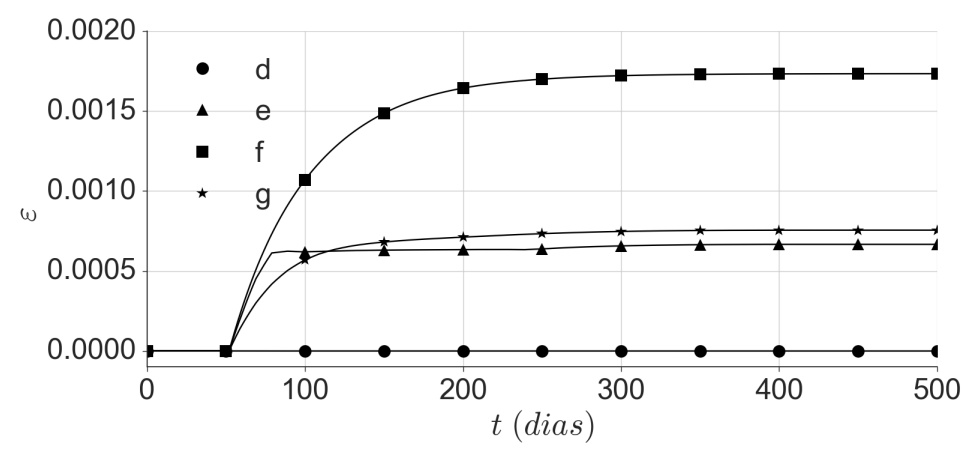

Figura 50 - Curvas de expansão dos extensômetros verticais. 


\section{Conclusão}

Foi possível desenvolver um modelo numérico para expansão por RAS em meios bidimensionais que contemple regimes não uniformes de umidade, baseado no método dos elementos finitos, que se mostrou adequado para a implementação computacional.

Foram utilizadas duas abordagens para a modelagem do campo higrométrico. Numa delas foi implementado um algoritmo para o cálculo da superfície livre de percolação em meios porosos, fazendo uso de malha fixa de elementos finitos e permeabilidade constante, com precisão suficiente para os casos estudados. Noutra, a modelagem da difusão d'água transiente em meio poroso foi realizada pela segunda lei de Fick com permeabilidade dependente da RAS.

Comparando-se ambas abordagens, é possível perceber que quando todo o domínio está saturado e se pretende modelar o processo de difusão d'água, a segunda lei de Fick é mais adequada. Para casos em que há a presença de domínios saturados e não saturados, um algoritmo que calcule a superfície livre de percolação se mostra mais interessante.

Posteriormente foi feito o acoplamento com um algoritmo para a resolução do problema mecânico pelo MEFP e utilizado o modelo paramétrico de Carrazedo (2004) para a expansão da RAS. O modelo se mostrou satisfatório para a modelagem do comportamento macroscópico do concreto. Foram feitas alterações no mesmo para contemplar regimes não uniformes de umidade e ciclos de molhagem e secagem, representando o comportamento esperado para o caso de provimento tardio de umidade.

A forma com que foram feitas tais alterações se mostrou bem simples e intuitiva, trazendo vantagens práticas no momento do seu emprego. Os valores de $t_{a}, t_{f}, \Delta \varepsilon$ e $\Delta A_{2}$ podem ser facilmente obtidos por meio de curvas de expansão experimentais. Mesmo com a atual simplicidade do modelo, é possível utilizar leis mais complexas para representação da variação de $\varepsilon$ e $A_{2}$ com o incremento de $t_{a}$.

A partir das alterações do modelo originalmente proposto, foram feitas simulações numéricas e os resultados obtidos estão de acordo com os dados experimentais de Multon e Toutlemonde (2010) e Pignatelli, Comi e Monteiro (2013) para regimes de umidade não uniforme. As alterações do modelo também foram capazes de reproduzir satisfatoriamente os resultados numéricos encontrados em Kawabata et al. (2016), guardadas as devidas diferenças entre os modelos de expansão empregados.

Em tais simulações foi também utilizado um coeficiente não-linear de permeabilidade obtido por Bazant e Najjar (1972). Tal modelo é capaz de alterar o coeficiente de permeabilidade de acordo com a degradação causada pela RAS. Com isso, obtendo-se uma 
melhor representação da realidade. Os parâmetros utilizados, para fins de comparação, são os mesmos encontrados em Kawabata et al. (2016).

Por fim, foi possível realizar a modelagem de uma barragem de gravidade de concreto submetida a variação no nível de água a montante. Os resultados obtidos mostram que o comportamento da deformação pode se tornar complexo numa estrutura de concreto quando submetida a RAS e ciclos de umidade não uniformes.

Segundo o trabalho desenvolvido, percebe-se ainda a necessidade dos seguintes aprimoramentos, apontados como trabalhos futuros:

- Uso de algum outro algoritmo mais preciso e completo para o cálculo da superfície de percolação em meios porosos, caso seja necessário maior acurácia e uso de outros dados do campo higrométrico, como o método dos elementos de contorno, por exemplo;

- Embora a alteração da equação de expansão com a adição dos parâmetros $t_{a}$ e $t_{f}$ consiga reproduzir os ensaios experimentais, ainda é difícil para a equação representar condições mais complexas de umidade como em Kawabata et al. (2016);

- A forma que ocorre o decaimento de $\varepsilon$ e $A_{2}$ com a ausência de umidade não é conhecida, sendo necessário ensaios laboratoriais para correta representação;

- A consideração do efeito da RAS no coeficiente de permeabilidade para o caso do campo higrométrico modelado pelo cálculo da superfície livre de percolação e

- Implementação da zona de capilaridade logo acima da superfície freática para o modelo de percolação em meio poroso, representando melhor a transição entre o domínio completamente saturado e o não saturado. 


\section{Referências}

ACADMESH2D, versão Beta: software acadêmico para geração de malhas bidimensionais. PIEDADE NETO, D.; FAGÁ JÚNIOR, R.; PACCOLA, R. B. Universidade de São Paulo, Escola de Engenharia de São Carlos, Departamento de Estruturas, 2012. Mídia digital. Disponível em: <http://www.set.eesc.usp.br/softwares_depto/acadmesh/>.

ACADVIEW: software para pós-processamento em elementos finitos 2D e 3D. PACCOLA, R. B.; CODA, H. B. Universidade de São Paulo, Escola de Engenharia de São Carlos, Departamento de Estruturas, 2005. Mídia digital. Disponível em: < http: //www.set.eesc.usp.br/portal/pt/softwares/27-pesquisa/softwares/157-acadview $>$.

ANDRIOLO, F. R. AAR dams affected in brazil report on the current situation. In: INTERNATIONAL CONFERENCE ON ALKALI-AGGREGATE REACTION IN CONCRETE, 11., 2000, Quebec. Proceedings... Quebec, 2000. p. 1243-1252.

ASSOCIAÇÃO BRASILEIRA DE NORMAS TÉCNICAS. NBR 1557r7-1: Agregados - reatividade álcali-agregado parte 1: Guia para avaliação da reatividade potencial e medidas preventivas para uso de agregados em concreto. Rio de Janeiro, 2008.

BATHE, K.-J.; KHOSHGOFTAAR, M. R. Finite element free surface seepage analysis without mesh iteration. International Journal for Numerical and Analytical Methods in Geomechanics, v. 3, p. 13-22, 1979.

BAZANT, Z. P.; NAJJAR, L. J. Nonlinear water diffusion in nonsaturated concrete. Mat. Struc., v. 5, p. 3-20, 1972.

BAZANT, Z. P.; STEFFENS, A. Mathematical model for kinetics of alkali-silica reaction in concrete. Cement and Concrete Research, v. 30, p. 419-428, 2000.

BÉRUBÉ, M.-A. et al. Laboratory assessment of alkali contribution by aggregates to concrete and applicatoin to cocnrete strucutres affected by alkali-silica reactivity. Cement and Concrete Research, v. 32, p. 1215-1227, 2002.

BONET, J. et al. Finite element analysis of air supported membrane structures. Comput. Methods Appl. Mech. Engrg., v. 190, p. 579-595, 2000.

BORJA, R. I.; KISHNANI, S. S. On the solution of elliptic free-boundary problems via newton's method. Computer Methods in Applied Mechanics and Engineering, v. 88, p. 341-361, 1991.

BRAUN, P. V. C. B. Convivendo com reações expansivas em barragens - a experiência da EMAE. In: SIMPÓSIO SOBRE REAÇÃO ÁLCALI-AGREGADO EM ESTRUTURAS DE CONCRETO, 2., 2006, Rio de Janeiro. Anais... Rio de Janeiro: IBRACON, 2006. p. $1-19$.

CAPRA, B.; BOURNAZEL, J. P. Modeling of induced mechanical effects of alkali aggregate reactions. Cement and Concrete Research, v. 28, p. 251-260, 1998. 
CARRAZEDO, R. Modelagem numérica da expansão do concreto devido a reação álcali-agregado. Dissertação (Mestrado) — Universidade Federal do Paraná, Curitiba., 2004.

CARRAZEDO, R. Estudo e Desenvolvimento de Código Computacional para Análise de Impacto entre Estruturas Levando em Consideração Efeitos Térmicos. 128 p. Tese (Doutorado) — Universidade de São Paulo, Escola de Engenharia de Estruturas, São Carlos, 2009.

CARRAZEDO, R.; SANCHES, R. A. K.; LACERDA, L. A. Numerical modeling of orthotropic concrete expansion due to alkali-aggregate reaction with a parametric model. 10th World Congress on Computational Mechanics, 2014.

CHATTERJI, S.; CHRISTENSEN, P. Studies of alkali-silica reaction. part 7. modelling of expansion. Cement and Concrete Research, v. 20, p. 285-290, 1990.

CHATTERJI, S.; THAULOW, N.; JENSEN, A. D. Studies of alkali-silica reaction. part5: Verification of a newly proposed reaction mechanism. Cement and Concrete Research, v. 19, p. $177-183,1989$.

CHATTERJI, S. et al. Studies of alkali-silica reaction. part 3: Mechanisms by which $\mathrm{NaCl}$ and $\mathrm{Ca}(\mathrm{OH})_{2}$ affect the reaction. Cement and Concrete Research, v. 16, p. 246-254, 1986.

CIARLET, P. G. Studies in Mathematics and its Applications. Amsterdam: North Holland, 1993.

CODA, H. B. Análise não linear geométrica de sólidos e estruturas: uma formulação posicional baseada no MEF. Tese (Doutorado) — Universidade de São Paulo, Escola de Engenharia de Estruturas, São Carlos, 2003.

COLLINS, R. J.; BAREHAM, P. D. Alkali-silica reaction: Suppression of expansion using porous aggregate. Cement and Concrete Research, v. 17, p. 89-96, 1987.

CONSTANTINER, D.; DIAMOND, S. Alkali release from feldspars into pore solutions. Cement and Concrete Research, v. 33, p. 549-554, 2003.

COUTO, T. A. Reação álcali-agregado. Estudo do fenômeno em rochas silicosas. 191 p. Dissertação (Mestrado) - Universidade Federal de Goiás, Escola de Engenharia Civil, Goiânia, 2008.

CRANK, J. The Mathematics of Diffusion. [S.l.]: Oxford University Press, 1975.

GLASSER, L. S. D.; KATAOKA, N. The chemistry of alkali-aggregate raction. Cement and Concrete Research, v. 11, p. 1-9, 1981.

GOMES NETO, D. P.; BARRETO, L. S. Uma discussão sobre a reação álcaliagregado (RAA), seu mecanismo e os fatores que influenciam. In: IX CONGRESSO INTERNACIONAL SOBRE PATOLOGIA E RECUPERAÇÃO DE ESTRUTURAS (CINPAR), 2013, João Pessoa. Anais... João Pessoa, 2013.

GRIMAL, E. et al. Creep, shrinkage and anisotropic damage in aar swelling mechanism-part i: a constitutive model. ACI Structural Journal, v. 105, p. 227-235, 2008a. 
GRIMAL, E. et al. Creep, shrinkage and anisotropic damage in aar swelling mechanism - part ii: identification of model parameters and application. ACI Structural Journal, v. 105, p. 236-242, 2008b.

GUTHRIE, G. D.; CAREY, J. W. A thermodynamic and kinetic model for paste-aggregate interactions and the alkali-silica reaction. Cement and Concrete Research, v. 76, p. 107-120, 2015.

HASPARYK, N. P. Investigação dos mecanismos de reação álcali-agregado - efeito da cinza de cascac de arroz e da sílica ativa. 257 p. Dissertação (Mestrado) - Universidade Federal de Goiás, Escola de Engenharia Civil, Goiânia, 1999.

JENSEN, A. D.; CHATTERJI, S.; THAULOW, P. C. adn N. Studies of alkali-silica reaction - part ii. effect of air-entrainment of expansion. Cement and Concrete Research, v. 14, p. 311-314, 1984.

KAWABATA, Y. et al. Modelling of evolution of transfer properties due to expansion of concrete induced by internal swelling reaction. In: 15TH INTERNATION CONFERENCE ON ALKALI-AGGREGATE REACTION, 2016, Sã Paulo. Anais... São Paulo, 2016.

LACERDA, E. G. M. de. Análise Não Linear de Treliças Pelo Método dos Elementos Finitos Posicional. Dissertação (Mestrado) - Universidade Federal do Rio Grande do Norte, Natal, 2014.

LARIVE, C. Apports combinés de l'expérimentation et de la modélisation à la compréhension de l'alcali-réaction et de ses e ets mécaniques. 335 p. Tese (Doutorado) l'École Nationale des Ponts et Chaussées, Paris, 1997.

LÉGER, P.; COTÉ, P.; TINAWI, R. Finite element analysis of concrete swelling due to alkali-aggregate reactions in dams. Computers and Structures, v. 60, p. 601-611, 1996.

LIANG, T.; MINGSHU, T. Correlation between reaction and expansion of alkali-carbonate reaction. Cement and Concrete Research, v. 25, p. 470-476, 1995.

LIANG, T.; MINGSHU, T. A case study of two airport runways affected by alkali-carbonate reaction; part two: microstructural investigations. Cement and Concrete Research, v. 27, p. 329-336, 1997.

LIANG, T.; MINGSHU, T. Expansion mechanism of alkali-dolomite and alkali-magnesite reaction. Cement and Concrete Composites, v. 21, p. 361-373, 1999.

LIANG, T. et al. A case study of two airport runways affected by alkali-carbonate reaction; part one: evidence of deterioration and evaluation of aggregates. Cement and Concrete Research, v. 27, p. 321-328, 1997.

LINDGARD, J. et al. Akali-silica reactions (ASR): Literature review on parameters influencing laboratory performance testing. Cement and Concrete Research, v. 42, p. 223-243, 2014.

MEHTA, P. K.; MONTEIRO, P. J. M. Concrete Mocrostructure, Properties and Materials. 3. ed. [S.1.]: McGraw-Hill Education, 2005. 
MULTON, S.; SELliER, A.; CYR, M. Chemo-mechanical modeling for prediction of alkali silica reacton (ASR) expansion. Cement and Concrete Research, v. 39, p. 490-500, 2009 .

MULTON, S.; TOUTLEMONDE, F. Effect of applied stresses on alkali-silica reaction-induced expansions. Cement and Concrete Research, v. 36, p. 912-920, 2006.

MULTON, S.; TOUTLEMONDE, F. Effect of moisture conditions and transfers on alkali silica reaction damaged strutures. Cement and Concrete Research, v. 40, p. 924-934, 2010.

OGDEN, R. W. Non-linear Elastic Deformations. New York: Ellis Horwood, 1984.

OLIVEIRA, J. R. S. Modelagem da expansão do concreto devido à RAA com decaimento do módulo de elasticidade. Dissertação (Mestrado) - Universidade Federal do Paraná, Curitiba, 2013.

PAPPAlARDO, A.; PAUlETTI, R. M. O.; PIMENTA, P. M. Simulação numérica da reação álcali-agregado em barragens de concreto. Revista Mackenzie de Engenharia e Computação, v. 1, p. 181-199, 2000.

PAPPALARDO JR., A. Uma metodologia para a modelagem matemática de barragens de concreto afetadas pela reação álcali-agregado. Tese (Doutorado) — Escola Politécnica, Universidade de São Paulo, São Paulo, 1998.

PECCHIO, M. et al. Produtos da reação Álcali-silicato em concretos de edificações da região do grande recife - PE. In: II SIMPÓSIO SOBRE REAÇÃO ÁLCALI-AGREGADO EM ESTRUTURAS DE CONCRETO, 2006, Fortaleza. Anais... Rio de Janeiro, 2006.

PIETRUSZCZAK, S. On the mechanical behavior of concrete subjected to alkali-aggregate reaction. Computers \& Structures, v. 58, p. 1093-1097, 1996.

PIGNATELLI, R.; COMI, C.; MONTEIRO, P. J. M. A coupled mechanical and chemical damage model for concrete affected by alkali-silica reaction. Cement and Concrete Research, v. 53, p. 196-210, 2013.

POYET, S. et al. Influence of water on alkali-silica reaction: experimental study and numerical simulation. Journal of Mateials in Civil Engineering (ASCE), v. 18, p. 588-596, 2006.

QIAN, C.; ZHUANG, Y.; HUANG, H. Numerical calculation of expansion induced by alkali silica reaction. Construction and Building Materials, v. 103, p. 117-122, 2016.

RAJABIPOUR, F. et al. Alkali-silica reaction: Current understanding of the reaction mechanisms and the knowledge gaps. Cement and Concrete Research, v. 76, p. 130-146, 2015.

SAMPAIO, M. do S. M. Análise Não Linear Geométrica de Cascas Laminadas Reforçadas com Fibras. 190 p. Tese (Doutorado) - Universidade de São Paulo, Escola de Engenharia de Estruturas, São Carlos, 2014.

SANCHEZ, L. F. M. et al. Comparative study of a chemo-mechanical modeling for alkali silica reation (ASR) with experimental evidences. Construction and Building Materials, v. 72 , p. $301-315,2014$. 
SAOUMA, V. E. et al. A mathematical model for the kinetics of the alkali-silica chemical reaction. Cement and Concrete Research, v. 68, p. 184-195, 2015.

SCANDIUZZI, L.; BATTAGIN, A. F.; KIHARA, Y. Estudos da reação álcali-agregado em obras brasileiras. In: XXIV SEMINÁRIO NACIONAL DE GRANDES BARRAGENS, 2001, Fortaleza. Anais... Fortaleza, 2001. p. 197-209.

SILVEIRA, A. L. Z. de P. Estudo da Reação álcali-agregado em Rochas Carbonáticas. 194 p. Dissertação (Mestrado) — Universidade de Brasília, Instituto de Geociências, Brasília, 2006.

STANTON, T. E. Expansion of concrete through reaction between cement and aggregate. Proceedings of the American Society of Civil Engineers, v. 66, p. 1781-1811, 1940.

STEFFENS, A.; LI, K.; COUSSY, O. Aging approach to water effect on alkali-silica reaction degradation of structures. Journal of Engineering Mechanics (ASCE), v. 129, p. 50-59, 2003.

TREMBLEY, C. et al. Experimental investigation of the mechanisms by which $\mathrm{LiNO}_{3}$ is effective against ASR. Cement and Concrete Research, v. 40, p. 583-597, 2010.

TUNG, W. S. et al. A SABESP e a reação álcali-agregado. In: SIMPÓSIO SOBRE REAÇÃO ÁLCALI-AGREGADO EM ESTRUTURAS DE CONCRETO, 2., 2006, Rio de Janeiro. Anais... Rio de Janeiro: IBRACON, 2006. p. 1-16.

ULM, F. et al. Thermo-chemo-mechanics of asr expansion in concrete structures. Journal of Engineering Mechanics (ASCE), v. 126, p. 233-242, 2000.

URHAN, S. Alkali silica and pozzolanic reactions in concrete. part 1: Interpretation of published results and an hypothesis concerning the mechanism. Cement and Concrete Research, v. 17, p. 141-152, 1987.

VALDUGA, L. Reação álcali-agregado - mapeamento de agregados reativos do Estado de São Paulo. 225 p. Dissertação (Mestrado) — Universidade Estadual de Campinas, São Paulo, 2002.

VAYGHAN, A. G.; RAJABIPOUR, F.; ROSENBERGER, J. L. Composition-rheology relationships in alkali-silica reaction gels and the impact on the gel's deleterious behavior. Cement and Concrete Research, v. 83, p. 45-56, 2016.

VEIGA, F. N.; GONÇALVES, I. N.; HASPARYK, N. P. Microscopia eletrônica de varredura de géis provenientes de usinas hidroelétricas. In: SIMPÓSIO SOBRE REATIVIDADE ÁLCALI-AGREGADO EM ESTRUTURAS DE CONCRETO, 1., 1997, Goiânia. Anais... Goiânia: CBGB/FURNAS, 1997. p. 69-79.

WANG, H. F.; ANDERSON, M. P. Introduction to Groundwater Modelling: Difference and Finite Element Method. [S.1.]: Academic Press, 1982.

WIGUM, B. J. Alkali-aggregate reactions in concrete - Properties, classification and testing of norwegian cataclastic rocks. Tese (Doutorado) — University of Trondheim, Noruega, 1995. 
WU, T.; TEMIZER, I.; WRIGGERS, P. Multiscale hydro-thermo-chemo-mechanical coupling: Application to alkali-silica reaction. Computational Materials Science, v. 84, p. 381-395, 2014.

ZHENG, H.; DAI, H. C.; LIU, D. F. A variational inequality formulation for unconfined seepage problems in porous media. Applied Mathematical Modelling, v. 33, p. 437-450, 2009. 